\title{
Zusammenhang zwischen angiogenen Faktoren (sFlt-1/PIGF-Ratio) und klinischen Parametern des Schwangerschaftsausgangs bei manifesten hypertensiven Schwangerschaftserkrankungen
}

\author{
Dissertation \\ zur Erlangung des akademischen Grades \\ Dr. med. \\ an der Medizinischen Fakultät \\ der Universität Leipzig
}

eingereicht von:

Anne Tauscher, geb. am 04.09.1977 in Rostock

angefertigt an der:

Universität Leipzig

Abteilung für Geburtsmedizin, Universitätsklinikum Leipzig

Betreuer:

Prof. Dr. med. Holger Stepan

Beschluss über die Verleihung des Doktorgrades vom : 19.02.2013 


\section{Inhaltsverzeichnis}

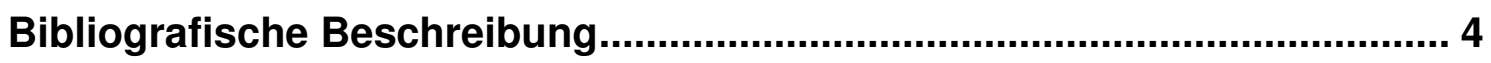

Abkürzungsverzeichnis .............................................................................. 5

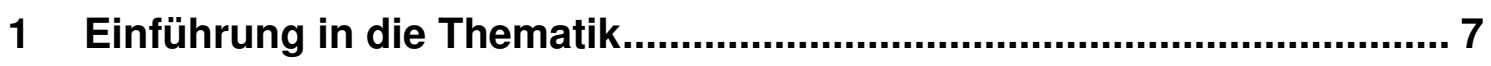

1.1 Hypertensive Schwangerschaftserkrankungen .............................. 7

1.1.1 Terminologie / Definition .................................................... 7

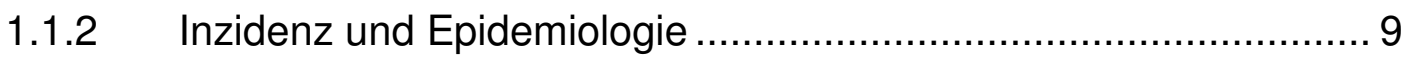

1.1.3 Ätiologie und Pathogenese ..................................................... 11

1.1.4 Klinik und Management .......................................................... 14

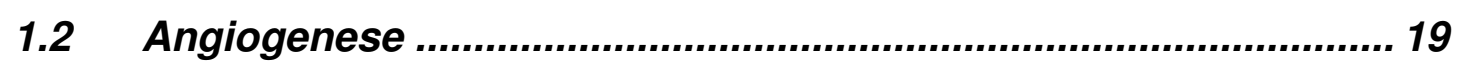

1.2.1 Angiogene Faktoren........................................................... 19

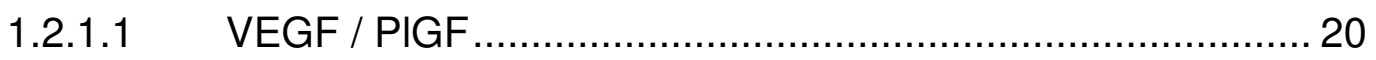

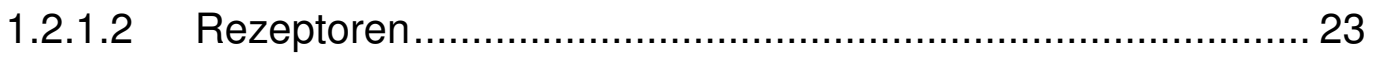

1.2.1.3 Gleichgewicht der Faktoren ................................................. 26

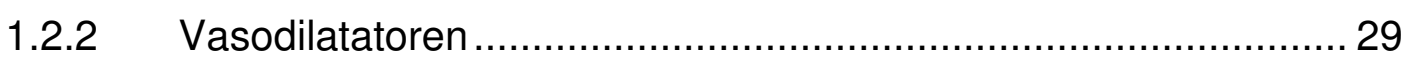

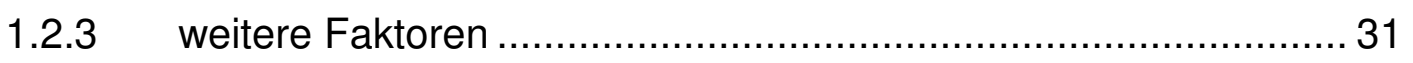

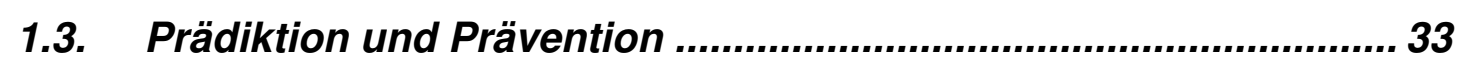

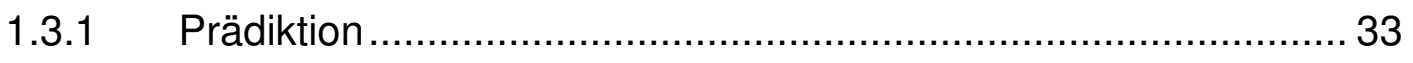

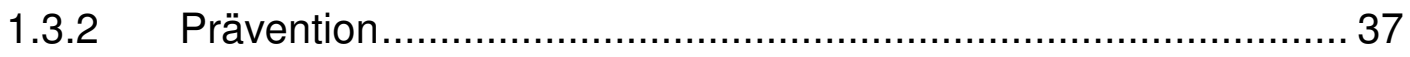

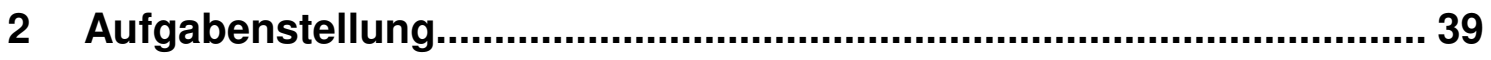

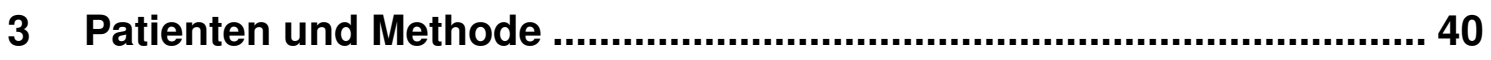

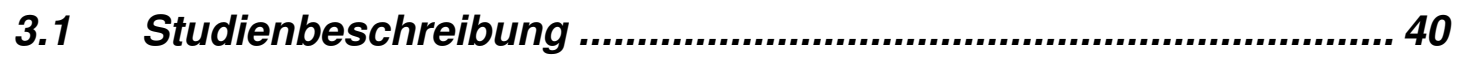

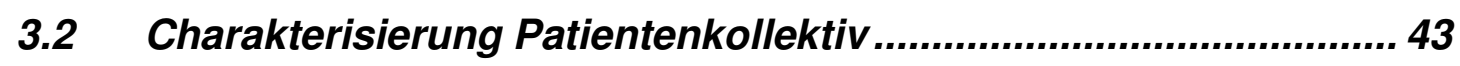

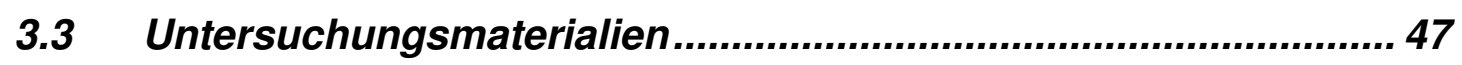

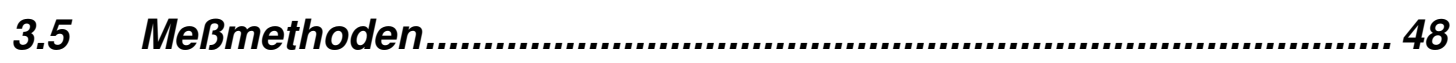

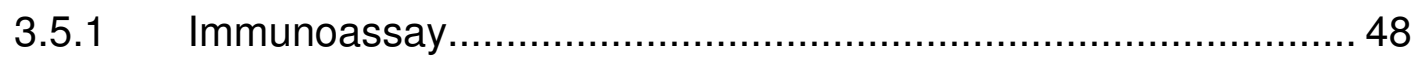

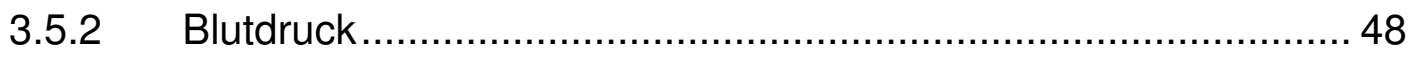

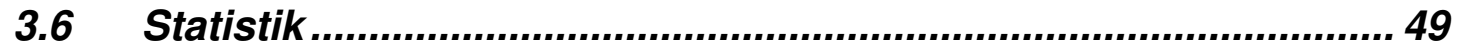




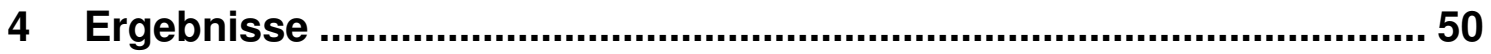

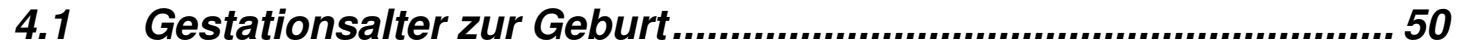

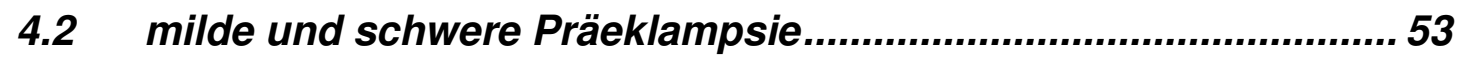

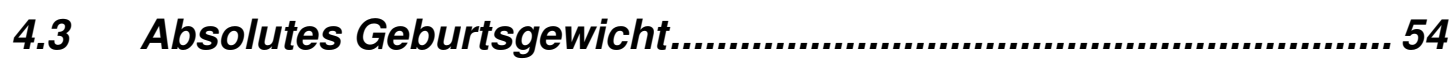

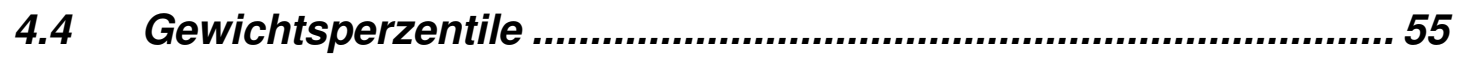

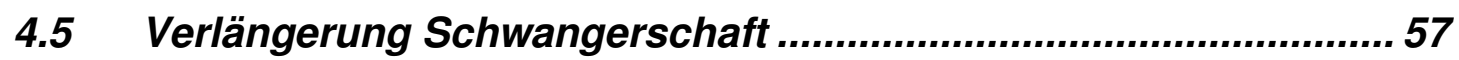

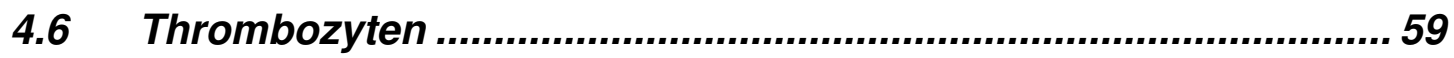

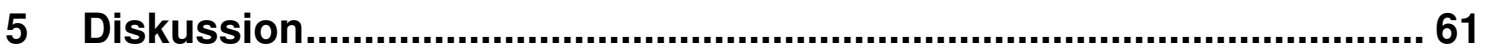

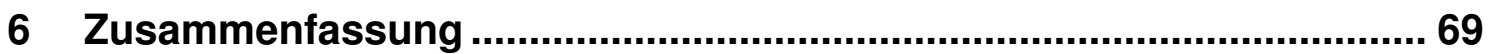

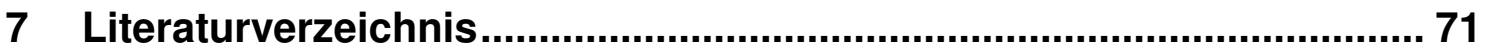

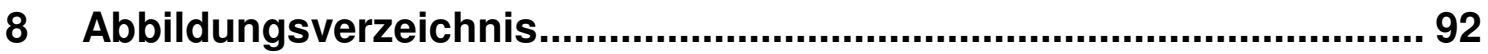

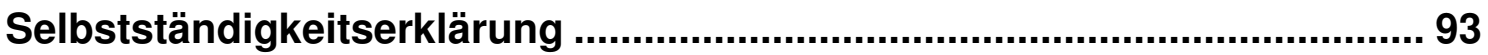

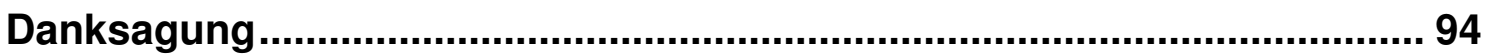




\section{Bibliografische Beschreibung}

Tauscher, Anne

\section{Zusammenhang zwischen angiogenen Faktoren (sFlt-1/PIGF-Ratio) und klinischen Parametern des Schwangerschaftsausgangs bei manifesten hypertensiven Schwangerschaftserkrankungen}

Universität Leipzig, Dissertation

94 S., 208 Lit., 18 Abb., 4 Tab.

\section{Referat:}

Die Bedeutung der angiogenen Faktoren ,soluble fms-like tyrosine kinase-1“ (sFlt-1) und ,placental growth factor“ (PIGF) in der Pathogenese der Präeklampsie (PE) ist in den letzten Jahren hinreichend belegt worden. Bei Patienten mit manifester PE lassen sich dramatisch hohe sFlt-1- bzw. sehr niedrige PlGF-Werte nachweisen. Mittlerweile konnte in Studien die sFlt-1/PIGF-Ratio als sensitiver Parameter ermittelt werden. Ziel der vorliegenden Arbeit ist es, die Zusammenhänge zwischen klinischen Parametern der manifesten Präeklampsie und der sFlt-1/PlGF-Ratio zu spezifizieren. Dabei soll geprüft werden, ob bei manifester PE die Höhe der sFlt-1/PlGF-Ratio vor Entbindung klinische Bedeutung hat und mit Parametern des Schwangerschaftsausgangs in Beziehung steht. 


\section{Abkürzungsverzeichnis}

A. uterina

ACE

ADMA

ALAT

ASAT

ASS

$\mathrm{AT}_{1}$-AA

$\mathrm{AT}_{2}$

AWMF

COX

CRP

CYR6

DGGG

ELISA

FFTS

FGF

Flk-1

Flt-1

Grav.

HCG

HIF- $1 \alpha /-2 \alpha$

i.m.

i.v.

ICAM

IMA

ISSHP

IUFT

IUGR
Arteria uterina

Angiotensin Converting Enzym

asymmetric dimethylarginine

Alanin-Aminotransferase

Aspartat-Aminotransferase

Actetylsalicylsäure

$\mathrm{AT}_{1}$-Autoantikörper

Angiotensin 2

Arbeitsgemeinschaft der Wissenschaftlichen Medizinischen

Fachgesellschaften e.V.

body mass index

Cyclooxygenase

C-reaktives Protein

Cystein rich 61

Deutsche Gesellschaft für Gynäkologie und Geburtshilfe

Enzyme-Linked-Immunosorbent-Essay

fetofetales Transfusionssyndrom

fibroblast growth factor

fetal liver kinase-1

fms-like tyrosinekinase-1

Gravidität

human chorion gonadotropin

Hypoxie induzierter Faktor-1 $\alpha /-2 \alpha$

intramuskulär

intravenös

intercellular adhesion molecule-1

ischaemia modified albumin

international Society for the Study of Hypertension in Pregnancy

intrauteriner Fruchttod

intrauterine growth restriction 
Abkürzungsverzeichnis

LDH Lactatdehydrogenase

MAP mittlerer arterieller Blutdruck

MoM multiple of the median

NGAL neutrophil gelatinase-associated lipocalin

NO Stickstoffmonoxid

NOS Stickstoffmonoxidsynthase

NOV nephroblastoma overexpressed

PAPP-A pregnancy-associated plasma protein A

PE Präeklampsie

$\mathrm{PGI}_{2} \quad$ Prostcyclin

PlGF placental growth factor

PP-13 Plazentaprotein-13

PTX3 Pentraxin 3

RAS Renin-Angiotensin-System

RIA Radio-Immunoassay

sEng soluble endoglin

sFlt-1 soluble fms-like tyrosinekinase

$\mathrm{SIH}$ schwangerschaftsinduzierte Hypertonie

TGF- $\beta_{1} /-\beta_{3} \quad$ tumor growth factor- $\beta_{1} /-\beta_{3}$

VCAM vascular adhesion molecule-1

VEGF vascular endothelial growth factor

VEGFR-1/-2 vascular endothelial growth factor receptor

WHO Worl Health Organization 


\section{Einführung in die Thematik}

\subsection{Hypertensive Schwangerschaftserkrankungen}

\subsubsection{Terminologie / Definition}

Die Terminologie und das Verständnis für hypertensive Schwangerschaftserkrankungen haben sich in den letzten Jahrzehnten maßgeblich gewandelt. Für diese Erkrankung mit unterschiedlichster klinischer Erscheinungsvielfalt gab es verschiedenste Synonyme („Schwangerschaftstoxikose“; „EPH-Gestose“). Die Bemühungen um eine einheitliche Klassifikation und Terminologie sind mittlerweile fortgeschritten. Die Leitlinien der nationalen Fachgesellschaften unterscheiden sich nur noch in einigen wenigen Details. Neueste Empfehlungen und Leitlinien werden regelmäßig auf den Weltkongressen der ISSHP verglichen und diskutiert.

In dieser Arbeit wird die Klassifizierung hypertensiver Erkrankungen in Schwangerschaft und Wochenbett aus den Leitlinien der DGGG (Arbeitsgemeinschaft Schwangerschaftshochdruck/ Gestose; AWMF 015/018 (S2); Stand August 2010) verwendet und übernommen. Diese Definitionen sind in Anlehnung an die Empfehlungen amerikanischer und australischer Fachgesellschaften sowie der International Society for the Study of Hypertension in Pregnancy [1, 2, 3, 4, 5].

\section{Gestationshypertonie}

Die Gestationshypertonie ist durch nach der 20. SSW aufgetretene Blutdruckwerte $\geq 140 / 90 \mathrm{mmHg}$ ohne eine Proteinurie bei einer zuvor normotensiven Schwangeren, die auch zwölf Wochen nach der Geburt normale Blutdruckwerte aufweist, definiert.

\section{$\underline{\text { Präeklampsie }}$}

Bei der Präeklampsie treten Gestationshypertonie und Proteinurie $\geq 300 \mathrm{mg} / 24 \mathrm{~h}$ nach der abgeschlossenen 20. SSW gleichzeitig auf. Sollten folgende alternative Zusatzkriterien nach der 20. SSW auftreten, kann auch bei Fehlen der Proteinurie die Diagnose Präeklampsie gestellt werden (non-proteinuric-preeclampsia) [1]: 
- Nierenfunktionseinschränkung (Kreatinin $\geq 0,9 \mathrm{~g} / \mathrm{l}$ oder Oligurie $<500 \mathrm{ml} / 24 \mathrm{~h}$ )

- Leberbeteiligung (Transaminasenanstieg, schwere Oberbauchschmerzen)

- Lungenödem oder Zyanose

- hämatologische Störungen (Thrombozytopenie, Hämolyse)

- neurologische Symptome (schwere Kopfschmerzen, Sehstörungen)

- fetale Wachstumsrestriktion

Von einer Schweren Präeklampsie spricht man, wenn zusätzlich mindestens eines der obengenannten oder nachfolgender Kriterien erfüllt wird [4, 1]:

- $\quad$ Blutdruck $>170 / 110 \mathrm{mmHg}$

- Proteinurie $>5 \mathrm{~g} / 24 \mathrm{~h}$.

Eklampsie

Im Rahmen einer Präeklampsie auftretende tonisch-klonische Krampfanfälle, die keiner anderen Ursache zugeordnet werden können. Diese sind nur in 50\% der Fälle mit einer schweren Hypertonie assoziiert und können sogar in 14-34\% der Fälle komplett ohne Hypertonie oder Proteinurie auftreten [6, 7].

\section{HELLP-Syndrom}

Das HELLP-Syndrom ist durch die klassische Trias aus Hämolyse, pathologisch erhöhten Leberenzymen und erniedrigten Thrombozyten $(<100 \quad \mathrm{Tsd} / \mu \mathrm{l})$ gekennzeichnet. Laborchemisches Korrelat für die Hämolyse sind ein erniedrigtes Haptoglobin $(<0,3 \mathrm{~g} / \mathrm{l})$, erhöhte LDH Spiegel ( $>2$ faches des oberen Referenzbereiches) oder ein erhöhter indirekter Bilirubinspiegel $(>1.2 \mathrm{mg} / \mathrm{dl})$. In $5-15 \%$ der Fälle liegt keine signifikante Proteinurie, in bis zu 20\% der Fälle keine Hypertonie vor, in 15\% fehlen Hypertonie und Proteinurie gleichzeitig [8].

\section{Chronische Hypertonie}

Im Gegensatz zur Gestationshypertonie werden bei der chronischen Hypertonie die erhöhten Blutdruckwerte $(\geq 140 / 90 \mathrm{mmHg})$ entweder präkonzeptionell oder in der ersten Schwangerschaftshälfte diagnostiziert. Die Hypertonie persistiert postpartal mehr als zwölf Wochen. 


\section{Propfpräeklampsie}

Die Propfpräeklampsie ist eine chronische Hypertonie mit einer Gestationsproteinurie oder einer vor der 20. SSW bestehenden Proteinurie, bei der nach der 20. SSW zusätzlich entweder die Proteinurie oder der Blutdruck ansteigt oder eines der Zusatzkriterien der schweren Präeklampsie auftritt.

\subsubsection{Inzidenz und Epidemiologie}

Weltweit geht man von einer Inzidenz der hypertensiven Schwangerschaftserkrankungen von 2-8\% aus [9]. 15\% aller Patientinnen mit Präeklampsie entwickeln ein HELLP-Syndrom [10]. Das HELLP-Syndrom nimmt mit $0,3-0,8 \%$ aller Geburten an Häufigkeit zu und die Eklampsie nimmt mit einer Häufigkeit von 0,03-0,1\%, dank verbesserter Schwangerschaftsvorsorgen, ab [11]. In 10-15\% kann das HELLP-Syndrom mit einer Eklampsie auftreten [8]. 10\% der Präeklampsien treten vor der 32. SSW auf. 10-15\% der schweren Verlaufsformen, wie HELLP-Syndrom und Eklampsie, manifestieren sich erst im Wochenbett [11].

Sowohl in der Inzidenz als auch in der Mortalität sind je nach Region und Entwicklung des Gesundheitssystems starke Schwankungen $\mathrm{zu}$ beobachten. Einerseits ist ein deutliches Gefälle von Entwicklungsländern zu entwickelten Ländern zu beobachten, andererseits sind vor allem Gegenden mit dunkelhäutiger Bevölkerung betroffen. Nach Angaben der WHO liegt die Müttersterblichkeit in westlichen Ländern bei 1:4000; in Asien bei 1:132 und in Afrika bei 1:19 [12]. Weltweit sterben jährlich 600.000 Frauen an schwangerschaftsspezifischen Komplikationen, 99\% davon in Entwicklungsländern [13]. Von diesen Todesfällen sind 10-15\% mit einer Präeklampsie bzw. Eklampsie assoziiert $[14,15]$. Die Inzidenz der Eklampsie ist in Europa mit 2-3/10.000 Geburten sehr niedrig, wesentlich verbreiteter in Entwicklungsländern mit 16-69/10.000 Geburten [16].

Mit einem Anteil von $15 \%$ an allen Frühgeburten ist die Präeklampsie eine Hauptursache für perinatale Morbidität und Mortalität, letztere beträgt 20-25\% [10]. Durch Verschiebung der Kosten in den neonatologischen Intensivbereich steigen die 
Gesamtkosten. Allein 20\% der Kosten für die neonatologische Spezialpflege werden durch Präeklampsien verursacht [17].

Für die Präeklampsie gibt es einige prädisponierende Faktoren, deren relative Risiken mittlerweile gut untersucht sind. In erster Linie ist die Präeklampsie eine Erkrankung der Erstgebärenden. Verschiedene epidemiologische Studien haben nachgewiesen, dass das Risiko an einer Präeklampsie zu erkranken, bei Partnerwechsel einer Mehrgebärenden, nach Samen- oder Eizellspende oder auch invers in Abhängigkeit von der Zeit der Exposition mit dem Partnersperma, höher ist [18, 19, 20]. Weitere bekannte Risikofaktoren sind eine vorbestehende Hypertonie und eine Nierenerkrankung, ein Intervall zwischen zwei Schwangerschaften $\geq 10$ Jahre, präkonzeptionell ein diastolischer Blutdruck $\geq 80 \mathrm{mmHg}$ sowie eine chronische Proteinurie [21].

Eine Auswertung aller Untersuchungen und Metaanalysen von 1966 - 2002 hat die im Folgenden genannten relativen Risiken für die Entwicklung einer Präeklampsie ergeben [22].

\section{RISIKOFAKTOREN}

- Antiphospholipid Syndrom

- Z.n. Präeklampsie

- Body Mass Index $>35$

- Vorbestehender Diabetes

- Mehrlingsschwangerschaft

- Nulliparität

- familäre Anamnese

- Alter $\geq 40$ Jahre relatives Risiko

\section{7}

7.2

4

3.6

1.9

Die Präeklampsie ist größtenteils eine reversible Erkrankung mit zunächst vollständiger Rückbildung der Symptome nach Beendigung der Schwangerschaft, in den meisten Fällen innerhalb von 3 Monaten postpartal [23]. Bei etwa 6\% der Patientinnen mit Präeklampsie bleibt allerdings auch nach dem Wochenbett eine Hypertension bestehen [23]. Das Risiko 20-25 Jahre nach einer Präeklampsie eine chronische Hypertonie zu entwickeln, liegt bei über 90\% [24]. Was die Langzeitmortalität anbetrifft, haben Frauen mit einer Präeklampsie in der Anamnese ein 8fach erhöhtes Risiko an einer kardiovaskulären Erkrankung zu versterben [25]. 


\subsection{3 Ätiologie und Pathogenese}

Die Präeklampsie ist eine Multisystemerkrankung, deren Ätiologie allgemein als multifaktoriell angesehen [26] und als „Krankheit der Theorien“ bezeichnet wird. Die gestörte Plazentation und damit einhergehende Dysbalance der angiogenen Faktoren gilt als ursächlicher Mechanismus in der Pathogenese der Erkrankung. Mit dieser Theorie gelingt es, die Krankheit genauer zu verstehen. Ziel ist es noch immer, daraus eine effiziente Früherkennung und sinnvolle Therapiekonzepte abzuleiten. Einige erfolgsversprechende Ansätze gab es hierzu in jüngster Zeit [27, 28]. Abbildung 1 stellt schematisch die Pathogenese der Präeklampsie dar, auf welche im folgenden Kapitel eingegangen wird.

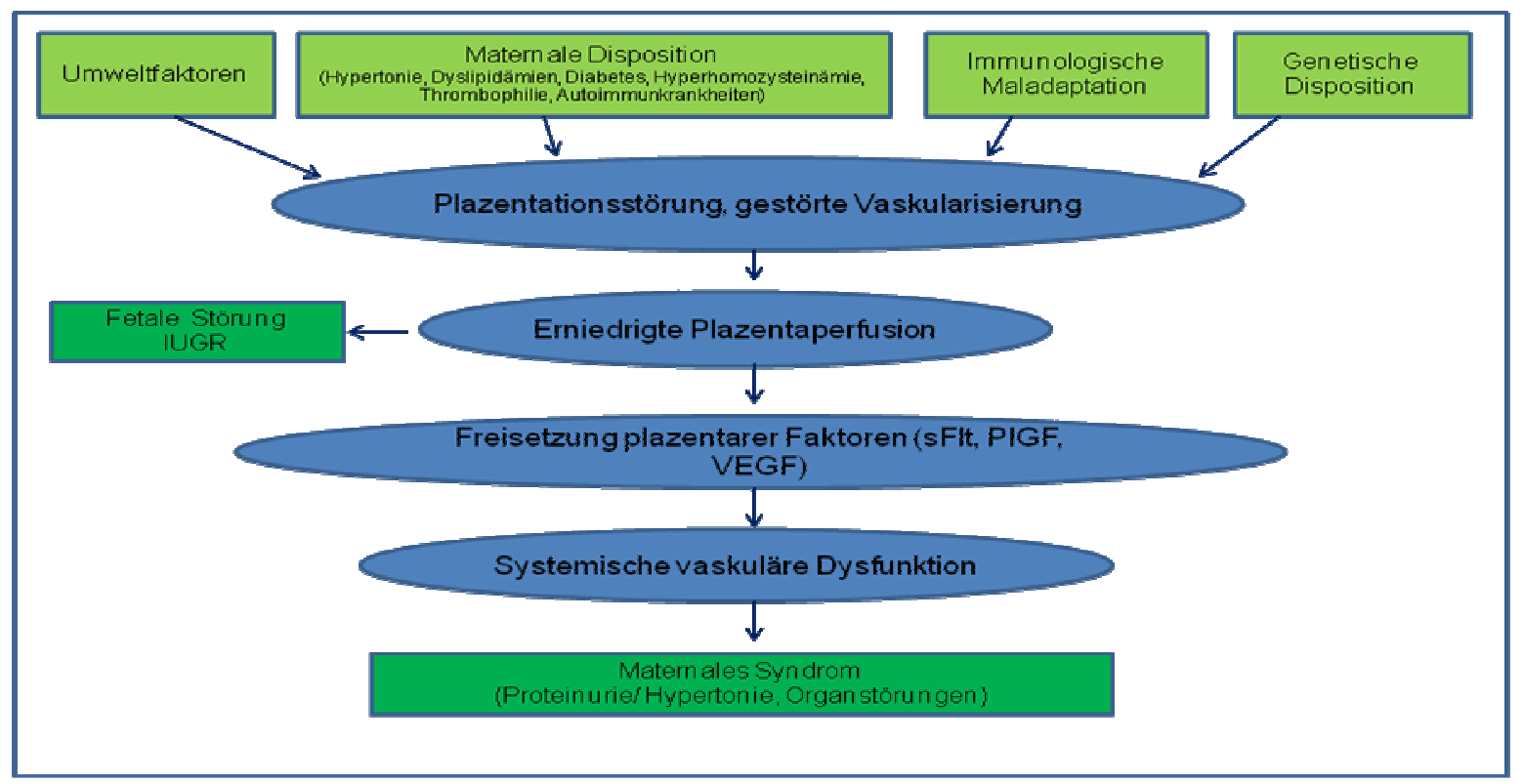

Abbildung 1: Pathogenese der Präeklampsie (mod. nach [10, 29])

Für den Mechanismus der gestörten Plazentation gibt es verschiedene Erklärungsansätze. Vermutlich ergänzen sich die verschiedenen theoretischen Ansätze und sind in Kombination $\mathrm{zu}$ betrachten. $\mathrm{Zu}$ nennen sind hier genetische/immunologische und Umweltfaktoren. Immunologisch ist die Toleranz des maternalen Organismus gegenüber semiallogenetischen fetalen Zellen und paternalen Antigenen gestört. 
$\mathrm{Zu}$ Beginn der Plazentation entstehen aus den unreifen, zytotrophoblastären Stammzellen in den Zotten der sich entwickelnden Plazenta der villöse und der extravillöse Trophoblast. Der villöse Trophoblast besteht aus dem Zytotrophoblasten und dem äußeren Synzytiotrophoblasten. Durch einen starken proliferativen Reiz an den Haftstellen der Zotten, der uterinen Basalmembran, vermehren sich die Stammzellen des extravillösen Trophoblasten rasch. Zeitgleich zur Ausbildung der Trophoblastzellsäulen, welche tief in die Dezidua vordringen, wandern Trophoblastzellen in die Arterien und Venen der Dezidua ein. Die endovaskulären Trophoblastzellen verteilen sich entlang der Innenwand der Gefäße und ersetzen die Endothelzellen durch Verdrängung. Sowohl die muskulären Elemente als auch die Elastica interna werden aufgelöst, bis letztendlich die Wandstruktur der Gefäße der Endstrecke der A. uterina komplett umgebaut ist [30] (Abbildung 2).

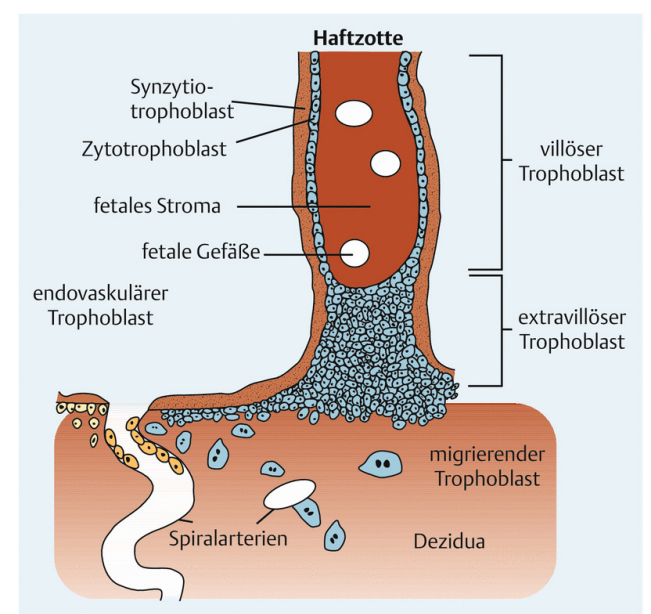

Abbildung 2: schematische Darstellung der Plazentation [31]

Die Interaktion mit der maternalen extrazellulären Matrix und Invasion des extravillösen Trophoblasten wird durch Integrin $\alpha 1$ gefördert. Die Expression von Integrin $\alpha 1 \mathrm{im}$ Zytotrophoblasten wird durch VEGF stimuliert. Fehlende Expression von Integrin $\alpha 1 \beta 1$ bei Präeklampsie verursacht eine nur oberflächliche Invasion in die Dezidua [32]. Eine unzureichende Trophoblastinvasion mit einer mangelnden Dilatation der Spiralarterien wurde als anatomisch-morphologisches Korrelat in 
Plazenten von Schwangerschaften mit intrauteriner Wachstumsretardierung, Präeklampsie sowie von frühen Spontanaborten gefunden [31].

Morphologische Veränderungen der Zottenarchitektur und Gefäßanomalien finden sich vor allem in Plazenten von Schwangeren mit Early-onset-Präeklampsie (PE <34. SSW). Im Gegensatz hierzu konnten diese Veränderungen in Plazenten von Patientinnen mit einer Late-onset-Preäeklampsie ( $\mathrm{PE} \geq 34$. SSW) nicht gefunden werden [33]. Es bleibt vorerst spekulativ, ob der Late-onset-Präeklampsie eine andere Pathogenese oder ein anderes morphologisches Korrelat zugrunde liegt.

Die Umwandlung der Spiralarterien führt zu einer bis zu 3-fachen Vergrößerung des Durchmessers des Gefäßlumens und ist bis zur 18.-20. SSW abgeschlossen [29]. Durch den fehlenden Abfall des Gefäßwiderstandes in der Peripherie des uterinen Kreislaufs wird die Plazenta unzureichend perfundiert.

Grundsätzlich werden hier zwei Vorgänge unterschieden: die Vaskulogenese und die Angiogenese. Vaskulogenese bezeichnet die de-novo Synthese von Gefäßen aus zirkulierenden pluripotenten mesenchymalen Vorläuferzellen innerhalb der Chorionzotten [34]. Aus Hämangioblasten differenzieren sich hämatopoetische Stammzellen und Angioblasten und bilden unter Einfluss von fibroblast growth factor (FGF) und vascular endothelial growth factor (VEGF) ein primitives vaskuläres Gefäßsystem. Während der Angiogenese bilden sich neue Gefäßstrukturen aus bereits vorbestehenden Gefäßen. Zwei Formen der Angiogenese sind bekannt: „,branching“ und „non branching“ Angiogenese. „Branching“-Angiogenese bezeichnet die zweigartige Aufteilung der Gefäße. Im Gegensatz hierzu steht bei der ,non branching“-Angiogenese die Proliferation der Endothelzellen im Vordergrund [35, 36, 37].

Bleibt die Umwandlung des plazentaren Gefäßbettes von einem hypoxischen Hochwiderstandssystem in ein Niedrigwiderstandssystem mit ansteigenden $\mathrm{O}_{2}$-Sättigungen aus [38, 39], führt die daraus resultierende plazentare Ischämie zu einem Ungleichgewicht in der Produktion von Angiogenese- und Wachstumsfaktoren [40, 41]. Die bekanntesten Faktoren sind hier vor allem sFlt, PIGF, VEGF und sENG; aber auch andere Faktoren wie $\mathrm{AT}_{1}$-Autoantikörper, Plazentaprotein 13, „cystein rich 61“ und „nephroblastoma overexpressed" spielen eine Rolle. 
Das Ungleichgewicht der plazentaren Faktoren im mütterlichen Kreislauf bewirken als endokrine Signale tiefgreifende Veränderungen und Anpassungen in den verschiedenen Organsystemen der Mutter. Die endotheliale Dysfunktion führt zur Ausbildung systemisch erhöhter vaskulärer Widerstände und der Aktivierung des Gerinnungssystems mit Entwicklung des maternalen Syndroms der Präeklampsie.

\subsubsection{Klinik und Management}

Die Vielfalt der klinischen Symptome spiegelt die Natur der Präeklampsie als Multiorganerkrankung wider.

Im Zentralnervensystem führt der generalisierte Vasospasmus zu einem Hirnödem und Mikroblutungen mit konsekutivem Auftreten einer gesteigerten zerebralen Erregbarkeit, anfänglich in Form von Kopfschmerzen und Sehstörungen (Augenflimmern/ Skotome etc.), in der Maximalform als eklamptischer Anfall. Kardinalsymptome der Präeklampsie sind die Proteinurie und die Hypertonie, wobei bei letzterer der Verlust bzw. die Umkehr der zirkadianen Rhythmik im Vordergrund steht. Die Symptome im kardiovaskulären System können in seltenen Fällen so ausgeprägt sein, dass eine Linksherzinsuffizienz mit Lungenödem auftritt.

Ausscheidung von Harnsäure, Kalzium und Kallikrein im Urin sind als Zeichen der tubulären Schädigung vermindert und gehen der glomerulären Schädigung und den klinischen Symptomen der Präeklampsie voraus. In Folge der glomerulären Funktionseinschränkung mit einer um 30-40\% reduzierten Filtrationsrate kommt es zu einer nicht selektiven Proteinurie [42]. Durch den Eiweißverlust und dem damit sinkenden kolloidosmotischen Druck entstehen in $85 \%$ der Fälle Ödeme - in schweren Fällen kommt es zur Ausbildung von Aszites, Pleura- und Perikardergüssen. Der Flüssigkeitsverlust in den Intrazellulärraum verursacht eine Verminderung des Plasmavolumens und eine Hämokonzentration ( $\mathrm{Hk} \geq 38 \%$ ), was sich klinisch in der Nierenfunktionsstörung mit einer Oligo- bis Anurie äußert. 
Epigastrische Schmerzen, Übelkeit und Erbrechen kündigen als Folge der Leberschwellung das HELLP-Syndrom an und können in 20-40\% der Fälle der laborchemischen Manifestation um Tage vorausgehen [8].

Laborchemisches Zeichen der Hämolyse ist der Haptoglobinabfall und die Erhöhung der LDH um die $\geq 3$-fache Standardabweichung von den Normalwerten. Im Gerinnungssystem führt die Präeklampsie $\mathrm{zu}$ einer generalisierten Gerinnungsaktivierung.

Klinische Manifestationen wie vorzeitige Plazentalösung, Nierenversagen, HELLP-Syndrom treten eher vor der 32. SSW auf, während vor allem die intra- und postpartale Eklampsie häufiger am Geburtstermin zu beobachten ist $[43,6]$. Bei einem neuaufgetretenen Bluthochdruck vor der 32. SSW besteht eine 50\% Wahrscheinlichkeit eine Präeklampsie zu entwickeln, 10\% davon mit einer schweren Verlaufsform [44]. Bemerkenswerterweise haben 34\% der Frauen mit einer Eklampsie einen diastolischen Blutdruck $\leq 100 \mathrm{mmHg}[6]$. Daran wird die Heterogenität des klinischen Erscheinungsbildes auch bei schweren Verläufen deutlich.

An der Tatsache, dass die Schwangerschaftsbeendigung, genaugenommen die Entfernung der Plazenta, die einzige kausale Therapie ist, hat sich grundlegend nichts geändert. Dennoch stehen vor allem die Prolongation der Schwangerschaft mit konsekutiver Senkung der fetalen und maternalen Morbidität und Mortalität im Mittelpunkt. Durch Senkung der iatrogenen Frühgeburtlichkeitsrate wird insgesamt ein besseres Outcome erreicht.

Im klinischen Alltag sind für das Managment der Präeklampsie folgende Parameter wegweisend: Schwere der Erkrankung, Zustand von Mutter und Fetus und das Schwangerschaftsalter. Die Festlegung des optimalen Entbindungszeitpunktes ist die zentrale Frage in der Behandlung, vor allem bei den frühen schweren Präeklampsien. Im Durchschnitt vergehen zwischen Diagnose und Entbindung 14 Tage [45].

Betrachtet man die Charakteristika hypertensiver Schwangerschaftserkrankungen, so wird deutlich, dass die chronische Hypertonie und die Gestationshypertonie die wesentlich komplikationsärmeren Erkrankungen sind. Bei beiden ist die fetale und 
maternale Prognose gut, die Schwangerschaftsverlängerung fast immer möglich und klinische Symptome, wie Kopfschmerzen und Augenflimmern selten [46].

Die Early-onset-Präeklampsie ist in der Regel durch einen schwereren, raschen und unaufhaltsamen Verlauf gekennzeichnet und die Entbindung häufig innerhalb von 48-72 h erforderlich. Dies betrifft 25-55\% Prozent der Frauen mit einem Blutdruck von $\geq 160 \mathrm{mmHg}$ (systolisch) bzw. $\geq 110 \mathrm{mmHg}$ (diastolisch) und einer Proteinurie [45].

Folgende maternale Faktoren erfordern, unabhängig vom Schwangerschaftsalter und der fetalen Reife, die sofortige Entbindung: schwere therapierefraktäre Hypertonie, Niereninsuffizienz, akutes Lungenödem, disseminierte intravasale Gerinnung, vorzeitige Plazentalösung und Eklampsie $[8,5]$.

Ein konservatives Management in der 25.-32. SSW verbessert die kindlichen Überlebenschancen, ohne dass dadurch die Morbidität und die Mortalität der Mutter erhöht werden. Dies wurde von verschiedenen Autoren in randomisierten kontrollierten Studien gezeigt [45, 47, 48, 49] (Tabelle 1).

\begin{tabular}{|c|c|c|}
\hline & Aggressives Managment & Konservatives \\
\hline Kriterien & $\mathrm{n}=46$ & $\mathrm{n}=49$ \\
\hline Sectio caesarea & $85 \%$ & $73 \%$ \\
\hline Gestationsalter & 30,8 SSW (+/- 1,7 Wochen) & $32,9 \operatorname{SSW}(+/-1,5$ \\
\hline Neonatale Intensivtherapie & $100 \%$ & $76 \%$ \\
\hline $\begin{array}{l}\text { Behandlungsdauer auf neonataler } \\
\text { Intensivstation }\end{array}$ & 36,6 Tage $(+/-17,4)$ & 20,2 Tage (+/- 14) \\
\hline Geburtsgewicht & $1233 \mathrm{~g}(+/-287)$ & $1622 \mathrm{~g}(+/-360)$ \\
\hline Respiratory distress syndrom & $50 \%$ & $22,4 \%$ \\
\hline Nekrotisierende Enterokolitis & $10,9 \%$ & $0 \%$ \\
\hline Bronchopulmonale Dysplasie & $8,7 \%$ & $4,1 \%$ \\
\hline Intrazerebrale Blutung & $6,5 \%$ & $2 \%$ \\
\hline
\end{tabular}

Tabelle 1: Neonatales Outcome bei schwerer Präeklampsie [12, 45]

Randomisierter Vergleich zwischen aggressivem und konservativem Managment zwischen der 28. und 32. SSW ( $n=95)$ 
Folgendes Managment ist empfohlen und im allgemeinen Standard [50]:

- <24. SSW: Die Beendigung der Schwangerschaft sollte den Eltern wegen des hohen Risikos für Gesundheit und Leben der Mutter empfohlen werden, die fetalen Überlebenschancen sind auch bei konservativen Managment sehr gering [51].

- 24.- 34. SSW: Der Abschluß der Lungenreife mit Glucocorticoiden (Betamethason/Dexamethason 2x12 mg i.m. im Abstand von 24h) ist das Hauptziel. Zusätzlich wurde nach Glucocorticoidtherapie eine verminderte Inzidenz von intrazerebralen Blutungen bei sehr kleinen Frühgeborenen beschrieben [52].

- 34. - 37. SSW: Die fetale Morbidität ist nach Entbindung im Gegensatz zu den Risiken einer Prolongation der Schwangerschaft zu vernachlässigen und die zügige Entbindung sollte angestrebt werden [4].

- > 37. SSW: Es gibt keine Legitimation für eine Schwangerschaftsprolongation mehr $[3,53]$.

Eine Blutdrucksenkung ist ausschließlich zur Verhinderung von mütterlichen Komplikationen erforderlich, eine kindliche Indikation zur antihypertensiven Therapie besteht nicht. Studien haben gezeigt, dass Mütter von einer zu früh begonnenen antihypertensiven Therapie nicht profitieren. Im Gegenteil: es steigt die fetale Morbidität, und die zu früh begonnene antihypertensive Therapie führt signifikant häufiger zu einer ausgeprägten fetalen Wachstumsrestriktion [54]. Laut den Leitlinien der DGGG bedarf es einer Behandlung erst ab Blutdruckwerten $\geq 170 / 100 \mathrm{mmHg}$; bei Propfpräeklampsien bereits ab Blutdruckwerten $\geq 160 / 100 \quad \mathrm{mmHg}$. Um eine Minderperfusion der Plazenta und des Feten $\mathrm{zu}$ verhindern, sollte eine rasche Blutdrucksenkung vermieden werden und die mittleren diastolischen Werte 95-105 mmHg nicht unterschreiten [55].

In der Akuttherapie galt lange Dihydralazin als Mittel der Wahl. Eine Metaanalyse zeigte, dass Dihydralazin mit einem schlechteren fetalen und maternalen Outcome im Vergleich zu Nifedipin assoziiert ist, so daß aktuell Nifedipin oder Urapidil in der 
Akuttherapie gebräuchlich sind [56, 57]. Beide Medikamente sind für den Gebrauch bei Schwangeren nicht zugelassen und werden im Off-Label-Use eingesetzt.

In der Langzeittherapie ist nach wie vor $\alpha$-Methyldopa der Standard. Alternativ stehen Nifedipin (nicht im 1. Trimenon wegen fraglicher Teratogenität), Dihydralazin (NW: Kopfschmerzen/Reflextachykardie) und selektive $\beta_{1}$-Blocker (Gefahr der fetalen Wachstumsrestriktion) zur Verfügung.

Beim HELLP-Syndrom gilt grundsätzlich die gleiche Therapie wie bei der Präeklampsie. Es sollte additiv die Therapie mit Glucocorticoiden erfolgen, da mehrheitlich ein positiver Effekt auf den prä- und postpartalen klinischen und biochemischen Verlauf gezeigt werden konnte [58, 59]. Empfohlen sind die Gabe von $32 \mathrm{mg} / \mathrm{d}$ i.v. Methylprednisolon, alternativ ist die Verabreichung von Dexamethason 2-3x10 mg/d i.v. möglich. Das HELLP-Syndrom geht im akuten Schub mit einer hohen Rate an disseminierten intravasalen Gerinnungstörungen (21\%) einher [12].

Bei einer schweren Präeklampsie sollte zur Prävention der Eklampsie Magnesium i.v. (initial 4-5 g/15min i.v. als Kurzinfusion, Erhaltungstherapie 1-2 g/h i.v. mittels Perfusor) gegeben werden. Die prophylaktische Magnesiumtherapie senkt das Risiko für einen eklamptischen Anfall um 58\% [60]. 


\subsection{Angiogenese}

\subsubsection{Angiogene Faktoren}

Die maternale Adaptation an die Schwangerschaft ist ein vielschichtiger Prozess. Die vermehrte Freisetzung von Vasodilatatoren führt $\mathrm{zu}$ einem Absinken des Gefäßwiderstandes und zur Aufrechterhaltung einer normalen endothelialen Funktion. Diesen hämodynamischen Änderungen im Kreislaufsystem geht die ungestörte Adaptation auf uteroplazentarer Ebene voraus. (s.Kap. 1.1.3)

Vasodilatative Faktoren regulieren die Adaptation im uteroplazentaren Gefäßbett nicht nur während der Plazentation sondern bereits während der Implantation, was durch folgende Beobachtungen unterstrichen wird. Vasodilatation und Hyperpermeabilität fördern die Ausbildung des dezidualen Ödems während der Implantation. Die Dilatation der Spiralarterien beginnt noch vor der Invasion des Trophoblasten [61, 62]. Verschiedene Mediatoren, angiogene und vasodilatative Faktoren bilden ein komplexes Netzwerk und ermöglichen als Einheit die Aufrechterhaltung einer normalen systemischen und uteroplazentaren Zirkulation (Abbildung 3).

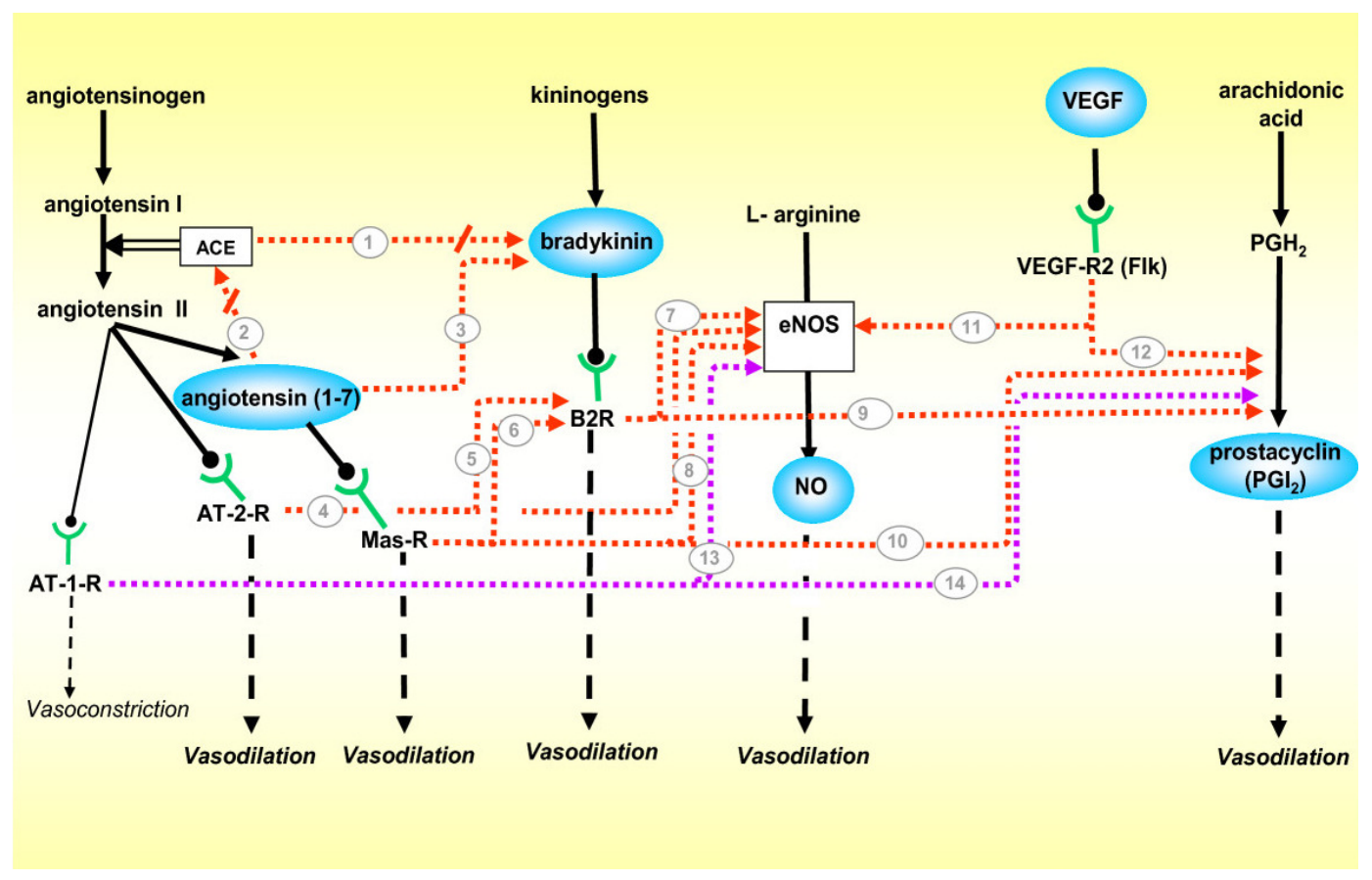

Abbildung 3: Interaktion der vasodilatativen Faktoren [62] 
Die klinischen Untersuchungen in dieser Arbeit beziehen sich ausschließlich auf PIGF (aus der VEGF-Familie), sFlt (löslicher VEGF-Rezeptor) und dem Quotienten der beiden Faktoren. Aus diesem Grunde werden diese Faktoren nachfolgend ausführlich erörtert. Im Anschluss (Kap. 1.2.2/1.2.3) wird auf andere, teils neue, vasodilatative und angiogene Faktoren eingegangen, welche weitere Ansätze in der Präeklampsieforschung geben könnten.

\subsubsection{VEGF / PIGF}

Vascular endothelial growth factor (VEGF) und placental growth factor (PlGF) sind entscheidende Regulatoren der embryonalen Vaskulo- und Angiogenese. Während der plazentaren Gefäßentwicklung fördert VEGF die Proliferation, Migration und das Überleben von Endothelzellen [63, 64, 65]. Die Inaktivierung von VEGF in Mäusen führte 11-12 Tage postkonzeptionell zum Absterben der Feten [66]. Heterozygot VEGF-defiziente Mäuse zeigen diverse Entwicklungsanomalien in Form einer gestörten Fusion von Angioblasten als Vorläufer für das Endothel, einer verminderten Gefäßbildung im Dottersack und folglich einer gestörten Vaskularisierung des Embryos [67]. Diese beiden Tatsachen unterstreichen die Wichtigkeit des vaskulären Wachstumsfaktors schon $\mathrm{zu}$ Beginn der Schwangerschaft. Als vaskulärer Permeabilitätsfaktor reguliert VEGF die vaskuläre Durchlässigkeit und spielt unter anderem eine bedeutende Rolle in der Entzündungskaskade [68]. In dieser Funktion scheint VEGF während der Implantation die uterine Empfänglichkeit maßgeblich mit zu beeinflussen. Im Blastocyten wurde die mRNA Expression von VEGF nachgewiesen, so dass einerseits an der Implantationsstelle die Bindung an die Liganden der endometrialen Rezeptoren ermöglicht wird und andererseits direkt durch die Implantation die Angiogenese induziert wird [69]. VEGF ist ein Endothel abhängiger Vasodilator [68]. Dieser Effekt wird über $\mathrm{NO}$ und $\mathrm{PGI}_{2}$ vermittelt [62]. 


\section{Struktur VEGF}

VEGF ist ein Homodimer aus der Gruppe der Glykoproteine. In der Familie der vaskulären endothelialen Wachstumsfaktoren sind 6 Unterformen (VEGF A-F) und der Plazenta Wachstumsfaktor PIGF bekannt. Durch alternatives Spleißen der Exons 6 und 7 können von VEGF-A acht verschiedene Isoformen synthetisiert werden. Diese unterscheiden sich in der Länge der Polypeptidketten und werden entsprechend der Anzahl der Aminosäuren als $\mathrm{VEGF}_{121}, \mathrm{VEGF}_{145}, \mathrm{VEGF}_{148}, \mathrm{VEGF}_{162}, \mathrm{VEGF}_{165}$, $\mathrm{VEGF}_{183}, \mathrm{VEGF}_{189}$ und $\mathrm{VEGF}_{206}$ bezeichnet. Die VEGF-Subtypen zeigen sowohl eine Spezifität hinsichtlich der Bindung an die verschiedenen VEGF-Rezeptoren als auch in ihrer biologischen Wirkung. Die Subtypen VEGF-A, VEGF-B und PIGF sind hauptsächlich Effektoren an vaskulären Endothelzellen, während VEGF-C und VEGF-D an der Regulation der lymphatischen Angiogenese beteiligt sind (Abbildung 4). VEGF wird in der Plazenta vor allem im Zytotrophoblasten, Synzytiotrophoblasten und villösen Stroma exprimiert [70, 71].

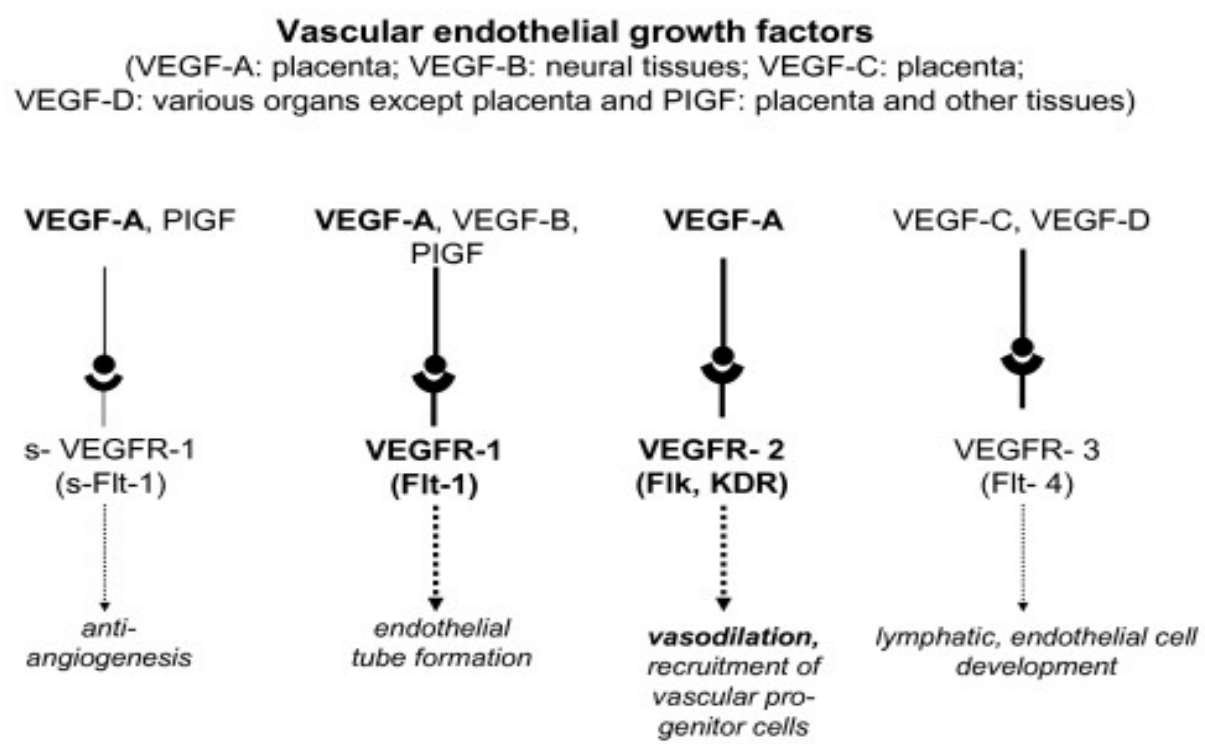

Abbildung 4: VEGF Formen, deren biologische Wirkung und Rezeptoren [62] 
Hypoxische Bedingung führen $\mathrm{zu}$ einer gesteigerten Expression, hauptsächlich von VEGF, in geringerem Maße auch von Flt-1, Flk-1 und sFlt-1 [72, 73, 74]. Eine Ischämie in der Plazenta ist folglich durch gesteigerte Expression von sFlt Auslöser der Präeklampsie.

Ein weiterer Transkriptionsregulator von VEGF und Flt-1 ist HIF-1 $\alpha$ [75]. In Plazenten präeklamptischer Patientinnen wurden signifikant erhöhte Konzentrationen von HIF-1 $\alpha$ und HIF-2 $\alpha$-Protein nachgewiesen [76].

Eremia et al. haben gezeigt, das VEGF in der Niere für die Aufrechterhaltung der normalen glomerulären Zellfensterung essentiell ist [77, 78]. Die Vermutung, dass der Glomerulusschaden im Sinne einer Endotheliose bei der Präeklampsie durch VEGF mitverursacht wird, ist naheliegend. Ein weiteres Indiz für VEGF als wichtiger Faktor in der Entstehung der Präeklampsie ist die Tatsache, dass in der onkologischen Therapie mit monoklonalen VEGF-Antikörper behandelte Patienten, einen Bluthochdruck und eine Proteinurie entwickeln [79, 80]. Im Verlauf einer normalen unauffälligen Schwangerschaft konnte ein kontinuierlicher Anstieg von VEGF im Serum festgestellt werden, der kurz nach der Geburt wieder auf das Niveau vor der Schwangerschaft abfällt [81].

\section{PIGF}

PlGF (placental growth factor) ist ein weiteres Glykoprotein aus der Familie der vaskulären endothelialen Wachstumsfaktoren mit einer zu 53\% identischen Sequenz und gleicher biologischer Wirkung von VEGF [82]. Von PIGF sind zwei Isoformen, PlGF-1 und -2, bekannt. Da PlGF in der humanen Plazenta unmittelbar im Synzytiotrophoblasten exprimiert wird, besteht ein direkter Kontakt zur maternalen Zirkulation [83]. VEGF und PIGF sind gemeinsam mit Angiopoetin-1 und -2 an Umwandlung, Wachstum und Differenzierung während der Gefäßentwicklung beteiligt [84]. PlGF bindet an den VEGFR-1 (Abbildung 5) und verdrängt dort VEGF, was synergistische Effekte am VEGFR-2 verursacht [85]. Während einer unauffälligen Schwangerschaft steigt PIGF im Serum bis zu einem Maximum in der 29.-32. SSW kontinuierlich an, um dann bis zur Geburt wieder abzufallen [86]. 
1.2.1.2

Rezeptoren

\section{VEGF Rezeptor}

VEGF/PIGF aktivieren über folgende 3 spezifische Rezeptor-Tyrosinkinasen verschiedene Signaltransduktionswege und vermitteln so ihre biologischen Effekte:

- VEGF-Rezeptor-1 (fms-like tyrosinekinase, Flt-1);

- VEGF-Rezeptor-2 (fetal liver kinase 1, Flk-1 bzw. kinase insert domain region, KDR)

- VEGF-Rezeptor-3 (Flt 4)

Die Rezeptoren bestehen aus verschiedenen Domänen, wobei die Tyrosinkinasedomäne Bestandteil der intrazellulären Domäne ist. Außerdem existieren eine transmembranösen Domäne, eine regulierende juxtamembranösen Domäne, eine Sequenz mit verschiedenen Tyrosinresten und insgesamt sieben extrazelluläre Immunglobulin-ähnliche Domänen [87, 88] (Abbildung 5). Durch die Bindung an die spezifischen Membranrezeptoren kommt es zur Dimerisierung, Autophosphorylierung und Konformationsänderung der zytosolischen Domäne, wobei die Aktivierung intrazellulärer Kinasen weitere Signalkaskaden in Gang setzt [63, 89]. Andere zelluläre Proteine wie Neuropillin-1 und -2, Heparine, Integrine und Cadherine sind an der Regulation der Aktivität der Rezeptoren beteiligt. Hauptsächlich werden die Rezeptoren auf Endothelzellen exprimiert, konnten aber auch auf verschiedenen Nicht-Endothelzellen nachgewiesen werden.

\section{sFlt}

sFlt (soluble fms-like tyrosine kinase) ist die lösliche Form des membrangebundenen Rezeptors Flt-1 (Abbildung 5). Durch alternatives Spleißen fehlen diesem die siebente Immunglobulin-ähnliche Domäne, die Transmembransequenz und die intrazelluläre Tyrosinkinasedomäne. VEGF weist eine hohe Affinität zu sFlt auf und bildet mit diesem einen stabilen Komplex [90]. 
Die Konkurrenz von sFlt mit dem membrangebundenen Rezeptor Flt-1 um VEGF bewirkt eine kompetitive Hemmung mit Unterdrückung der biologischen Effekte von VEGF. Verabreicht man schwangeren Ratten sFlt, führt das $\mathrm{zu}$ einer präeklampsieähnlichen Symptomatik mit Hypertonie, Proteinurie und glomerulärer Dysfunktion, was sowohl in vitro als auch in vivo Modellen gezeigt wurde [91, 92].

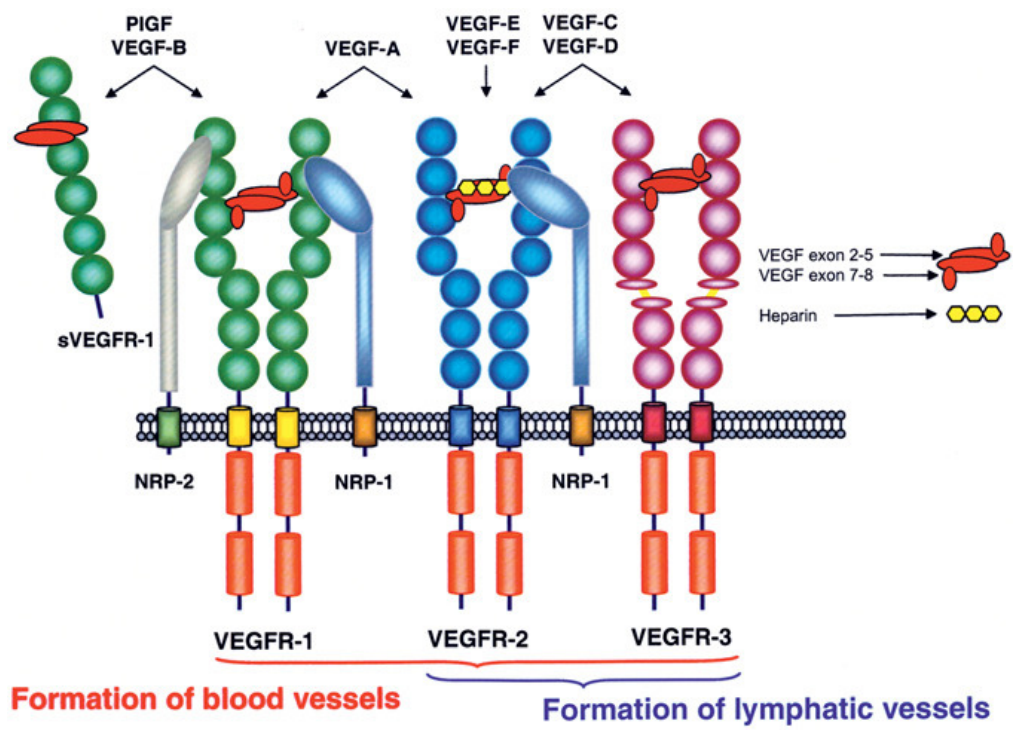

Abbildung 5: Rezeptoren der verschiedenen VEGF Subtypen [87]

\section{sEng}

Der Co-Rezeptor Endoglin (sEng) wurde 1999 von Raab et al. erstmals beschrieben [93]. Endoglin bindet mit hoher Affinität unter anderem TGF- $\beta_{1}$ und TGF- $\beta_{3}$ und bildet einen Komplex mit deren Typ-I- und Typ-II-Rezeptoren. sEng wird hauptsächlich auf Endothelzellen exprimiert [94]. Die Bedeutung von sEng in der Angiogenese wird durch folgende Erkenntnisse deutlich: Eine Mutation des Endoglin Genes verursacht die autosomal dominant vererbte hereditäre hämorrhagische Teleangiektasie Rendu-OslerWeber-Syndrom (HHT). Mäuse, denen das Endoglin Gen fehlt, starben an kardiovaskulären Fehlbildungen [95]. 
Wegweisend in der Untersuchung von sEng als weiterer ursächlicher Faktor in der Entstehung der Präeklampsie, war die Arbeit von Venkatesha et al. 2006 [96]. Die Verabreichung von sEng in Kombination mit sFlt führte bei schwangeren Ratten zu schweren Präeklampsien mit der Ausbildung eines HELLP-Syndroms und Wachstumsretardierungen. Vermutlich entsteht sEng, im Gegensatz zu sFlt, nicht durch alternatives Spleißen, sondern durch proteolytische Prozesse. Peptidsequenzen von sEng weisen darauf hin, dass es sich um ein N-terminales Spaltprodukt von Endoglin handelt, welches unter anderem in der Plazenta produziert wird. Die Arbeitsgruppe um Karumanchi et al. fand eine vierfach erhöhte Expression von sEng in Plazenten präeklamptischer Frauen im Vergleich zu gesunden Schwangeren [96]. sEng blockiert in Endothelzellen die TGF- $\beta 1$-vermittelte Aktivierung der NO-Synthase und damit die Vasodilatation. TGF- $\beta 1$ induziert in Perizyten die Bildung von VEGF [97]. Diskutiert wird auch eine Hemmung von VEGF über TGF- $\beta 1$ [96].

Unbestritten ist mittlerweile die Beteiligung von sEng als kausaler Faktor in der Pathogenese der Präeklampsie [98, 99]. Die sEng-Konzentration im Plasma gesunder schwangerer Frauen fällt im ersten und zweiten Trimenon zunächst etwas ab und steigt gegen Ende der Schwangerschaft, vermutlich mit zunehmender Plazentamasse, wieder an [100]. 


\subsubsection{Gleichgewicht der Faktoren}

Das durch Inaktivierung von VEGF/PIGF durch sFlt und sEng entstandene Ungleichgewicht zwischen den angiogenen Faktoren führt zur endothelialen Dysfunktion (Abbildung 6). Die Erkenntnis, dass die anti- und proangiogenen Faktoren aus dem Plasma präeklamptischer Frauen einen unmittelbaren Einfluß auf den Gefäßwiderstand haben, war ein entscheidender Ansatz zur Klärung der endothelialen Dysfunktion.
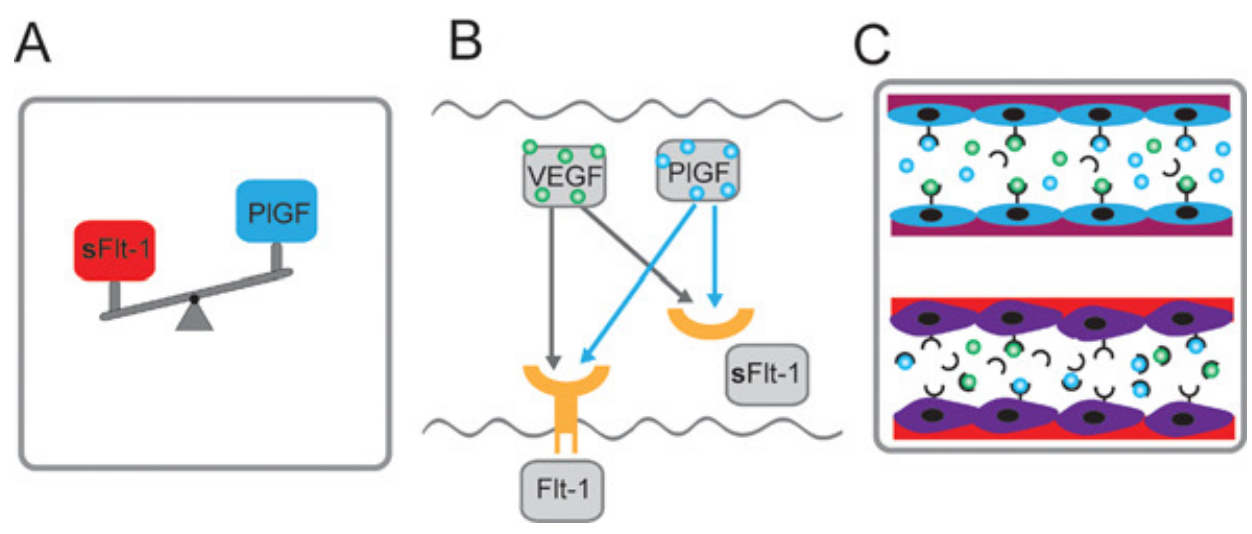

Abbildung 6: Gleichgewicht der angiogenen Faktoren [101]

A: Die Verschiebung des angiogenen Gleichgewichtes zugunsten sFlt-1 führt zu einer antiangiogenen Situation

B: sFlt konkurriert mit Flt-1 um VEGF/PIGF

C: Bindung von sFlt mit VEGF/PIGF führt zu abfallenden Serumkonzentrationen der Faktoren das endotheliale Gleichgewicht ist gestört.

Torry et al. zeigten 1998 als erste Arbeitsgruppe, dass die Präeklampsie mit erniedrigten PIGF-Spiegeln assoziiert ist [102]. In Vitro Studien an isolierten humanen Widerstandsgefäßen führten nach Inkubation mit VEGF bzw. dem Plasma präeklamptischer Frauen zunächst zu einer Senkung der endothelabhängigen Relaxation [103, 104]. Im Gegensatz zur Arbeit von Brockelsby wurde 2003 gezeigt, dass VEGF und PIGF zu einer Gefäßrelaxation führt, welche durch Zugabe von sFlt antagonisiert wird [105]. Damit wurde deutlich, dass sFlt als direkter Antagonist von VEGF und PIGF agiert. Maynard et al. zeigten in dieser Studie auch, dass die Serumspiegel von sFlt bei erkrankten Frauen erhöht sind. Eine erhöhte Expression des sFlt-1-Rezeptors wurde auch bei Erstgebärenden im Vergleich zu Mehrgebärenden nachgewiesen [106]. 
Dies ist eine mögliche Erklärung für das bekannte 3-5fach erhöhte Risiko einer Nullipara an einer Präeklampsie zu erkranken.

$\mathrm{Zu}$ den VEGF-Serumspiegeln gab es sehr unterschiedliche Aussagen. Einige Arbeitsgruppen fanden höhere VEGF-Serumkonzentrationen bei präeklamptischen Frauen im Vergleich zu den Kontrollgruppen [107, 108, 109], andere beobachteten erniedrigte Serumspiegel [110, 111, 112]. Die Ursache hierfür liegt in der Messmethode (RIA vs. ELISA). Erhöhte VEGF-Spiegel sprechen für die Bestimmung des GesamtVEGF - einschließlich des an Carrierproteine (z.B. sFlt) gebundenen VEGF's. Erniedrigte bzw. unveränderte Spiegel wurden bei der Bestimmung des freien ungebundenen VEGF's, welches das entscheidende für die biologische Wirkung ist, festgestellt [113]. Die Sensitivität für die Bestimmung von VEGF und PIGF liegt mit den üblichen Essays bei 30 und 7 pg/ml. Die VEGF-Spiegel liegen bei gesunden Schwangeren und im ersten Trimenon in der Regel unterhalb dieser zuverlässigen Nachweisgrenze [114], so dass PIGF der nützlichere Screeningmarker in der Routine ist.

In zwei großen klinischen Studien konnte bestätigt werden, dass im Plasma von Schwangeren, die eine Präeklampsie entwickeln, die sFlt- und sENG-Konzentrationen drastisch ansteigen, wohingegen PIGF spiegelbildlich abfällt [86, 100]. Mittlerweile wurde dies in zahlreichen Studien reproduziert $[115,116,27,117,118,119,120,121$, $122]$.

Erste klinische Untersuchung zu sFlt und sEng, im Rahmen der CPEP (Calcium for Pre-eclampsia Prevention) Studie von Levine et al. 2004, erbrachte folgende Erkenntnisse: Im Durchschnitt kommt es fünf Wochen vor Auftreten der Erkrankung zum Anstieg des sFlt-Serumspiegels. Signifikante Unterschiede in den PIGF-Spiegeln von gesunden und erkrankten Frauen werden ab der 13.-16. SSW beobachtet, allerdings sind die Unterschiede in den Wochen unmittelbar vor Auftreten der Erkrankung wesentlich aussagekräftiger und korrelieren mit dem sFlt-Anstieg. Die Änderungen in den Serumspiegel von sFlt und PIGF sind bei Schwangeren mit einer Early-onsetPräeklampsie oder einer Präeklampsie in Kombination mit einer Wachstumsretardierung grundsätzlich ausgeprägter. 
In Nähe des Geburtstermins sind die Unterschiede zwischen den Serumspiegeln gesunder und präeklamptischer Frauen nicht so markant [86]. Bei Frauen die an einer Präeklampsie erkranken, werden bereits in der 17.-20. SSW, durchschnittlich 2-3 Monate vor Auftreten der Erkrankung, signifikant erhöhte sEng-Spiegel gemessen [100]. Steigen die sEng-Spiegel an, wird ein zeitgleicher Anstieg der sFlt-1/PIGF-Ratio beobachtet.

Allerdings ist keiner der Marker spezifisch für die Präeklampsie. Folgende weitere schwangerschaftstypische Erkrankungen sind auf eine angiogene Dysbalance zurückzuführen und zeigen, wenn auch moderater und weniger drastisch als bei der Präeklampsie, Veränderungen in den Serumspiegeln von sFlt, PIGF und dem sFlt1/PlGF-Quotienten:

- IUGR [123, 124, 125, 126, 127, 128]

- vorzeitige Plazentalösung [129]

- intrauteriner Fruchttod unklarer Ursache [130]

- Fetofetales Transfusionssyndrom [131]

- 'mirror syndrome’[132] 


\subsubsection{Vasodilatatoren}

\section{Stickstoffmonoxid (NO)}

Stickstoffmonoxid entsteht durch die Spaltung von L-Arginin in Stickstoffmonoxid und L-Citrullin durch die NO-Synthase, die in 3 Formen exisitiert - neuronal, endothelial und induzierbar $\left(\mathrm{Ca}^{2+}\right.$-unabhängig). Stickstoffmonoxid wird eine entscheidende Rolle in der Vasodilatation vor der Trophoblastinvasion an der Implantationsstelle zugeschrieben [61, 133]. Was die lokale Expression der endothelialen NO-Synthase in den plazentaren Bestandteilen anbetrifft, ist die Studienlage recht unterschiedlich [62]. Unbestreitbar ist jedoch, dass der vasodilatative Effekt von VEGF über Stickstoffmonoxid vermittelt wird [62]. Die Arbeitsgruppe von Savvidou et al. konnte einen Zusammenhang zwischen einer Perfusionsstörung im Doppler der A. uterina und der Serumkonzentration von ADMA (asymmetric dimethylarginine), einem endogenen Inhibitor der endothelialen NO-Synthase, bei präeklamptischen Frauen zeigen, ein weiteres Indiz für die Beteiligung von Stickstoffmonoxid an der endothelialen Dysfunktion [134].

\section{Renin-Angiotensin System (RAS)}

Einige Publikationen haben das Renin-Angiotensin-System als Fokus für das gestörte angiogene Gleichgewicht untersucht. Entgegengesetzt ursprünglicher Annahmen hat das Renin-Angiotensin-System neben vasokonstriktiven auch vasodilatative Komponenten. Angiotensin II wirkt am $\mathrm{AT}_{2}$-Rezeptor und Angiotensin-(1-7) am mas-Rezeptor vasodilatativ [135]. Beide vermitteln ihre vasodilatative Wirkung über $\mathrm{NO}, \mathrm{PGI}_{2}$ und Kinine und haben zusätzlich u.a. antiangiogene und antiproliferative Effekte [62]. Bei Schwangeren steigen von Angiotensin-(1-7) sowohl die Serumkonzentrationen (1,5fach) als auch die Ausscheidungsraten im Urin (ab 12.-14.SSW) im Vergleich zu Nichtschwangeren. Bei präeklamptischen Patientinnen wurden einerseits erniedrigte Angiotensin-(1-7)-Spiegel im Serum, andererseits eine unveränderte Expression von Angiotensin-(1-7) und Angiotensin-konvertierendem Enzym (ACE) sowie ansteigende Angiotensin II-Spiegel in der Plazenta nachgewiesen [136, 137] . 
Hierdurch wird eine Umverteilung im Renin-Angiotensin-System zugunsten des vasokonstriktiven Armes (Angiotensin II am $\mathrm{AT}_{1}$-Rezeptor) hervorgerufen.

Die gestörte immunologische Toleranz ist einer der Faktoren, die in der Pathogenese der Präeklampsie immer wieder eine entscheidende Rolle spielt. Wallukat et al. entdeckten einen Autoantikörper mit agonistischen (vasokonstriktiven) Eigenschaften am $\mathrm{AT}_{1}$-Rezeptor [138]. Die Beteiligung der Autoantikörper an der Pathogenese der Präeklampsie wurde auch von anderen Arbeitsgruppen gezeigt [139, 140]. Über die Art und Weise der Beeinflußung gibt es verschiedene Untersuchungen. Einerseits hat man in Mausmodellen einen Anstieg von sFlt-1 nach Gabe von Autoantikörpern beobachtet [141]. Andere Studien konnten das nicht belegen, dort waren die Serumspiegel von sFlt, VEGF und PlGF in Anwesenheit von Autoantikörpern unverändert [142]. Wie auch immer erhöhte $\mathrm{AT}_{1}$-Autoantikörper wurden sowohl bei Patientinnen mit Präeklampsie als auch mit maligner Hypertension gefunden. Andere Untersuchungen fanden massiv erhöhte $\mathrm{AT}_{1}$-Rezeptor-Heterodimere bei präeklamptischen Schwangeren im Vergleich zu normotensiven Schwangeren [143].

\section{Prostaglandine}

$\mathrm{PGI}_{2}$ (Prostacyclin) und $\mathrm{TXA}_{2}$ (Thromboxan $\mathrm{A}_{2}$ ) sind die in der Schwangerschaft am besten studierten Mediatoren im Prostaglandinsystem. $\mathrm{PGI}_{2}$ wirkt vasodilatativ, ist der effektivste endogene Inhibitor der Plättchenaktivierung und wird vom Endothel synthetisiert [144]. Es wirkt entweder direkt oder als Gegenspieler des vasokonstriktiven und gerinnungsaktivierenden $\mathrm{TXA}_{2}$. Eine verminderte Prostacyclinfreisetzung bei hypertensiven Schwangerschaftserkrankungen führt zu einer thrombozytären Hyperaktivität mit nachfolgend gesteigerter Thromboxanfreisetzung. Im villösen Zytotrophoblasten und im Zottenstroma von Plazenten präeklamptischer Frauen wurde eine vermehrte Produktion von Thromboxan nachgewiesen. In Studien konnte für beide Metaboliten eine verminderte bzw. vermehrte Exkretion im Urin festgestellt werden [145]. Dies führt $\mathrm{zu}$ einer Verschiebung der Thromboxan/Prostacyclin-Ratio zugunsten des TXA 2 [146, 147]. Diese Ergebnisse waren Anlass für zahlreiche klinische Studien mit Low-dose-Aspirin - in der Hoffnung die Gabe eines COX (Cyclooxygenase) Hemmers würde das Ungleichgewicht, durch eine Reduktion der Thromboxansynthese, zugunsten von Prostacyclin wiederherstellen. 
In der CLASP-Studie (Collaborative Low-Dose Aspirin Study in Pregnancy) waren die Ergebnisse mit einer Reduktion der Präeklampsieinzidenz um 12\% eher bescheiden [148]. Dies lies vermuten, dass mehr als nur eine gesteigerte Thromboxansynthese für die Präeklampsie ursächlich ist.

\subsection{3 weitere Faktoren}

\section{Plazentaprotein 13 (PP 13)}

PP-13 wird als ,pregnancy-related protein“ vom Synzytiotrophoblasten synthetisiert. Durch Bindung von Proteinen der extrazellulären Matrix zwischen Plazenta und Endometrium ist es an der Regulation der Embryogenese, Embryoimplantation und Trophoblastinvasion beteiligt [149]. 1983 wurde PP-13 erstmals beschrieben und isoliert [150]. Bei Schwangerschaftskomplikation wie Präeklampsie, Wachstumsretardierung und Frühgeburtlichkeit wurden im 1. Trimenon zunächst erniedrigte maternale PP-13-Serumwerte, im 2./3. Trimenon dann erhöhte PP-13-Serumwerte, nachgewiesen [151].

\section{Pentraxin 3 (PTX3)}

PTX3 wird als Akute-Phase-Protein u.a. von Endothelzellen produziert, spielt eine Rolle im Immunsystem und ist dort maßgeblich an der Erkennung von Antigenen beteiligt. Seit einiger Zeit wird es in Zusammenhang mit der gestörten maternalen Response im Rahmen der Präeklampsie gebracht. Erste Studien im ersten Trimester haben signifikant höhere PTX3-Level bei Frauen, die später eine Early-onsetPräeklampsie entwickelten, nachgewiesen [152, 153].

\section{CYR61 (CCN1) und NOV (CCN3)}

CYR61 (Cystein rich 61) und NOV (nephroblastoma overexpressed), ebenfalls Wachstums- und Angiogenesefaktoren, sind an der Regulation unterschiedlicher Prozesse wie Adhäsion, Proliferation und Angiogenese beteiligt und werden u.a. durch Integrine vermittelt $[154,155]$. 
Die pro-angiogenetische Wirkung von CYR61 und NOV wurde in verschiedenen Untersuchungen belegt. Die Expression konnte in den Endothelzellen der Gefäße während der Embryogenese und in den villösen Stromazellen nachgewiesen werden [31]. In anderen Untersuchungen führten ausbleibende Gefäßverzweigungen und nachfolgend eine gestörte Vaskularisierung der Plazenta bei CYR61-defizienten Mäusen zum Absterben der Embryonen [156]. Signifikant niedrigere Expressionslevel von CYR61 und NOV konnten in Plazenten von Schwangeren, die eine Präeklampsie vor der 34. SSW entwickelten, nachgewiesen werden [31]. 


\subsection{Prädiktion und Prävention}

Seit über zwei Jahrzehnten sind Forscher auf der Suche nach zuverlässigen Screeningverfahren und sinnvollen präventiven Maßnahmen für die Präeklampsie. Erst mit zunehmendem Verständnis über die Pathophysiologie der Erkrankung, sowie die Biologie der in diese Prozesse involvierten Mediatoren, gelang es, erste Erfolge zu erreichen.

\subsubsection{Prädiktion}

Die einzig kausale Therapie der Präeklampsie ist weiterhin die Entbindung. Durch eine frühzeitige und exakte Diagnose ist eine Risikostratifizierung möglich, was einerseits die adäquate Betreuung in einem Perinatalzentrum, andererseits die rechtzeitige Intervention mit Acetylsalicylsäure ermöglicht. Die Prognose der schwangerschaftsspezifischen Multisystemerkrankung wird hierdurch erheblich verbessert. Frühzeitig meint hier, vor allem zu einem Zeitpunkt, an dem zwar die pathophysiologischen Veränderungen erfolgt sind, klinische Symptome aber noch nicht aufgetreten sind. Optimal wäre eine Früherkennung im 1. Trimenon oder spätestens zu Beginn des 2. Trimenons.

Die zielgerichtete Einteilung in Risikogruppen ausschließlich nach maternalen Risikofaktoren und Anamnese ist sinnvoll und erhöht im Sinne einer Vorselektion die Zuverlässigkeit weiterer Tests. Dennoch ist die Vorauswahl ausschließlich mit den bisher üblichen Methoden nicht aussagekräftig genug. Eine Auswertung in United Kingdom ergab, dass nach dieser Screeningstrategie 60\% aller schwangeren Frauen einer Hochrisikogruppe zugeordnet werden, davon aber weniger als $30 \%$ eine Präeklampsie entwickeln [153, 157]. In der Prädiktion sollten sowohl die fetoplazentare Einheit als auch maternale Komponenten berücksichtigt werden. Ein Review der WHO untersuchte über 50 publizierte Screeningtests im Zeitraum von 1966-2004 und befand keinen der Tests als ausreichend für die zuverlässige Erkennung der Präeklampsie in der klinischen Routine [158]. Die gleiche Arbeitsgruppe gab eine nochmalige Empfehlung zu den Anforderungen an einen prädiktiven Test: schnell, reproduzierbar, zuverlässig, allgemein verfügbar und kostengünstig. Ein weiteres Kriterium für einen 
Präeklampsie-Screeningtest ist die leichte, möglichst nicht invasive und risikoarme Durchführbarkeit in der Frühschwangerschaft. Bedingung für einen aussagekräftigen Screeningtest sind eine hohe positive Likelihood Ratio $(>10)$ und eine niedrige negative Likelihood Ratio $(<0,1)$ [158]. Die meisten der bisher untersuchten Marker haben einen schlechten positiven Vorhersagewert und sind in ihrer Nutzung durch Änderung der Serumspiegel erst zu einem fortgeschrittenen Zeitpunkt der Erkrankung eingeschränkt.

Fibronektin, Thromboxan und Prostacyclin wurden in Studien als Biomarker für die endotheliale Dysfunktion auf maternaler Ebene untersucht. Etwa 4 Wochen vor Auftreten einer manifesten Präeklampsie wurden erhöhte Fibronektinspiegel im Serum gefunden [159]. In einer Untersuchung ist bei einem Cut-off-Wert von $225 \mathrm{mg} / \mathrm{l}$ eine positive Prädiktion von $48 \%$ beschrieben [160]. Da die Fibronektinspiegel im 3. Trimenon physiologischerweise um 20\% ansteigen, ist die Beurteilung allerdings schwierig und eine Anwendung in der klinischen Routine kaum sinnvoll [161]. Auf Thromboxan und Prostacyclin wurde bereits im letzten Kapitel eingegangen. Mit NGAL (neutrophil gelatinase-associated lipocalin) kam ein neuer Marker in die Diskussion. Das Glykoprotein wird von neutrophilen Granulozyten freigesetzt und mit endothelialer Dysfunktion in Zusammenhang gebracht. In Studien wurden bereits in der 9.-11. SSW erhöhte Serumlevel gefunden. Bei einer positiven Likelihood Ration von nur 5,5 wäre allenfalls eine Kombination mit anderen Markern für eine suffiziente Prädiktion denkbar [162, 163].

Ein weiteres von der Präeklampsie betroffenes Organ auf maternaler Ebene ist die Niere. Im Zusammenhang mit der gestörten glomerulären Filtrationsrate wurden in Untersuchungen für Cystatin C erhöhte Serumlevel bei Präeklampsie gefunden [164, 165]. Cystatin C stört als Proteasehemmer die Trophoblastinvasion. Erste erfolgreiche Untersuchungen gibt es zu Cystatin $\mathrm{C}$ und CRP als unabhängige Marker in Kombination mit dem uterinen Doppler [166]. Bereits Ende der 80er-Jahre haben Studien die Kalziumausscheidung als potentiellen Prädiktor für die renale Dysfunktion im Rahmen einer Präeklampsie untersucht. Die von manchen Autoren nachgewiesene Hypokalciurie zwischen der 10.-24. SSW konnte sich als Screeningmethode wegen fehlender Reproduzierbarkeit und schlechter positiver Prädiktion nicht durchsetzen [167, 168]. 
HCG und Inhibin A waren als Produkte der fetoplazentaren Einheit vielversprechende Kandidaten als Prädiktoren für die biochemischen Veränderungen auf dieser Ebene. Verschiedene Studien konnten zwar einen Zusammenhang zwischen HCG und der späteren Entwicklung einer SIH bzw. Präeklampsie nachweisen: ein 1,7fach erhöhtes Risiko für eine SIH bzw. ein 6,9fach erhöhtes Risiko für eine Präeklampsie bei HCG-Werten $\geq 2,0$ MOM zwischen der 15.-18.SSW, scheitern in ihrer Verwendbarkeit allerdings auch an einem schlechten positivem Vorhersagewert [169]. Auch Inhibin A und andere Endothelzelladhäsionsmoleküle wie zum Beispiel ICAM-1 (intercellular adhesion molecule-1) und VCAM-1 (vascular cell adhesion molecule-1), sind zwischen der 13.-18. SSW bei Frauen mit späterer Präeklampsie signifikant erhöht [170, 171], konnten sich aber auch in keinem Testverfahren etablieren. Sowohl IMA (ischaemia modified albumin) als auch PAPP-A (pregnancy-associated plasma protein A) und PP-13 (Plazentaprotein-13) zeigen veränderte Serumspiegel im ersten Trimenon und sind als neue Marker der gestörten plazentaren Dysfunktion und Hypoxie vor allem in der Kombination mit dem uterinen Doppler hoffnungsträchtig. Bedauerlicherweise sind die Ergebnisse für den positiven Vorhersagewert der einzelnen Marker bisher auch nicht zufriedenstellend [172, 173, 174, 175].

Die verlässlichsten reproduzierbaren Ergebnisse auf der Suche nach Serummarkern für die Prädiktion hat man bisher für die angiogenen Faktoren PIGF, sFlt-1, sEng und dem Quotienten aus sFlt-1/PIGF bzw. sEng/PIGF gefunden. Die Quotienten liefern die beste Aussagekraft, was aus Sicht der pathophysiologischen Überlegung einer Dysbalance der proangiogenen und antiangiogenen Faktoren einen Sinn ergibt. In einer Studie von de Vivo et al. wird für die sFlt-1/PIGF-Ratio eine Sensitivität und Spezifität von 88,5\% bei einer negativen Likelihood Ratio von 0,13 angegeben [119]. Die günstigsten Ergebnisse werden erzielt, wenn als Outcome Marker eine Early-onset-Präeklampsie definiert ist. Bei der Early- onset-Präeklampsie beträgt die Sensitivität $89 \%$ und die Spezifität 97\% im Vergleich zur Late-onset-Präeklampsie, bei der die Sensitivität bei 74\% und die Spezifität bei 89\% liegt [27]. Kusanovic et al. untersuchten den Quotienten aus sEng und PIGF und errechneten in der 20.-25. SSW für die Early-onsetPräeklampsie überzeugende Ergebnisse: eine Sensitivität von 100\%, eine Spezifität von 98\% und eine positive Likelihood Ratio von 89,6 [118]. 
Ein weiteres überzeugendes Argument für die Anwendung obengenannter angiogener Faktoren, vor allem in der klinischen Routine, ist die Möglichkeit der automatisierten Messung in Hochdurchsatzautomaten (Elecsys®/ Cobas, Roche Diagnostic) [27].

Die Dopplersonografie der A. uterina spiegelt die Widerstandsverhältnisse im plazentaren Gefäßbett wieder und wurde erstmals 1983 von Campell et al. beschrieben [176, 177]. Obwohl der Doppler eine sehr sensitive Methode ist, wird er vor allem durch hohe falsch positive Raten, durch eine begrenzte Vorhersagekraft und eine begrenzte Spezifität limitiert [178]. Nichtsdestotrotz ist in der klinischen Routine dieses Verfahren bei guter Praktikabilität durchaus etabliert. Durch Empfehlung zweizeitiger Dopplermessungen in der 18.-22. SSW und in der 24. SSW konnten bessere Vorhersagewerte erzielt werden: Bei persistierendem erhöhten Widerstandsindex oder bilateralem Notch liegt ein 68fach erhöhtes Präeklampsierisiko mit einem negativen Vorhersagewert von 99,5\% und einer positiven Prädiktion von $28 \%$ vor [179]. Ziel ist es, die Screeningverfahren in das 1. Trimenon $\mathrm{zu}$ verlagern. Studien $\mathrm{zu}$ Doppleruntersuchungen in der 11.-13. SSW ergaben ähnliche Ergebnisse: Für die Early-onset-Präeklampsie ergibt sich bei einer Sensitivität von $82 \%$ eine Falsch-Positive-Rate von 10\% [180].

Die Idee die Dopplersonografie mit einem unabhängigen Serumparameter zu kombinieren und so als Screeningmethode aufzuwerten, erscheint plausibel. Verschiedene Studien haben hierzu die Kombination von sFlt, sEng, PIGF und dem Doppler untersucht. Durch die parallele Messung von uterinem Doppler, sFlt-1 und PIGF wird allein die Spezifität für alle Präeklampsien, egal welcher Schwangerschaftswoche, von $46 \%$ auf $73 \%$ verbessert. Vergleichbar mit der isolierten Betrachtung der Faktoren werden noch bessere Testwerte für die Erkennung einer Early-onset-Präeklampsie erzielt: eine Spezifität von 95\%, eine Sensitivität von $83 \%$ und ein positiver Vorhersagewert von 71\% [117]. Die Arbeitsgruppe um Stepan et al. zeigte die Verbesserung der prädiktiven Fähigkeit der Perfusionsmessung durch die Kombination von uterinem Doppler mit den antiangiogenen Faktoren sEng und sFlt. Bei den Early-onset-Präeklampsien wurde eine Sensitivität von 99\%, eine Spezifität von 93\% und eine positive Vorhersage von 71\% erreicht [181] (Abbildung 7). 


$\begin{array}{llll}\text { Prädiktion: } & \text { Sens. } & \text { Spez. } & \text { PPA } \\ \text { Doppler } & & & \\ & & & \\ \text { Komplikation } & 68 \% & 60 \% & 58 \% \\ \text { PE } & 77 \% & 46 \% & 33 \% \\ \text { PE <34. SSW } & 67 \% & 76 \% & 31 \% \\ & & & \\ & & & \\ \text { Doppler + sEng + sFlt1 } & & & \\ & & & \\ \text { Komplikation } & 63 \% & 82 \% & 51 \% \\ \text { PE } & 60 \% & 89 \% & 50 \% \\ \text { PE < 34. SSW } & 99 \% & 93 \% & 71 \%\end{array}$

\section{Abbildung 7: Prädiktive Wertigkeit der uterinen Perfusionsdiagnostik und angiogener Faktoren im 2. Trimenon [181]}

Es existieren zahlreiche Biomarker deren Potential in der Kombination und in der Anwendung in Mehrphasentests liegt. Gelingt es ein Konzept zu entwickeln, das alle pathophysiologischen Abläufe der Präeklampsie widerspiegelt, wird es auch gelingen die Erkrankung zuverlässig und frühzeitig vorherzusagen. 2009 wurde ein vielversprechendes Modell als mögliches Ersttrimesterscreening publiziert: Durch die Kombination von uterinem Doppler, maternalen MAP (mittlerer arterieller Druck), PAPP-A und PIGF wurde eine Sensitivität und Spezifität von $94 \%$, eine positive Likelihood Ratio von 16,5, eine negative Likelihood Ratio von 0,06 und eine falsch positive Rate von 5\% erreicht $[182,153]$.

\subsubsection{Prävention}

Bisher gab es kaum einen sinnvollen Ansatz zur Prävention der Präeklampsie. Für folgende Wirkstoffe wurde, wenn auch ein minimaler und mit Einschränkungen verbundener Effekt, beschrieben: Low-dose Aspirin, Heparin und $\mathrm{Ca}^{++}$[183].

Die Verabreichung von niedrig dosiertem ASS zur Verhinderung der Präeklampsie wurde viel untersucht und kontrovers diskutiert. Eine Metaanalyse von 31 randomisierten Studien mit insgesamt 32.217 untersuchten Frauen stellte sowohl eine Reduktion der Inzidenz der PE als auch der Frühgeburtlichkeitsrate jeweils um ca. $10 \%$ fest [184]. 
Ein Cochrane Review lieferte ein ähnliches Ergebniss, wobei hier zusätzlich eine Reduktion von fetalen oder neonatalen Todesfällen festgestellt werden konnte [185]. Bisher ist die Gabe im Hochrisikokollektiv (vorausgegangene schwere Präeklampsie bzw. Wachstumsretardierung, Antiphospholipidantikörpersyndrom) allgemein empfohlen. Eine aktuelle Metaanalyse von 5 Studien kam zu dem Ergebniss, dass Lowdose Aspirin vor der 16. SSW verabreicht, das Risiko einer Early-onset-Präeklampsie, nicht aber einer Late-onset-Präeklampsie, reduziert [186]. Trotz des wiederholt umstrittenen Effektes steht mit Acetylsalicylsäure weiterhin ein risikoarmes, leicht verfügbares und kostengünstiges Medikament als präventive Option zur Verfügung.

In einzelnen Studien konnte für die Gabe von Low-dose Heparin ein präventiver Effekt ausschließlich bei Frauen mit einer Thrombophilie oder einer renalen Erkrankung nachgewiesen werden $[187,188]$. Eine andere Studie fand bei Schwangeren mit einem hohen Präeklampsierisiko, jedoch ohne nachgewiesene Thrombophilie, eine deutliche Risikoreduktion für das Auftreten einer schweren Komplikation wie einer Early-onsetPräeklampsie, einer vorzeitigen Plazentalösung, einer Wachstumsretardierung oder eines intrauterinen Fruchttodes [189]. Bislang ist der Einsatz von niedermolekularen Heparinen jedoch ohne gesicherte Studienbasis.

Die Einnahme von $\mathrm{Ca}^{++}$-Präparaten erwies sich nur für Frauen mit einem hohen Risiko für Bluthochdruck und in Gegenden mit einer $\mathrm{Ca}^{++}$-Mangelernährung als vorteilhaft, hatte aber keinerlei Effekt auf das perinatale Outcome [190]. Für diverse andere präventive Versuche, wie Antioxidantien (Vitamin $\mathrm{C}$ und $\mathrm{E}$ ), $\mathrm{Mg}^{++}$- oder Zink-Supplementierung, Eiweiss- oder Salzrestriktion, konnte keine Empfehlung ausgesprochen werden.

Der Einsatz von NO-Donatoren wurde, mit dem Ansatz die verminderte NO-Synthese im Plazentabett und im Endothel ausgleichen zu können, ebenfalls geprüft. Eine Studie im Risikokollektiv konnte immerhin die Rate komplikationsfreier Schwangerschaften verbessern, eine Reduktion der Präeklampsierate wurde nicht beobachtet [191].

Die Prophylaxe beschränkt sich weiterhin auf eine gezielte ASS- bzw. Heparin-Gabe in Risikogruppen. 


\section{Aufgabenstellung}

Die Bedeutung der angiogenen Faktoren ,soluble fms-like tyrosine kinase-1“ (sFlt-1) und ,placental growth factor“ (PIGF) in der Pathogenese der Präeklampsie (PE) ist in den letzten Jahren hinreichend belegt worden. Bei Patienten mit manifester PE lassen sich dramatisch hohe sFlt-1 bzw. sehr niedrige PIGF Werte nachweisen. Mittlerweile konnte in Studien die sFlt-1/PIGF-Ratio als sensitiver Parameter ermittelt werden.

Ziel der vorliegenden Arbeit ist es, die Zusammenhänge zwischen klinischen Parametern der manifesten Präeklampsie und der sFlt-1/PIGF-Ratio zu spezifizieren. Dabei soll geprüft werden, ob bei manifester PE die Höhe der sFlt-1/PIGF-Ratio vor Entbindung klinische Bedeutung hat und mit Parametern des Schwangerschaftsausgangs in Beziehung steht. 


\section{Patienten und Methode}

\subsection{Studienbeschreibung}

Für die Untersuchung des Zusammenhangs zwischen angiogenen Faktoren und klinischen Parametern des Schwangerschaftsausgangs bei manifesten hypertensiven Schwangerschaftserkrankungen wurden an der Abteilung für Geburtsmedizin des Universitätsklinikums Leipzig in einem Zeitraum von 2 Jahren (09/2007-08/2009) insgesamt 33 Fälle mit manifester Erkrankung rekrutiert. Die analysierten Fälle sind eine Subgruppenanalyse der Patientinnen, die durch die Abteilung für Geburtsmedizin in eine von Roche Diagnostics $\mathrm{GmbH}$ initiierte prospektive multizentrische Beobachtungsstudie „Diagnostik der Präeklampsie mittels neuer labordiagnostischer Marker (Elecsys®sFlt-1 und PlGF“ (Protokoll X 06 P 006) eingebracht wurden.

\section{Einschlusskriterien:}

- Einverständniserklärung

- $\quad$ Patient $\geq 16$ Jahre

- Einlingsschwangerschaft mit manifester hypertensiver Schwangerschaftserkrankung (Definition s.Kap. 1.1.1)

Alle Patientinnen dokumentierten ihr Einverständnis zur Teilnahme der Studie. Ein positives Votum der Ethik-Kommission der Medizinischen Fakultät der Universität Leipzig (Reg.- Nr. 202-2007) lag vor.

Die Datensammlung und -bearbeitung erfolgte unter Einhaltung des Datenschutzgesetzes. Sämtliche Daten wurden anonymisiert ausgewertet.

Der Studieneinschluss erfolgte, wenn zum Zeitpunkt der Vorstellung in der Klinik eine hypertensive Schwangerschaftserkrankung nach klinischen Kriterien vorlag oder zumindest der Verdacht bestand. 
Innerhalb der Studie wurden die hypertensiven Schwangerschaftserkrankungen in folgende Untergruppen unterteilt und in Anlehnung an die internationalen Richtlinien entsprechend der Working Group on High Blood Pressure in Pregnancy definiert [5] (s.Kap.: 1.1.1):

- Präeklampsie

- schwere Präeklampsie

- Propfpräeklampsie

- Eklampsie

- HELLP

Es wurden sowohl Early- als auch Late-onset-Präeklampsien untersucht.

In einem standardisierten Prüfbogen wurden folgende anamnestische und klinische Daten von jedem Patienten erhoben (Tabelle 2).

\begin{tabular}{|c|c|c|}
\hline ANAMNESE & KLINIK & LABORPARAMETER \\
\hline Ethnische Zugehörigkeit & neurologische Symptome & PIGF \\
\hline Rasse & Oligurie & sFlt \\
\hline Alter & Kopfschmerzen & Thrombozyten \\
\hline Gravidität / Parität & Oberbauchschmerzen & ALAT \\
\hline Gewicht & Ödeme & ASAT \\
\hline Größe & $\begin{array}{c}\text { Sonografie (Biometrie/AFI/ } \\
\text { Doppler) }\end{array}$ & Hämatokrit \\
\hline BMI & Maternales Outcome \\
\hline $\begin{array}{c}\text { Eigen-/Fam.anamnese bzgl. } \\
\text { Präeklampsie }\end{array}$ & $\begin{array}{c}\text { Fetales Outcome } \\
\text { (Geburtsgewicht/ Länge/ pH } \\
\text { /APGAR) }\end{array}$ & Bilirubin \\
\hline $\begin{array}{c}\text { Vorerkrankungen } \\
\text { Medikamente }\end{array}$ & Haptoglobin \\
\hline $\begin{array}{c}\text { Präexistenter Bluthochdruck/ } \\
\text { Diabetes }\end{array}$ & & Blutzucker \\
\hline
\end{tabular}

Tabelle 2: erhobene Daten in der Studie 
Bei den hypertensiven Schwangerschaftserkrankungen tritt, als Folge der Plazentationsstörung, gehäuft eine intrauterine Wachstumsretardierung auf und wurde in der Auswertung mit berücksichtigt. Isolierte Wachstumsretardierungen ohne Proteinurie und Hypertonie bzw. Zeichen eines HELLP-Syndroms wurden ausgeschlossen. Folgende Einteilung Neugeborener anhand von Gestationsalter und Geburtsgewicht in Gewichtsklassen wurde zugrundegelegt:

- small for gestational age (SGA): bezeichnet für das Gestationsalter zu kleine Neugeborene mit einem Geburtsgewicht $<10$. Perzentile, bei denen das genetisch determinierte Wachstumspotential erreicht und kein pathologischer Prozess ursächlich ist.

- appropriate for gestational age (AGA): normalgewichtige Neugeborene

- large for gestational age (LGA): bezeichnet für das Gestationsalter zu große Neugeborene mit einem Geburtsgewicht $>90$. Perzentile.

In den Normkurven werden Geschlecht und ethnische Zugehörigkeit berücksichtigt.

Die intrauterine Wachstumsretardierung stellt eine Subpopulation der SGA Feten dar und wird folgendermaßen definiert:

\section{Intrauterine growth restriction (IUGR)}

- Neugeborene mit einem (geschätztem) Geburtsgweicht $<5$. Perzentile oder sonografischer Abdomenumfang <5. Perzentile, bei denen auf Grund eines pathologischen Prozesses das genetische Wachstumspotential nicht ausgeschöpft wird.

Ein pathologischer Prozess liegt bei Auftreten eines Oligohydramnion (Fruchtwasserindex $[\mathrm{AFI}]<10$. Perzentile) oder eines pathologischen flows in der A. umbilicalis (Pulsatilitätsindex [PI] >95. Perzentile) nach der 20. SSW vor.

Im Gegensatz zum SGA Feten erhöht der zugrunde liegende pathologische Prozess bei der intrauterinen Wachstumsretardierung die Morbidität und Mortalität erheblich. 


\subsection{Charakterisierung Patientenkollektiv}

Die Evaluierung der Kohorte von 33 Einlingsschwangerschaften nach verschiedenen Kriterien und Merkmalen ergab folgende Verteilung.

In Tabelle 3 ist die Verteilung der allgemeinen Patientenmerkmale (Alter, Gewicht, BMI, Gravidität und Blutdruck), in Abbildung 8 die Verteilung der verschiedenen Erkrankungsmanifestationen (HELLP-Syndrom, schwere Präeklampsie, milde Präeklampsie, Eklampsie und Propfpräeklampsie) dargestellt.

Entsprechend der Unterteilung nach Early-onset- und Late-onset-Präeklampsie wurden zwei Gruppen gebildet: diejenigen mit Beendigung der Schwangerschaft $<34+0$ SSW und Patientinnen mit Entbindung $\geq 34+0$ SSW. Der Anteil der Early-onsetPräeklampsien dominiert in unserer Untersuchung mit $79 \%$ der Gesamtpopulation. Insgesamt trat bei 7 von den 33 Patientinnen eine Late-onset-Präeklampsie auf, bei allen anderen handelt es sich um eine Early-onset-Präeklampsie. Frauen, die nach der 34. SSW entbunden, aber vor der 34. SSW diagnostiziert wurden, wurden definitionsgemäß den Early-onset-Präeklampsien zugeordnet $(n=2)$.

Sowohl in der Altersverteilung als auch im Gewicht und BMI finden sich keine signifikanten Unterschiede zwischen diesen beiden Untergruppen (Tabelle 3). Der Vergleich der mittleren systolischen und diastolischen Blutdruckwerte zeigt keine signifikanten Unterschiede (151/94 mmHg vs. 146/91 mmHg).

Unter den 33 untersuchten Patientinnen fanden sich ausschließlich Nulli- und Erstpara. Da die Präeklampsie hauptsächlich eine Erkrankung der Erstgebärenden ist, überrascht es nicht, dass der Anteil der Nullipara am Gesamtkollektiv $73 \%$ beträgt. Der Anteil der Nullipara ist vor und nach der 34 . SSW gleich (73\% vs. $71 \%)$.

Ein weiterer Unterschied zeigt sich im Vergleich der assoziierten IUGR. Insgesamt traten in unserem Kollektiv 12 Fälle mit zusätzlicher Wachstumsretardierung auf. Eine fetale Wachstumsretardierung aufgrund der chronischen Plazentainsuffizienz tritt vor allem bei früher Manifestation auf. Der Anteil vor der 34. SSW lag mit 38\% höher als mit $29 \%$ in der Gruppe der Late-onset-Präeklampsie. 
Wie erwartet liegt bei den beobachteten Patientinnen zwischen der Schwangerschaftswoche der Diagnose und der Entbindung bei der Late-onsetPräeklampsie ein kürzerer Zeitraum als bei der Early-onset-Präeklampsie. Im Mittel lag die Verlängerung der Schwangerschaft vor der 34. SSW bei 10 Tagen und nach der 34. SSW bei 2 Tagen. Schwangerschaften vor der 34. SSW wurden im untersuchten Kollektiv durchschnittlich in Grav. 31+1 SSW, Patientinnen mit einer Late-onsetPräeklampsie im Durchschnitt in Grav. 38+2 SSW entbunden. Diese Beobachtung entspricht dem allgemein üblichen Management, bei der eine Schwangerschapftsprolongation jenseits der 34. SSW nicht indiziert ist und die Patientinnen mit einer Early-onset-Präeklampsie von einem abwartenden Verhalten bezüglich der Entbindung profitieren (s. Kap. 1.1.4).

\begin{tabular}{|c|c|c|c|c|}
\hline PATIENTENCHARAKTERISTIK & $\mathbf{5 3 4 . ~ S S W ~}$ & $\begin{array}{c}\text { (Mittelwert) } \\
\text { gesamt }\end{array}$ & $\mathbf{> 3 4 . ~ S S W ~}$ & ( Min - Max ) \\
\hline & $\mathbf{n = 2 6}$ & $\mathbf{n = 3 3}$ & $\mathbf{n = 7}$ & \\
\hline Alter (Jahre) & 29 & 28 & 28 & $(19-40)$ \\
\hline BMI (kg/m $\left.{ }^{2}\right)$ & 24,2 & 24 & 23,1 & $(17,8-35,7)$ \\
\hline Weight (kg) & 81,2 & 81,1 & 81,0 & $(54,3-119,7)$ \\
\hline Assoziierte IUGR (\%) & $38 \%$ & $36 \%$ & $29 \%$ & $(\mathrm{n}=10 / 12 / 2)$ \\
\hline Gravidität & 2 & 2 & 2 & $(1-4)$ \\
\hline Anteil OP (\%) & $73 \%$ & $73 \%$ & $71 \%$ & $(\mathrm{n}=19 / 24 / 5)$ \\
\hline SSW Diagnose & $29+5$ & $31+5$ & $38+1$ & $(24+0-39+5)$ \\
\hline SSW Entbindung & $31+1$ & $32+4$ & $38+2$ & $(26+0-40+0)$ \\
\hline Systolischer RR (mmHg) & 151 & 150 & 146 & $(115-184)$ \\
\hline Diastolischer RR (mmHg) & 94 & 93 & 91 & $(65-122)$ \\
\hline Prolongation SS (Tage) & 10 & 6 & 2 & $(0-49)$ \\
\hline
\end{tabular}

Tabelle 3: Patientencharakteristik

In Abbildung 8 ist die Untergliederung der Kohorte nach den verschiedenen Erkrankungsmanifestationen dargestellt. In der ersten Untergliederung wird zunächst zwischen Fällen mit bzw. ohne HELLP-Syndrom unterschieden, wobei ersteres mit $27 \%$ in der Gesamtpopulation wesentlich seltener ist. 
Innerhalb der 24 Fälle ohne ein HELLP-Syndrom werden weitere vier Erkrankungsmanifestationen differenziert. Zahlenmäßig dominieren hier mit 10 bzw. 11 Fällen die milde Präeklampsie und schwere Präeklampsie. Die Eklampsie ist eine Rarität und mit nur einem Fall vertreten. Eine Propfpräeklampsie trat in unserem Kollektiv in nur zwei Fällen auf. Bei der Betrachtung der prozentualen Verteilung der Wachstumsretardierungen in den jeweiligen Untergruppen fällt auf, dass der Anteil der Wachstumsretardierungen in der HELLP-Gruppe (44\%) am größten ist. Bei einer milden Präeklampsie beträgt der Anteil hingegen nur 30\%. Patientinnen mit einer schweren Präeklampsie waren in 36\% der Fälle mit einer IUGR assoziiert.

Late-onset-Präeklampsien wurden fast ausschließlich in der Gruppe der milden Präeklampsien beobachtet und traten dort in $60 \%$ der Fälle auf. Bei einer Early-onsetPräeklampsie sind die klinischen Verläufe zumeist fulminanter und schwerer (s. Kap. 1.1.4). So verwundert es nicht, dass $91 \%$ der Patientinnen mit einer schweren Präeklampsie eine Early-onset-Präeklampsie hatten. Wohingegen nur 40\% der Frauen mit einer milden Präeklampsie vor der 34. SSW erkrankten (Abbildung 8).

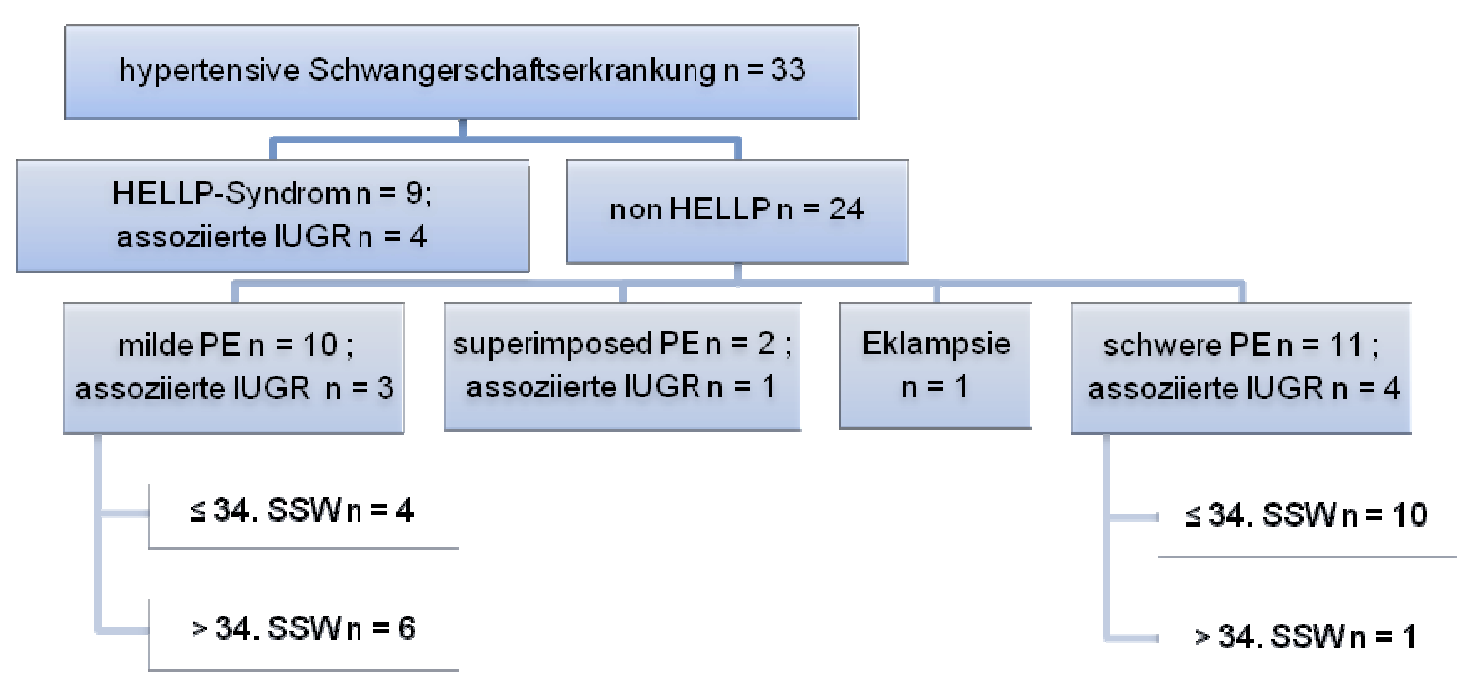

Abbildung 8: quantitative Verteilung der Erkrankungsmanifestationen in der Kohorte 
Zur weiteren Auswertung der Daten wurde die sFlt-1/PlGF-Ratio in vier Untergruppen unterteilt. Es zeigte sich bezüglich Early- und Late-onset-Präeklampsie bzw. IUGR folgende Verteilung (Tabelle 4).

\begin{tabular}{|c|c|cc|c|}
\hline \multicolumn{2}{|c}{ sFIt-1/PIGF-Ratio } & \multicolumn{1}{c|}{$\mathbf{5 3 4 . ~ S S W ~}$} & $\mathbf{> 3 4 . ~ S S W ~}$ & davon IUGR \\
\hline & $\mathrm{n}$ & Prozent $(\mathrm{n})$ & Prozent $(\mathrm{n})$ & Prozent $(\mathrm{n})$ \\
\hline $\mathbf{2 5 0}$ & 11 & $55 \%(6)$ & $45 \%(5)$ & $9 \%(1)$ \\
$\mathbf{2 5 0 - 5 0 0}$ & 10 & $80 \%(8)$ & $20 \%(2)$ & $30 \%(3)$ \\
$\mathbf{5 0 0 - 1 0 0 0}$ & 7 & $100 \%(7)$ & $0 \%(0)$ & $71 \%(5)$ \\
$>\mathbf{1 0 0 0}$ & 5 & $100 \%(5)$ & $0 \%(0)$ & $60 \%(3)$ \\
\hline
\end{tabular}

Tabelle 4: Anteil der Early-/ Late-onset-Präeklampsien und Wachstumsretardierungen

Der Anteil der Early-onset-Präeklampsien nimmt mit steigender sFlt-1/PIGF-Ratio zu und umgekehrt der Anteil der Late-onset-Präeklampsien mit steigender sFlt-1/PIGF-Ratio ab, ebenso nimmt der Anteil der Wachstumsretardierungen mit steigender sFIt-1/PIGF-Ratio zu.

Bei den Late-onset-Präeklampsien betrug die sFlt-1/PIGF-Ratio größtenteils <250. Mit steigender sFlt-1/PIGF-Ratio steigt auch der Anteil der Early-onset-Präeklampsien. Bei Werten $>500$ handelt es sich ausschließlich um Erkrankungen $\leq 34+0$ SSW. Der Anteil der Wachstumsretardierungen nimmt mit steigender sFlt-1/PlGF-Ratio und mit sinkendem Gestationsalter zu. Der größte Anteil wurde bei einer sFlt-1/PlGF-Ratio von 500 - 1000 beobachtet (Tabelle 4). 


\subsection{Untersuchungsmaterialien}

Im Zuge der stationären Aufnahme wurden den Probanden folgende venöse Blutproben zur Bestimmung der laborchemischen Parameter entnommen:

- $4 \mathrm{ml}$ Serum

- 4 ml EDTA Plasma

- $4 \mathrm{ml}$ Urinprobe

Zur Bestimmung der maternalen sFlt-1- und PlGF-Konzentration wurde Serum verwendet. Nach Eingang der Probe im Zentrallabor der Universität Leipzig erfolgte die Zentrifugation der Monovette. Das Serum wurde bis zur Messung bei $-80^{\circ}$ Celcius gelagert. Die Messung erfolgte mittels den Immunoassays Elecsys®PIGF und Elecsys ${ }^{\circledR}$ sFlt von Roche (s.Kap.3.4.1). Beide stehen mittlerweile als vollautomatisierte Messmethode für Routinetests zur Verfügung. Von den 33 Patienten wurden insgesamt 42 Proben auf sFlt und PlGF untersucht.

Im Folgenden werden die verwendeten Geräte und Materialien unter Angabe des Herstellers aufgeführt.

\section{Immunoassay}

Elecsys ${ }^{\circledR P I G F} /$ Elecsys ${ }^{\circledR}$ sFlt

Roche Diagnostics GmbH, Mannheim (D)

\section{Blutentnahme}

S Monovetten

Sarstedt AG \& Co, Nümbrecht (D)

\section{Meßgeräte}

COBAS $®$ e 601

Roche Diagnostics GmbH, Mannheim (D)

SYSMEX

Sysmex Deutschland GmbH, Norderstedt (D) 


\subsection{Meßmethoden}

\subsubsection{Immunoassay}

Elecsys ${ }^{\circledR P I G F / E l e c s y s}{ }^{\circledR}$ sFlt der Firma Roche sind Immunoassays zur quantitativen Bestimmung von PlGF und sFlt mittels Elektro-Chemi-Lumineszenz (ECL). Für die Analyse werden ein monoklonaler biotinierter Antikörper (als „Fänger“, Primärantikörper) und ein weiterer monoklonaler Antikörper, verbunden mit einem Ruthenium-Komplex (als „Detektor“, Sekundärantikörper), verwendet. Im Sandwichverfahren werden PlGF oder sFlt gebunden. Der Ruthenium Komplex wird durch Anlegen einer Spannung oxidiert und durch ein Elektron angeregt, um dann unter Abgabe von Lichtenergie spontan wieder zu zerfallen. Die Reaktion der Lichterzeugung kann beim ECL Reaktionsmechanismus wiederholt werden [192, 193]. Beide Verfahren haben eine Testzeit von 18 Minuten. Der Elecsys®PIGF benötigt ein Probevolumen von $50 \mu \mathrm{l}$ und erfasst einen Messbereich von 3-10.000 pg/ml. Beim

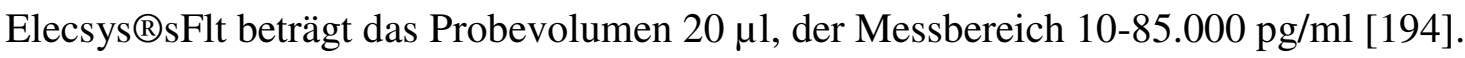

\subsubsection{Blutdruck}

Die Blutdruckmessung sollte aufgrund erheblicher Schwankungen in der Schwangerschaft standardisiert erfolgen und wurde nach folgender Empfehlung durchgeführt $[195,50]$ :

- sitzende Position, Lagerung des Armes auf Niveau des Herzens

- Ruhephase von mindestens 5 min vor der Messung

- korrekte Breite und Länge der Blutdruckmanschette $(16$ x $36 \mathrm{~cm}$ bei einem Armunfang $>34 \mathrm{~cm}$ )

- Erfassung des diastolischen Blutdruckes beim Verschwinden des Strömungsgeräusches (Korotkoff V)

- Bestätigung erhöhter Werte durch eine 2. Messung im Abstand von mind. $4 \mathrm{~h}$

- Messung des Blutdruckes jeweils am gleichen Arm 


\subsection{Statistik}

Die Auswertung der Daten und Erstellung der Boxplots erfolgte mit Hilfe der MINITAB $14^{\circledR}$ Statistical Software (1989 | 2002; USA). Von den Daten der zu vergleichenden Untergruppen wurden Median/ Mittelwert/ Standardabweichung/ 25. bzw.75. Quartile sowie Minimal-/Maximalwert bestimmt und im Boxplot dargestellt. Zum statistischen Vergleich wurde der Mann-Whitney-U-Test (WilcoxonRangsummentest) für unabhängige, nicht normal verteilte Stichproben verwendet. Die Korrellation wurde nach der Formel von Kendall (Rangkorrelationskoeffizient $\tau$ ) bestimmt. 


\section{Ergebnisse}

\subsection{Gestationsalter zur Geburt}

Vor der 34. SSW entbundene Schwangere haben im Durchschnitt einen deutlich höheren sFlt-1/PlGF-Quotienten als nach der 34. SSW entbundene Patientinnen (651 [ \pm 552$]$ vs. $162[ \pm 142] ; p<0,01)$. In Abbildung 9 wurde die sFlt-1/PlGF-Ratio bei Early- und Late-onset- Präeklampsie dargestellt.

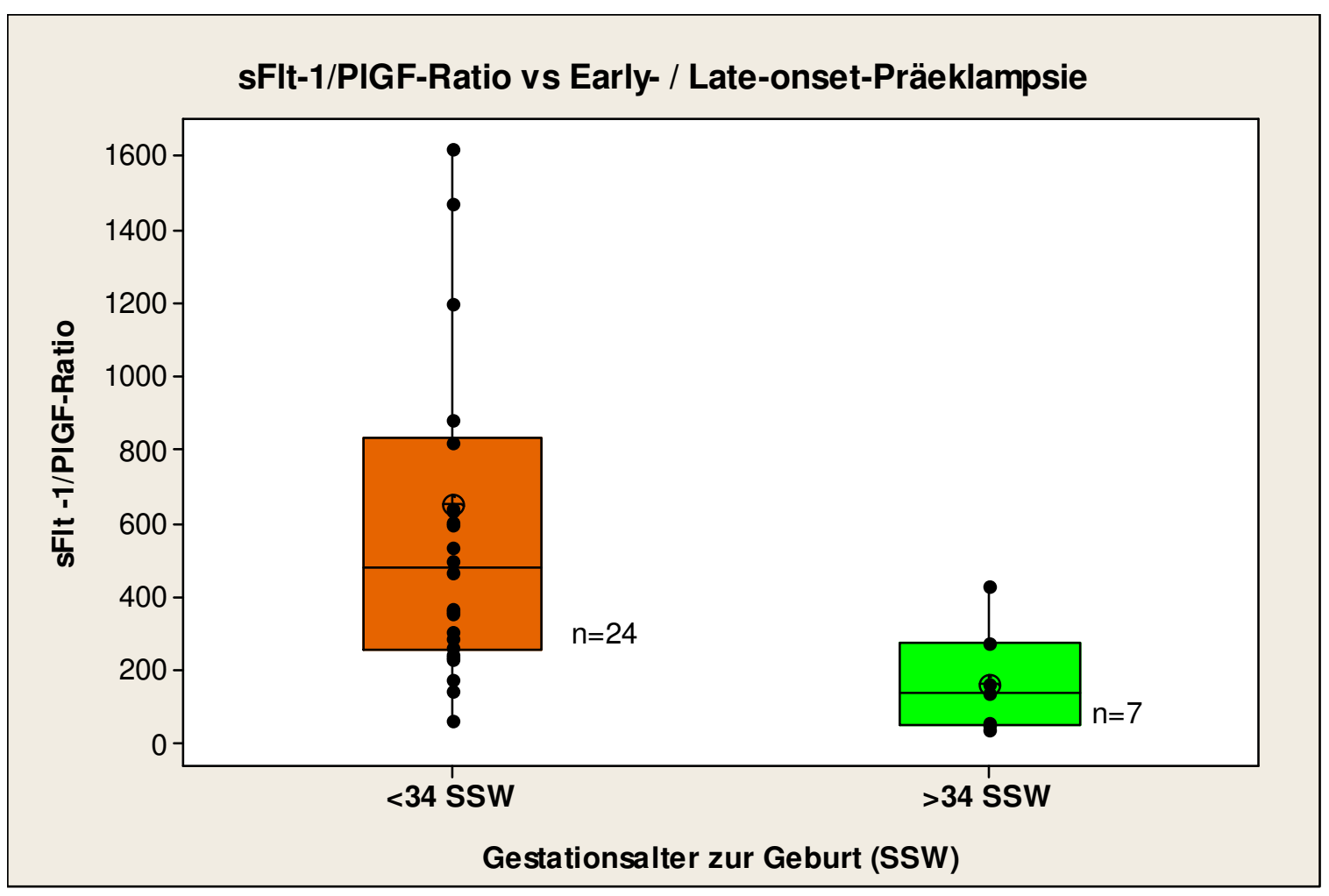

Abbildung 9: sFIt-1/PIGF-Ratio vs Gestationsalter zur Geburt (SSW)

Dargestellt sind: 1./3. Quartile, Median (gerader Strich), Mittelwert (Kreis mit Kreuz) und Einzelfälle (Punkte).

Bei höherer sFlt-1/PlGF-Ratio sinkt das Gestationsalter zur Geburt (Abbildung 10). Schwangere mit PE und einer sFlt-1/PlGF-Ratio >1000 erreichen nur ein mittleres Gestationsalter von 29+4 SSW ( \pm 9 Tage), währenddessen bei einer sFlt-1/PlGF-Ratio von $<25034+6$ SSW $( \pm 29$ Tage $)$ erreicht werden $(\mathrm{p}<0,05)$. 
Bei einer sFlt-1/PIGF-Ratio von 500-1000 liegt der durchschnittliche Entbindungszeitpunkt bei $31+1$ SSW ( \pm 24 Tage), bei einer sFlt-1/PlGF-Ratio von 250-500 bei $32+3$ SSW $( \pm 22$ Tage $)$. Die Unterschiede zwischen den Entbindungszeitpunkten betragen durchschnittlich 1-2 Wochen, je nach Höhe der sFlt-1/PIGF-Ratio.

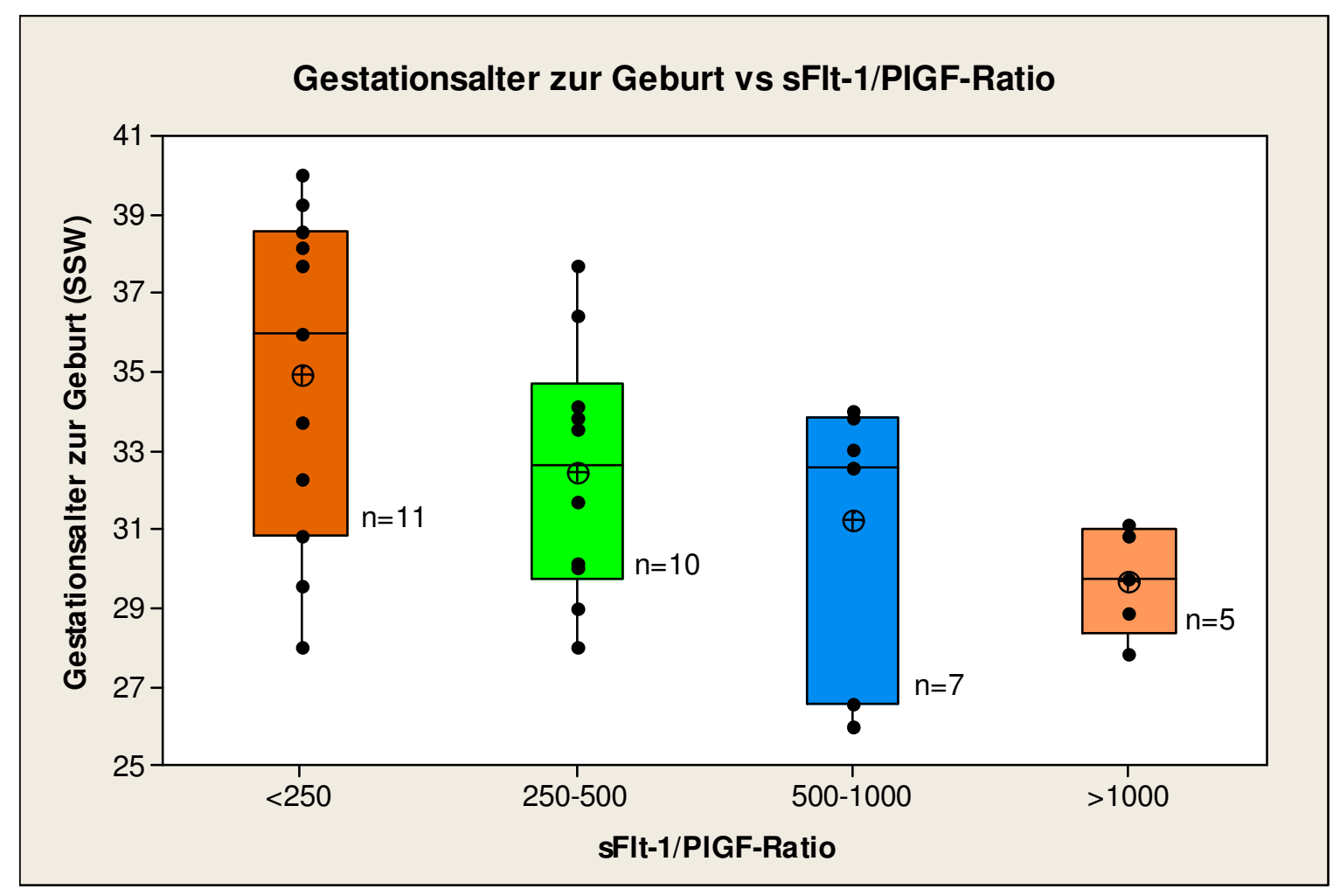

Abbildung 10: Gestationsalter zur Geburt (SSW) vs sFIt-1/PIGF-Ratio

Dargestellt sind: 1./3. Quartile, Median (gerader Strich), Mittelwert (Kreis mit Kreuz) und Einzelfälle (Punkte).

Zwischen dem Gestationsalter zur Entbindung und der sFlt-1/PlGF-Ratio besteht eine moderate Korrelation ( $\tau=-0,38 ; \mathrm{p}<0,05$; Abbildung 11). Die Korrelation wird stärker, wenn man die Erkrankungen mit zusätzlicher Wachstumsretardierung nicht mit betrachtet $(\tau=-0,5 ; p<0,05)$. 


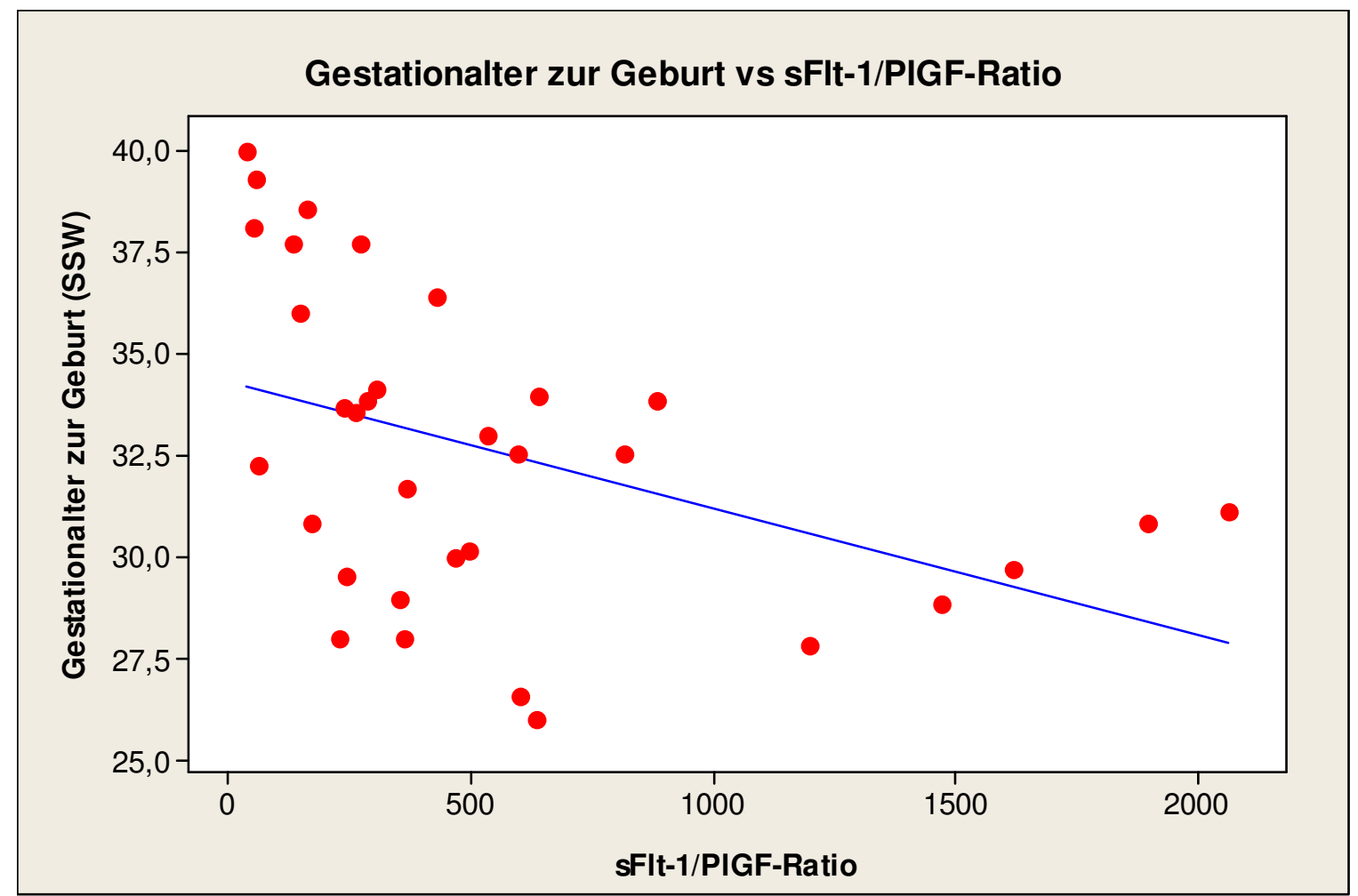

Abbildung 11: Gestationsalter zur Geburt (SSW) vs sFIt-1/PIGF-Ratio 


\section{2 milde und schwere Präeklampsie}

Die Höhe der sFlt-1/PIGF-Ratio korreliert signifikant mit dem Schweregrad der Erkrankung. Für die Definition einer schweren Präeklampsie wurden die Kriterien aus Kapitel 1.1.1 zugrundegelegt. Bei einer milden Präeklampsie ist die mittlere sFlt-1/PlGF-Ratio deutlich niedriger als bei einer schweren Präeklampsie $(178,8[ \pm 138,5]$ vs. $515[ \pm 375] ; \mathrm{p}<0,01)$ (Abbildung 12).

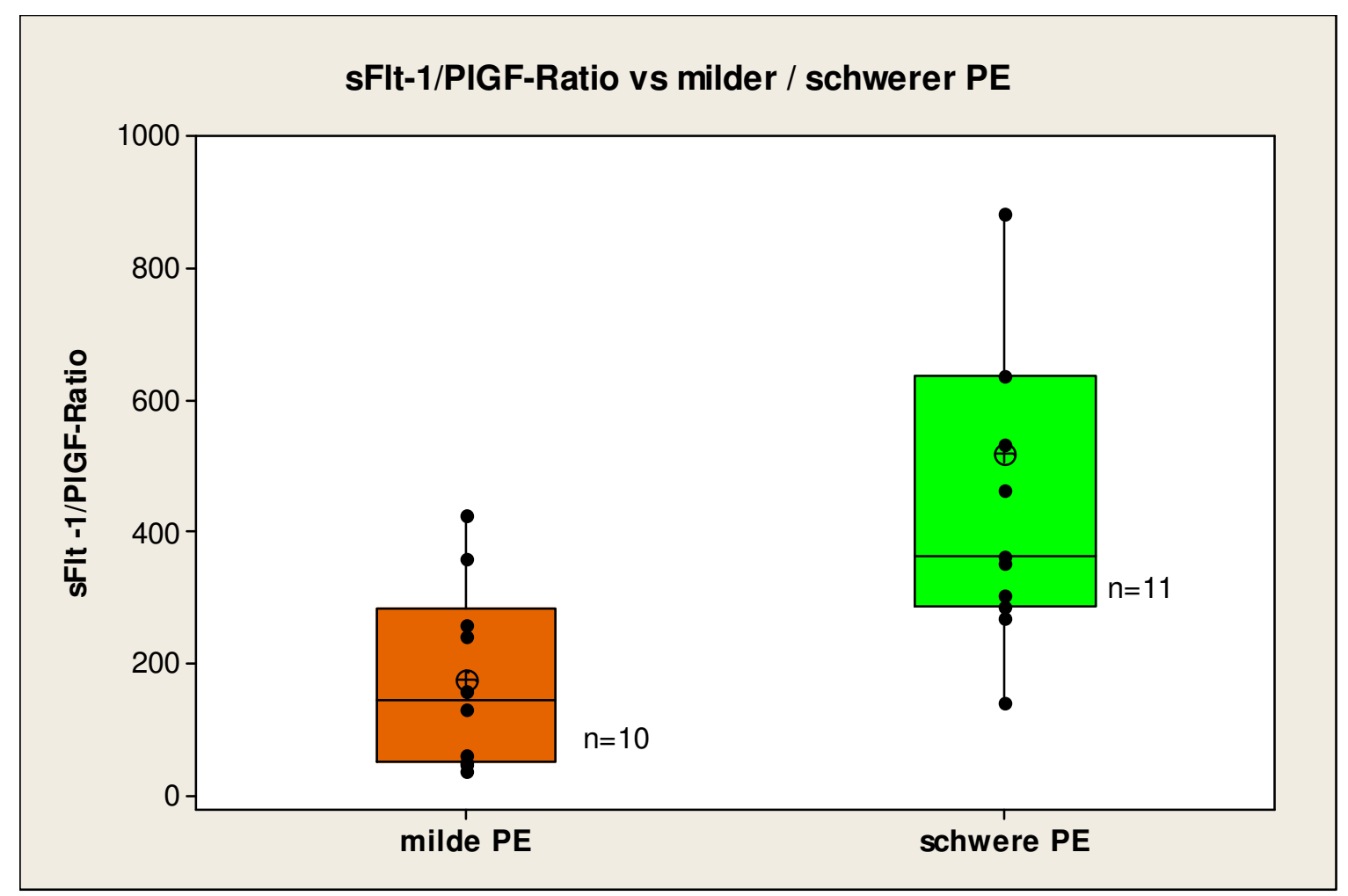

Abbildung 12: sFIt-1/PIGF-Ratio vs milder/schwerer Präeklampsie

Dargestellt sind: 1./3. Quartile, Median (gerader Strich), Mittelwert (Kreis mit Kreuz) und Einzelfälle (Punkte). 


\subsection{Absolutes Geburtsgewicht}

Das Geburtsgewicht nimmt äquivalent zum Gestationsalter zur Geburt mit steigender sFlt-1/PlGF-Ratio ab (Abbildung 13). Bei einer sFlt-1/PlGF-Ratio von $<250$ beträgt das mittlere Geburtsgewicht noch $2343( \pm 1079) \mathrm{g}$, bei einer sFlt-1/PlGF-Ratio von >1000 nur noch $1061( \pm 325)$ g $\quad(\mathrm{p}<0,05)$. Zwischen den letzten beiden Gruppen ist der Unterschied gering $(1061[ \pm 325]$ g vs. $1195[ \pm 520] \mathrm{g})$, wobei bei einer sFlt-1/PlGF-Ratio von 500-1000 die Häufung der Wachstumsretardierungen zu berücksichtigen ist. Dass das Ergebnis bei alleiniger Betrachtung des absoluten Geburtsgewichtes nicht ausschließlich durch den früheren Entbindungszeitpunkt verursacht ist, zeigt die Darstellung der Gewichtsperzentilen im Verhältnis zur sFlt-1/PlGF-Ratio im folgenden Kapitel.

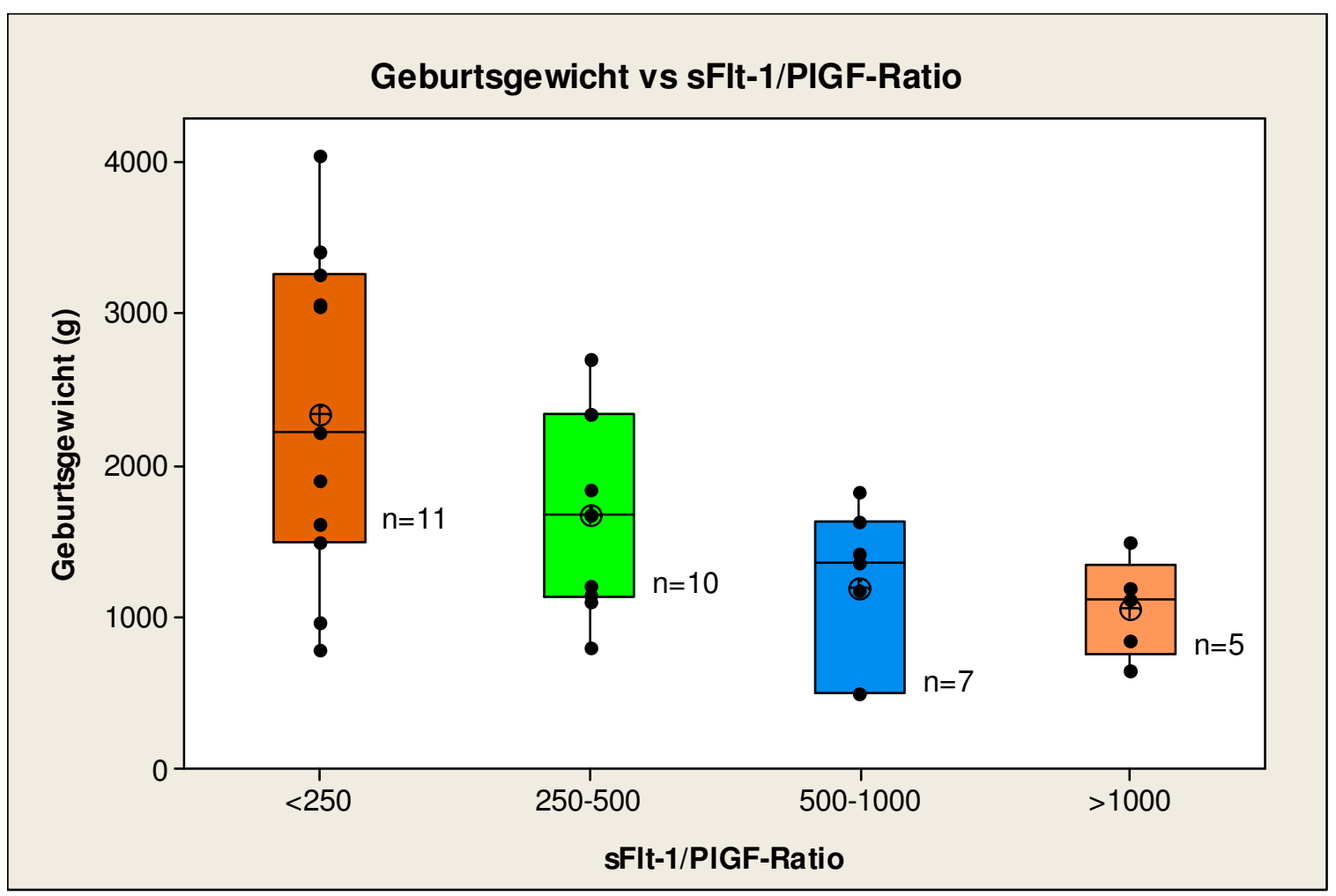

Abbildung 13: Geburtsgewicht (g) vs sFIt-1/PIGF-Ratio

Dargestellt sind: 1./3. Quartile, Median (gerader Strich), Mittelwert (Kreis mit Kreuz) und Einzelfälle (Punkte). 


\subsection{Gewichtsperzentile}

Ähnlich wie für das Geburtsgewicht besteht ein inverser Zusammenhang zwischen sFlt-1/PIGF-Ratio und Gewichtsperzentile (Abbildung 14). Während bei einer Ratio von $<250$ die mittlere Gewichtsperzentile noch bei $39( \pm 26) \%$ liegt, nimmt diese bei einer Ratio von $>1000$ auf $18( \pm 11,8) \%$ ab $(\mathrm{p}<0,05)$. Auffallend ist die niedrige Perzentile von $9 \%$ bei einer sFlt-1/PIGF-Ratio von 500-1000. Ursächlich hierfür ist die Verteilung der assoziierten IUGR im Gesamtkollektiv. Bei einer sFlt-1/PIGF-Ratio von 500-1000 sind 71\% der Schwangerschaften mit einer Wachstumsretardierung vergesellschaftet. Dies sind $42 \%$ aller Wachstumsretardierungen im Gesamtkollektiv. Mit sinkendem Quotienten fällt auch der Anteil der Wachstumsretardierungen ab - bei einer sFlt-1/PlGF-Ratio 250-500 beträgt dieser noch $30 \%$ und bei einer sFlt-1/PIGF-Ratio <250 nur noch 9\% (Tabelle 4).

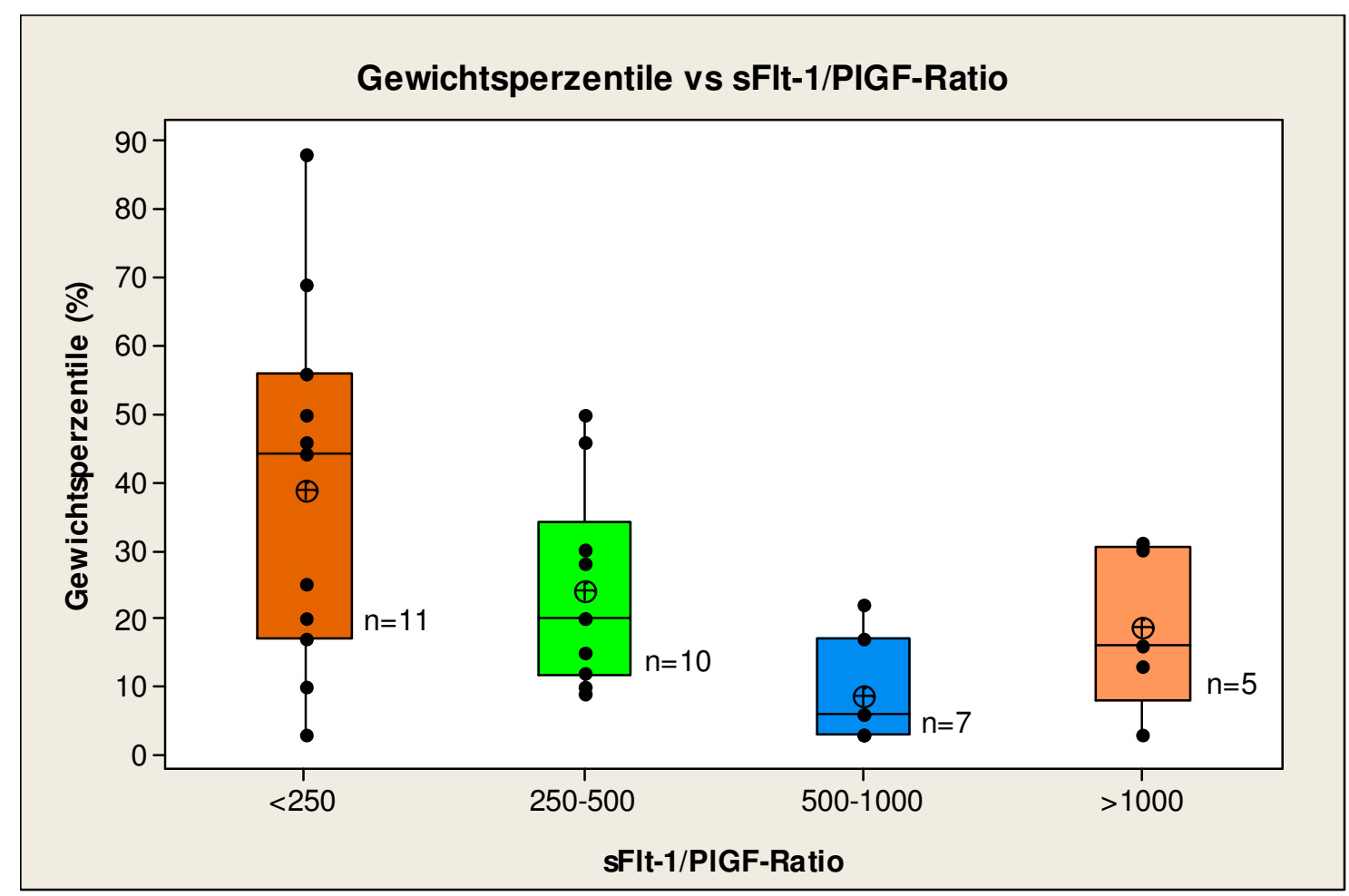

Abbildung 14: Gewichtsperzentile (\%) vs sFIt-1/PIGF-Ratio

Dargestellt sind: 1./3. Quartile, Median (gerader Strich), Mittelwert (Kreis mit Kreuz) und Einzelfälle (Punkte). 
In Abbildung 15 wurde der Zusammenhang zwischen Gewichtsperzentile und sFlt-1/PlGF-Ratio ohne die zusätzlichen Wachstumsretardierungen dargestellt. Bei einer hypertensiven Schwangerschaftserkrankung ohne IUGR beträgt die mittlere Gewichtsperzentile bei einer Ratio <250 noch $42,5( \pm 24,8) \%$, bei einer Ratio $>500$ hingegen nur noch $25( \pm 6,7) \%$. Mit steigender sFlt-1/PlGF-Ratio sinkt die Gewichtsperzentile, wobei hier keine signifikanten Unterschiede vorliegen. Bei der Darstellung der Gewichtsperzentilen ohne IUGR wurden die Untergruppen sFlt-1/PlGF-Ratio von 500-1000 und >1000 wegen geringer Fallzahl zusammengeführt.

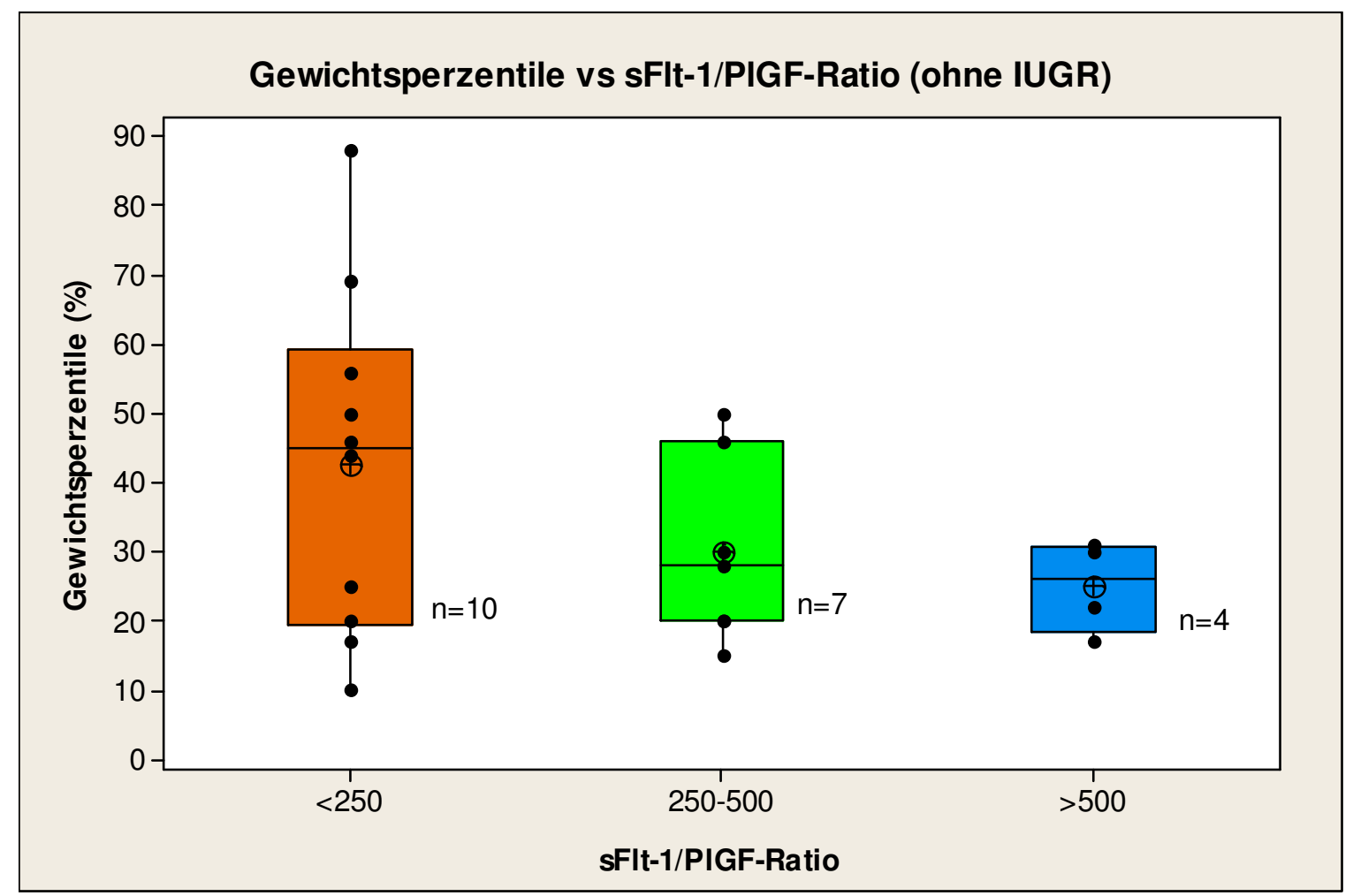

Abbildung 15: Gewichtsperzentile (\%) vs sFIt-1/PIGF-Ratio ohne IUGR

Dargestellt sind: 1./3. Quartile, Median (gerader Strich), Mittelwert (Kreis mit Kreuz) und Einzelfälle (Punkte). 


\subsection{Verlängerung Schwangerschaft}

Eine weitere Fragestellung war: ob die Zeit zwischen Diagnosestellung und Entbindung ebenso mit der sFlt-1/PlGF-Ratio korreliert. Vor allem für die Präeklampsien vor der 34. SSW wäre eine Prognoseabschätzung bezüglich der Schwangerschaftsprolongation für alle Beteiligten von enormem Wert.

Abbildung 16 zeigt, dass sich die Höhe der Ratio in der Dauer der Prolongation der Schwangerschaft widerspiegelt. Bei einer Ratio von $<250$ konnte eine durchschnittliche Schwangerschaftsverlängerung von $10( \pm 17,7)$ Tagen beobachtet werden, wohingegen diese bei einer Ratio von $>1000$ nur noch bei einem Mittelwert von 1,6 $( \pm 1,5)$ Tagen liegt.

Folgenden zwei Besonderheiten im Gesamtkollektiv sollten in der Betrachtung der Ergebnisse gesonderte Aufmerksamkeiten finden, da sie einen nicht unerheblichen Einfluss auf die Daten haben. Einerseits sind in den ersten beiden Gruppen (sFlt-1/ PlGF-Ratio <250 bzw. 250-500) alle Late-onset-Präeklampsien vertreten. Andererseits werden bei einer Ratio von 500-1000 in unserem Kollektiv gehäuft zusätzliche Wachsumsretardierungen beobachtet. Beide Faktoren haben offensichtlich Einfluss auf die Entscheidung zur Entbindung im klinischen Alltag. Um dieser Beobachtung Rechnung zu tragen, wurde in Abbildung 17 die durchschnittliche Schwangerschaftsverlängerung ohne die Fälle mit zusätzlicher Wachstumsretardierung dargestellt. Äquivalent zur Abbildung 15 wurden bei geringer Fallzahl die letzten beiden Gruppen zusammengeführt.

In Perinatalzentren wird jenseits der 34. SSW eine Prolongation der Schwangerschaft bei einer manifesten hypertensiven Schwangerschaftserkrankung nicht mehr angestrebt. Von den 21 Fällen mit einer Ratio von $<500$ wurde in den 7 Fällen mit einer Late-onsetPräeklampsie die Schwangerschaft entweder noch am selben Tag oder innerhalb weniger Tage beendet, andererseits bei den Early-onset-Präeklampsien die Schwangerschaft prolongiert. Hierdurch erklärt sich die große Spannweite bei einer Ratio <250 (Abbildung 16/ Abbildung 17). 
Besteht ausschließlich eine hypertensive Schwangerschaftserkrankung, ohne zusätzliche Wachstumsretardierung als Komplikation, ist die durchschnittliche Schwangerschaftsverlängerung kürzer, was sich vor allem bei einer Ratio >500 bemerkbar macht. Beträgt die mittlere Prolongation der Schwangerschaft bei einer Ratio von 250-500 noch 3,6 $( \pm 4,9)$ Tage, liegt diese bei einer sFlt-1/PlGF-Ratio >500 nur noch bei $0,2( \pm 0,5)$ Tagen $(\mathrm{p}<0,05)$, was bedeutet, dass der Großteil der Frauen bei einer derart hohen Ratio noch am selben Tag entbunden werden. Da die IUGR bekanntermaßen Einfluss auf die Höhe der Ratio hat, erscheint es plausibel, dass die sFlt-1/PlGF-Ratio in den Fällen mit zusätzlicher Wachstumsretardierung bezüglich ihrer Aussagekraft zur Schwere der hypertensiven Schwangerschaftserkrankung eingeschränkt ist.

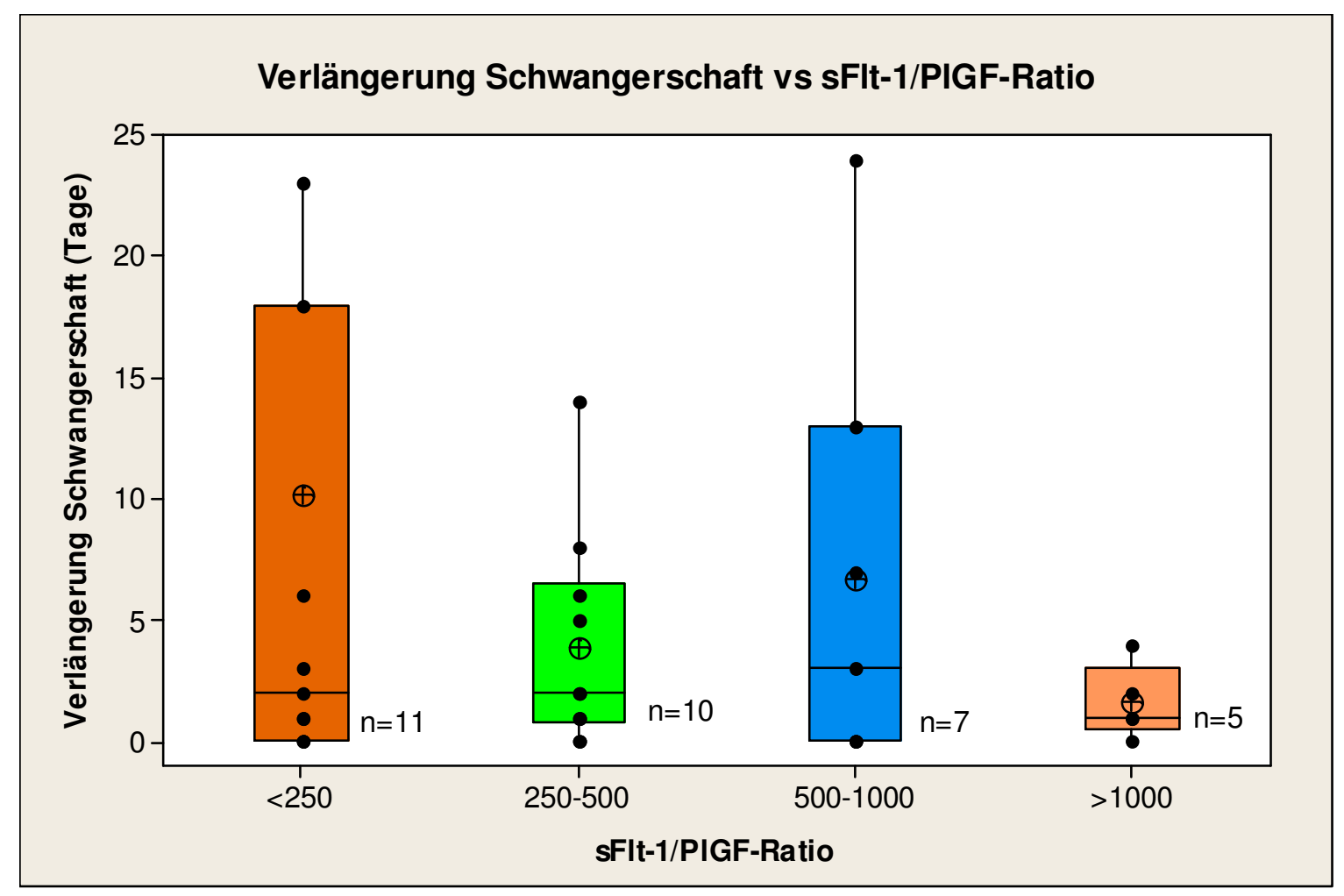

Abbildung 16: Verlängerung Schwangerschaft (in Tagen) vs sFlt-1/PIGF-Ratio

Dargestellt sind: 1./3. Quartile, Median (gerader Strich), Mittelwert (Kreis mit Punkt) und Einzelfälle (Punkte). 


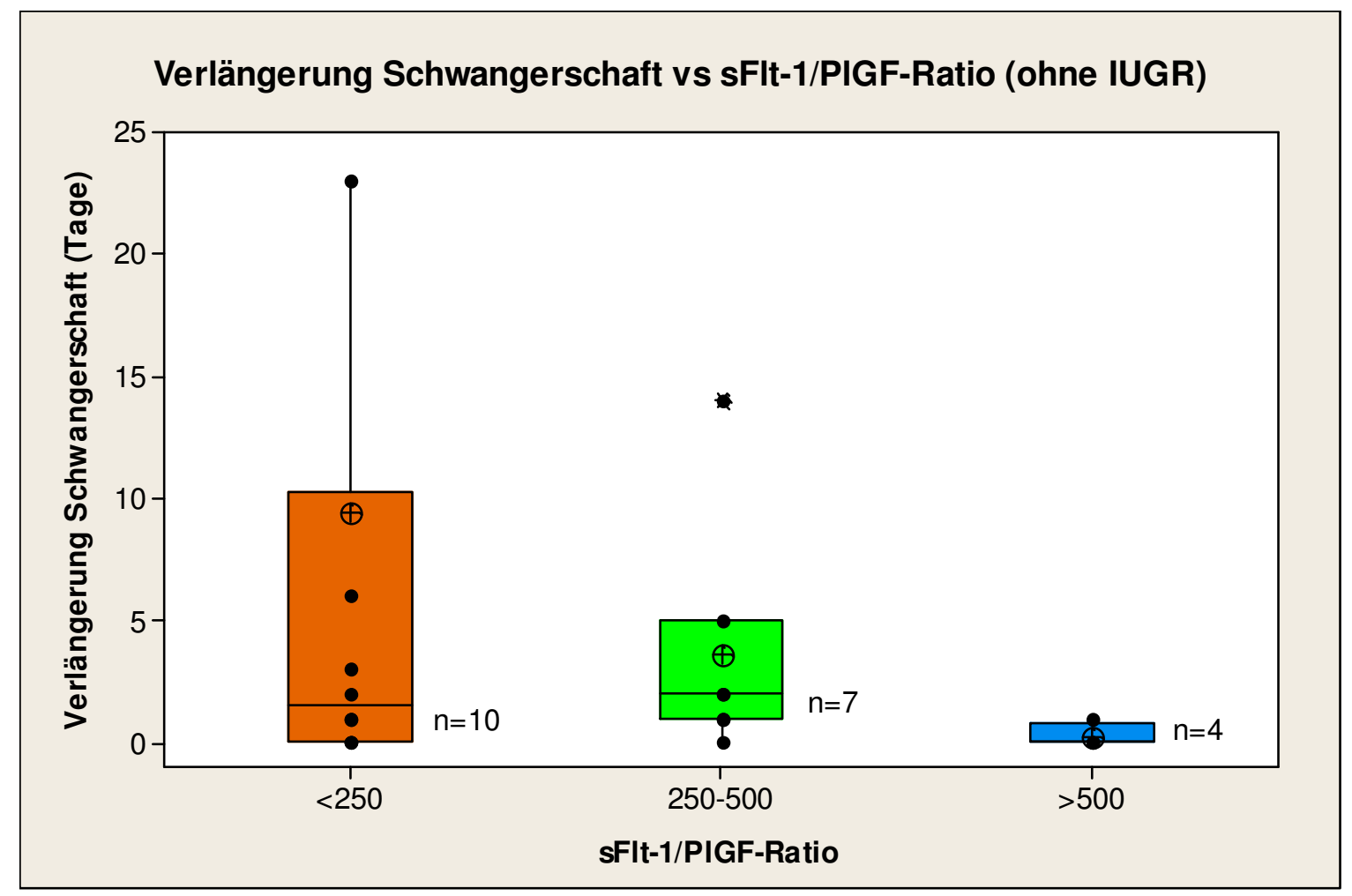

Abbildung 17: Verlängerung Schwangerschaft (in Tagen) vs sFIt-1/PIGF-Ratio (ohne IUGR)

Dargestellt sind: 1./3. Quartile, Median (gerader Strich), Mittelwert (Kreis mit Kreuz) und Einzelfälle (Punkte).

\subsection{Thrombozyten}

Zwischen sFlt-1/PlGF-Ratio und Thrombozytenzahl wurde ebenso ein inverser Zusammenhang vermutet. Bei der Auswertung der Thrombozyten wurde sich, bei geringer Anzahl der HELLP-Fälle $(\mathrm{n}=9)$, auf die Einteilung in zwei Gruppen (sFlt-1/PlGF-Ratio <500 vs. >500) beschränkt. Ein signifikanter Unterschied konnte für die Präeklampsie nachgewiesen werden $(239[ \pm 67] \mathrm{Tsd} / \mu 1$ vs. 154 [31] Tsd/ $\mu 1 ; \mathrm{p}<0,01)$. Definitionsgemäß ist der mittlere Absolutwert der Thrombozyten beim HELLP-Syndrom niedriger. In der HELLP-Gruppe ist gleiche Tendenz zu erkennen $(13[ \pm 53] \mathrm{Tsd} / \mu \mathrm{l}$ vs. $113[54] \mathrm{Tsd} / \mu \mathrm{l})$, allerdings konnte hier keine Signifikanz nachgewiesen werden (Abbildung 18). 
Kritisch anzumerken ist, das in der HELLP-Gruppe die mittlere Thrombozytenzahl $>100 \mathrm{Tsd} / \mu \mathrm{l}$ beträgt. Ursächlich hierfür ist die Vermischung von partiellen und kompletten HELLP-Syndromen. In einigen Fällen waren fallende Thrombozyten $(<150 \mathrm{Tsd} / \mu \mathrm{l})$ in Kombination mit weiteren klinischen Parametern (erhöhte Transaminasen/ Proteinurie/ erhöhte Blutdruckwerte) zur Entbindungsentscheidung ausschlaggebend.

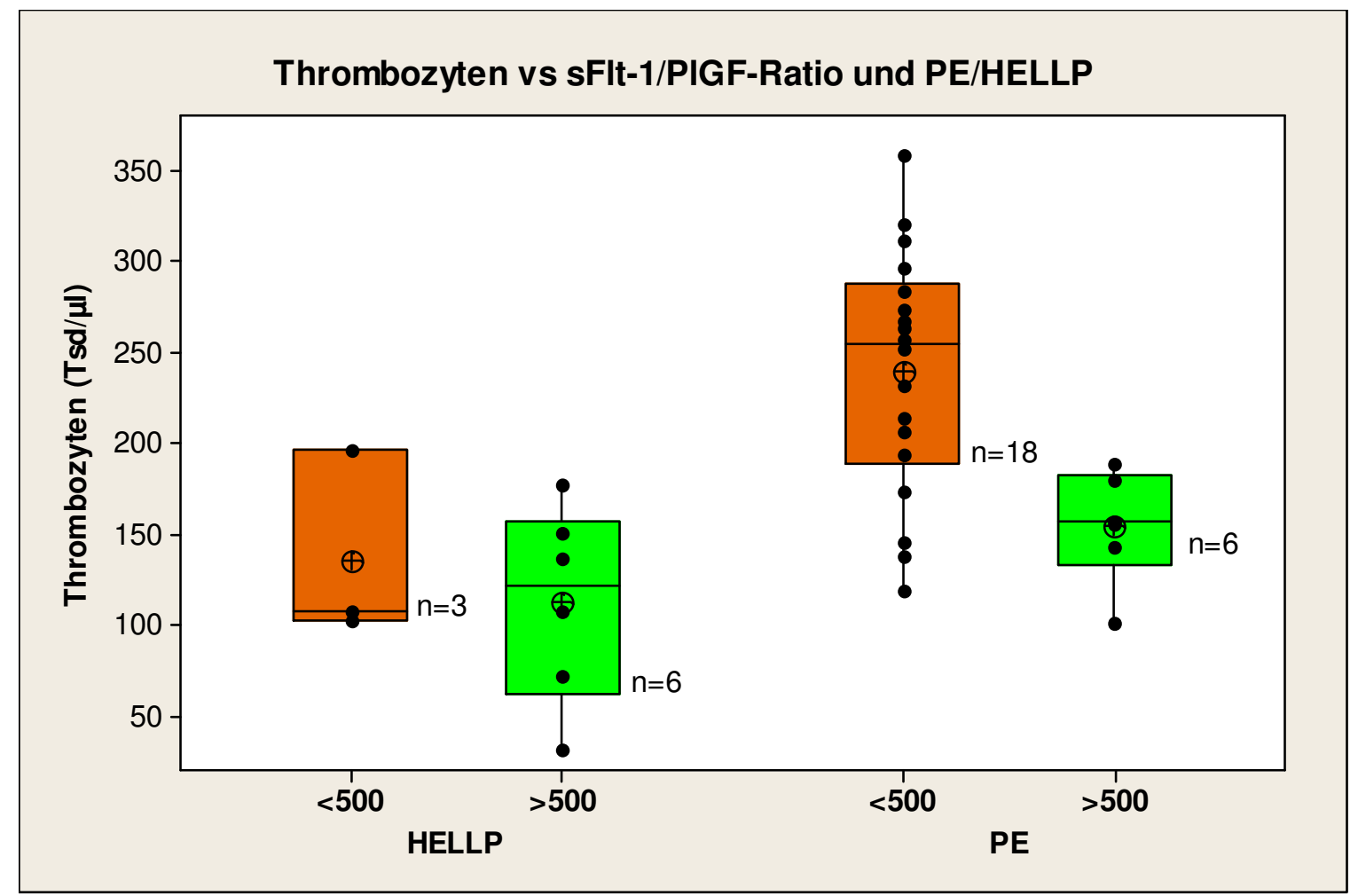

Abbildung 18: Thrombozyten (Tsd/ $\mu$ l) vs sFIt-1/PIGF-Ratio

Dargestellt sind: 1./3. Quartile, Median (gerader Strich), Mittelwert (Kreis mit Punkt) und Einzelfälle (Punkte). 


\section{Diskussion}

Die Störung der angiogenen Balance kombiniert mit immunologischen, inflammatorischen und genetischen Faktoren, ist der entscheidende Ansatz in der Klärung der Ätiologie hypertensiver Schwangerschaftserkrankungen. Die Erkenntnis, dass der antiangiogene Faktor sFlt-1 bei erkrankten Frauen drastisch ansteigt und spiegelbildlich dazu der angiogene Faktor PlGF abfällt, war ein entscheidender Durchbruch in der Präeklampsieforschung und Anlass für zahlreiche weitere Arbeiten $[100,86]$. Die Ursachen für die auslösenden Faktoren der plazentaren Überproduktion von sFlt-1 wurden allerdings bis heute noch nicht endgültig geklärt.

Sowohl in der Diagnostik als auch in der Prädiktion haben einige experimentelle Studien die Relevanz der Bestimmung der sFlt-1/PlGF-Ratio in der Praxis nachgewiesen. Wegweisend für die Anwendung der sFlt-1/P1GF-Ratio in der klinischen Routine ist die Einführung des kommerziell erhältlichen und vollautomatisierten Tests Elecsys ${ }^{\circledR}$ sFlt-1 und Elecsys®PIGF zur Messung der beiden Proteine.

Zum jetzigen Stand der Erkenntnisse dient die Bestimmung der sFlt-1/PIGF-Ratio in der Praxis vor allem zum sicheren Ausschluss oder Bestätigung einer Präeklampsie. Klinisch grenzwertige Befunde bezüglich eines Bluthochdruckes oder einer Proteinurie können bei einem negativen Quotienten differenzierter beurteilt werden und sind vor allem relevant, wenn es um praktische Entscheidungen wie stationäre Einweisung oder Geburtseinleitung geht [196]. Anhand der Bestimmung der sFlt-1/PlGF-Ratio können sowohl erkrankte Schwangere zuverlässig identifiziert als auch verschiedene hypertensive Schwangerschaftserkrankungen differenziert werden. In einer klinischen Multicenterstudie wurde ein Cut-off-Wert von 85 zur zuverlässigen Trennung von gesunden und erkrankten Schwangeren ermittelt [27].

Schwangere mit einem chronischen Hypertonus oder einem isolierten Schwangerschaftshypertonus können durch einen nur geringen Anstieg der sFlt-1/PlGF-Ratio von denen mit einer manifesten Präeklampsie selektiert werden [197, 198]. 
Eine kürzlich veröffentlichte Arbeit zeigte, dass sich die sFlt-1/PlGF-Ratio bei gesunden Schwangeren und Schwangeren mit einem Schwangerschaftshypertonus oder einer chronischen Hypertension vor der 34. SSW nicht unterscheiden. Jenseits der 34. SSW ist die sFlt-1/PIGF-Ratio bei erkrankten im Vergleich zu gesunden Frauen erhöht. Allerdings liegen die Werte mit 53,5 beim Schwangerschaftshypertonus und 31,6 beim chronischen Hypertonus unter dem Cut-Off-Wert von 85, welcher bei einer manifesten Präeklampsie oder einem HELLP-Syndrom in jedem Fall überschritten wird [101]. Die eindeutige Differenzierung eines chronischen Hypertonus bzw. Schwangerschaftshypertonus von einer manifesten Präeklampsie nach der 34. SSW ist für das weitere Management nicht unerheblich. Handelt es sich „nur“ um einen chronischen Hypertonus oder Schwangerschaftshypertonus, erlaubt es unter Umständen bei guter Blutdruckeinstellung abwartendes Verhalten bis zur 37. SSW oder sogar bis zum spontanen Wehenbeginn, wohingegen bei einer manifesten Präeklampsie die zügige Entbindung angestrebt wird.

In der Prädiktion der Präeklampsie kann die sFlt-1/PlGF-Ratio vor allem in Kombination mit der Dopplersonografie sinnvoll eingesetzt werden. Durch parallele Messung von uterinem Doppler und den angiogenen Faktoren sFlt-1 und PlGF wird für die Vorhersage bei den Early-onset-Präeklampsien eine Sensitivität von 83\%, eine Spezifität von $95 \%$ und eine positive Vorhersage von $71 \%$ erreicht [117]. Die zuverlässige Identifizierung von Risikopatienten zu einem möglichst frühen Zeitpunkt ermöglicht es, ein entsprechendes intensiviertes Monitoring bzw. eine Weiterbetreuung in einem Perinatalzentrum zu veranlassen.

Vorangegangene Beispiele verdeutlichen eindrücklich die klinische Relevanz der sFlt-1/PlGF-Ratio. Inwieweit anhand der Höhe der sFlt-1/PlGF-Ratio eine Vorhersage des Schwangerschaftsausgangs möglich ist, ist bisher unbekannt und nur wenig untersucht. Es gelang trotz diverser Modifikationen der Definition der Präeklampsie bisher nicht, in Klassifikationen bzw. diagnostischen Kriterien die klinische Vielfalt der Erkrankung zu berücksichtigen [199, 4, 157]. Aktueller Goldstandard in der Diagnostik der Präeklampsie ist die Messung des Blutdrucks und der Proteinurie. 
Allein diese beiden Parameter weisen einige Defizite auf, da einerseits atypische Verlaufsformen, wie die non-proteinuric-Präeklampsie oder normotensive HELLPSyndrome, schwierig $\mathrm{zu}$ erfassen und einzuordnen sind und andererseits weder Aussagen zum Verlauf der Erkrankung noch zur Auswirkung auf die fetale und maternale Morbidität getroffen werden können [200, 201].

Einige Untersuchungen zeigen bereits, dass anhand der Bestimmung der sFlt-1/PlGF-Ratio Aussagen über den klinischen Verlauf der Erkrankung möglich sind [101, 202, 198] .

Entscheidende Fragen sind: inwieweit spiegelt die Höhe der sFlt-1/PlGF-Ratio die Schwere und Dynamik der komplexen Erkrankung wider? Welche Erkenntnisse sind für die klinische Routine in der Bewertung der sFlt-1/PIGF-Ratio neu hinzugekommen?

In unserer retrospektiven Auswertung von 33 Einlingsschwangerschaften mit einer manifesten Präeklampsie konnten signifikante Zusammenhänge zwischen klinischen Parametern und der sFlt-1/PlGF-Ratio gezeigt werden.

Zwei entscheidende Ergebnisse unserer Auswertung zeigen, dass eine Korrelation zwischen der sFlt-1/PIGF-Ratio und der Schwere der Erkrankung besteht. Sowohl bei den Early- bzw. Late-onset-Präeklampsien als auch bei den schweren bzw. milden Präeklampsien unterscheidet sich die sFlt-1/PlGF-Ratio signifikant.

Die sFlt-1/PlGF-Ratio ist bei einer Präeklampsie vor der 34. SSW mit $651( \pm 552)$ wesentlich höher als bei einer Präeklampsie nach der 34. SSW mit $162( \pm 142)$. Ganz offensichtlich ist die sFlt-1/PIGF-Ratio ein geeigneter Marker, die zumeist fulminanteren Verläufe einer Präeklampsie vor der 34. SSW abzubilden. Ausschlaggebend für die verschiedenen Ausprägungsgrade der Early- und Late-onsetPräeklampsie sind ätiologisch unterschiedliche Mechanismen. Obwohl nicht hinreichend geklärt, wird bei der Late-onset-Präeklampsie unter anderem eine nur minimale plazentare Beteiligung diskutiert [203]. Diese Hypothese erklärt den geringeren Anteil an Wachstumsretardierungen in der Gruppe der Late-onset-Präeklampsien, wie auch in unserer Kohorte beschrieben (s. Kap. 4.1). 
Unsere Daten zeigen, dass zwischen dem Gestationsalter bei einer sFlt-1/PlGF-Ratio $>1000$ und $<250$ eine Differenz von ca. 5 Wochen liegt (29+4 SSW [ \pm 9 Tage] vs. 34+6 SSW [ \pm 29 Tage]). Demzufolge liegt die Vermutung nahe, dass mit steigender sFlt-1/PIGF-Ratio nicht nur mit einer frühzeitigeren Entbindung $\mathrm{zu}$ rechnen, sondern auch eine Vorhersage der verbleibenden Schwangerschaftsdauer von Vorstellung bis Entbindung möglich ist und dadurch nicht nur der Mutter, sondern auch Geburtshelfern und Pädiatern eine realistische Einschätzung der Prognose ermöglicht wird.

Die Vermutung, dass die Höhe der sFlt-1/PIGF-Ratio mit dem unmittelbaren Risiko einer $\mathrm{zu}$ erwartenden Entbindung korreliert, wird durch die Auswertung der Daten bestätigt. Die mittlere Schwangerschaftsverlängerung beträgt bei einer Ratio <250 noch $10[ \pm 17,7]$ Tage. Patientinnen mit einer sFlt-1/PIGF-Ratio $>1000$ werden dahingegen im Durchschnitt innerhalb von 1,6 [ $[ \pm 1,5]$ Tagen entbunden. Verlohren et al. haben in ihrer aktuellen Publikation einen Zusammenhang zwischen der sFlt-1/PlGF-Ratio und der Zeitspanne zwischen Diagnosestellung und Entbindung gezeigt [101].

Aufgrund verschiedener Besonderheiten in der Verteilung des Patientenkollektives werden nicht für alle Werte statistische Signifikanzen erreicht. Einerseits konnten wir, durch die niedrige Inzidenz der Präeklampsie, eine nur geringe Fallzahl an tatsächlich Erkrankten untersuchen $(\mathrm{n}=33)$. Andererseits führt die Durchmischung verschiedener hypertensiver Schwangerschaftserkrankungen und Erkrankungsmanifestationen zu einem inhomogenen Kollektiv.

Für unsere Auswertung betrifft dies vor allem die Vermischung von Early- und Late-onset-Präeklampsien und zusätzlich aufgetretener Wachstumsretardierungen. Es wurde bereits darauf hingewiesen, dass jenseits der 34 . SSW eine Schwangerschaftsverlängerung in den meisten Fällen nicht erstrebenswert ist, da hier kein Benefit für die fetale und maternale Morbidität zu erwarten sind [45, 47]. Es ist denkbar, dass durch einen generellen Anstieg der angiogenen und antiangiogenen Faktoren zum Schwangerschaftsende hin [204], die Aussagekraft der sFlt-1/PIGF-Ratio bei den Late-onset-Präeklampsien abschwächt wird [198]. 
Schließen wir bei der Betrachtung der Schwangerschaftsprolongation die Wachstumsretardierungen aus, besteht vor allem für eine sFlt-1/PlGF-Ratio >500 nicht nur ein signifikanter Unterschied in der Schwangerschaftsverlängerung im Vergleich zu Patientinnen mit einer Ratio von 250-500 (3,6 [ $\pm 4,9]$ vs. 0,25 [ $\pm 0,5]$ Tage), die Schwangerschaftsverlängerung ist im Durchschnitt noch dazu kürzer als bei den Fällen mit einer Wachstumsretardierung (s.Kap. 4.6).

Was verursacht diesen schwangerschaftsverlängernden Effekt bei einer zusätzlichen Wachstumsretardierung? Möglicherweise sind die klinischen Zeichen und Symptome einer Präeklampsie in diesen Fällen nicht so ausgeprägt bzw. nicht vorhanden, so dass die Indikation zur Entbindung später gestellt wird. Die sFlt-1/PlGF-Ratio gibt bei zusätzlicher IUGR die tatsächliche Schwere der Erkrankung verzerrt wieder. Denkbar wäre, dass die Patienten, abgesehen von einer schweren Wachstumsretardierung, einfach nicht so schwer krank sind. Einige Publikationen weisen darauf hin, dass bei einer Wachstumretardierung die sFlt-1/PIGF-Ratio unter Umständen genauso hoch wie bei einer Präeklampsie sein kann [203]. In den allermeisten Fällen ist die Ratio jedoch niedriger als bei einer schweren Präeklampsie.

Zwei aktuell publizierte Studien bestätigen unsere Hypothese bezüglich der Aussagekraft der sFlt-1/PlGF-Ratio zur Schwangerschaftsverlängerung. Karumanchi et al. haben in ihrer Arbeit eine inverse Korrelation zwischen der Zeit von Vorstellung bis zur Entbindung und der sFlt-1/PlGF-Ratio beschrieben. Auch in dieser Studie hat der Ausschluß der late onset Erkrankungen ein eindeutigeres Ergebnis geliefert [198]. In gleicher Arbeit wurde beschrieben, dass $86 \%$ aller Frauen mit einer sFlt-1/PlGF-Ratio $\geq 85$ und $<34$. SSW innerhalb von 2 Wochen entbinden, wohingegen dies bei einer sFlt-1/PIGF-Ratio $<85$ nur $15,8 \%$ waren. Verlohren et al. demonstrierten in einer Multicenterstudie eindrucksvoll gleichen Zusammenhang. Die durchschnittliche sFlt-1/PlGF-Ratio beträgt bei einer Entbindung innerhalb von zwei Tagen $616,42 \pm 81,5$, bei einer Entbindung innerhalb von 2-7 Tagen 547,93 $( \pm 98,39)$ und bei einer Entbindung $>7$ Tage 225,55 $( \pm 60,59)$ vor der 34. SSW. Patientinnen mit einer Erkrankung vor der 34. SSW haben bei einer sFlt-1/PIGF-Ratio $\geq 655,2$ ein hohes Risiko zeitnah entbunden zu werden [101]. Erkrankte Patientinnen mit einer hohen sFlt-1/PlGF-Ratio entbinden also nicht nur früher, sondern auch schneller. 
Ein weiterer Zusammenhang besteht zwischen der Höhe der sFlt-1/PlGF-Ratio und milder bzw. schwerer Präeklampsie $(178,8[ \pm 138,5]$ vs. $515[ \pm 375])$ und bestätigt die Hypothese, dass es eine Korrelation zwischen Schwere der Erkrankung und der sFlt-1/PlGF-Ratio gibt. Umso höher die sFlt-1/PlGF-Ratio, umso ernst zu nehmender ist die Situation. Kim et al. haben die Korrelation zwischen milder und schwerer bzw. Early- und Late-onset-Präeklampsie für die sEng-Konzentrationen im Serum erkrankter Frauen nachgewiesen [205].

In einer kürzlich veröffentlichten Studie der Arbeitsgruppe um Ananth Karumanchi wurde bei Patientinnen mit Verdacht auf eine Präeklampsie ein Zusammenhang zwischen der Höhe der sFlt-1/PlGF-Ratio und dem Auftreten eines definierten Schwangerschaftsausganges innerhalb von 2 Wochen nach Erstvorstellung beschrieben. Das Risiko für das Auftreten einer Komplikation ist bei einer sFlt-1/PIGF-Ratio in der 3. Tertile am höchsten. Vor der 34. SSW sind die Unterschiede am ausgeprägtesten und bestehen bemerkenswerterweise unabhängig von einer vorbestehenden Proteinurie oder einem Bluthochdruck [198].

Desweiteren haben wir uns die Frage gestellt, inwieweit es anhand der sFlt-1/PlGF-Ratio möglich ist, Aussagen bezüglich der fetalen Morbidität zu treffen. Allein die Kenntnis des Blutdruckes und anderer laborchemischer Parameter, wie Proteinurie, Leberwerte und Thrombozyten, lassen keinen validen Rückschluss auf den fetalen Schwangerschaftsausgang zu, dieser kann allenfalls erahnt werden.

Sowohl für das fetale Geburtsgewicht als auch für die Gewichtsperzentilen besteht in unserem Patientenkollektiv ein inverser Zusammenhang zur sFlt-1/P1GF-Ratio. Zwischen dem Geburtsgewicht bei einer sFlt-1/PIGF-Ratio $>1000$ und $<250$ liegt eine Diskrepanz von ca. 1300 g $(1061[ \pm 325]$ g vs. $2343 \quad[ \pm 1079]$ g). Die Gewichtsperzentilen nehmen mit steigender sFlt-1/PIGF-Ratio ebenso deutlich ab (s. Kap. 4.5). Allein die Tatsache, das jenseits einer sFlt-1/PlGF-Ratio >500 die Wachstumsretardierungen an Häufigkeit zu nehmen, ist ein eindeutiger Hinweis, dass die sFlt-1/PIGF-Ratio mit der fetalen Morbidität korreliert. Es wurde bereits darauf hingewiesen, dass dieses durch die Häufung der Early-onset-Präeklampsien, welche per se häufiger mit einer Wachstumsretardierung vergesellschaftet sind, in den oberen Bereichen der sFlt-1/PIGF-Ratio verursacht ist. 
Die angiogenen Faktoren spiegeln unmittelbar die plazentare Störung, welcher Herkunft auch immer, bei einer Wachstumsretardierung wieder.

Unsere Auswertung zeigte keine Zusammenhänge zwischen der sFlt-1/PIGF-Ratio, den Blutdruckwerten, einer Proteinurie und den laborchemischen Parametern (z.B. ALAT/ASAT) der Schwangeren. Andere Studien haben gleiche Ergebnisse bezüglich dieser Korrelation erbracht [205]. Die Datenlage über den Zusammenhang zwischen sFlt-1/PIGF-Ratio und dem Blutdruck ist recht unterschiedlich. In einer Publikation von Verlohren et al. bestand lediglich für den systolischen Blutdruck bei Präeklampsien vor der 34.SSW eine moderate Korrelation [101]. Troisi et al. wiederum fanden ausschließlich bei unkomplizierten Schwangerschaften eine positive Korrelation zwischen sFlt-1/PlGF-Ratio und Blutdruckwerten [206] und Molvarec et al. dahingegen konnten diesen Zusammenhang für präeklamptische Patientinnen nachweisen [207].

Eine Ausnahme waren in unserer Arbeit die Thrombozyten, welche sich, zumindest für die Präeklampsie, nicht für das HELLP-Syndrom, bei einer sFlt-1/PlGF-Ratio $<500 />500$ signifikant unterschieden $(239[ \pm 67] \mathrm{Tsd} / \mu 1$ vs. 154 [31] Tsd/ $\mu 1)$. Aufgrund der geringen Fallzahl bei den HELLP-Syndromen und der Vermischung von kompletten und partiellen HELLP-Syndromen ist ein Zusammenhang denkbar, die abschließende Bewertung jedoch nicht möglich. Mit Hilfe der Bestimmung der sFlt-1/PIGF-Ratio zwischen einer HELLP-induzierten und einer non-HELLP-Thrombozytopenie zu differenzieren und so unnötige vorzeitige Entbindungen zu vermeiden, ist in jedem Fall möglich [208].

Die Studie von Karumanchi et al. hat gezeigt, dass vor der 34.SSW neben einer hohen sFlt-1/PlGF-Ratio auch niedrige Thrombozytenzahlen, erhöhte systolische Blutdrücke, eine Proteinurie, erhöhte Harnsäure- und Kreatininwerte mit einem hohen Risiko für das Auftreten einer Schwangerschaftskomplikation assoziiert ist. Die laborchemischen Parameter haben, im Gegensatz zu Blutdruck, Proteinurie und sFlt-1/PlGF-Ratio, allerdings keinen prädiktiven Wert [198].

Abschließend lässt sich anhand der Ergebnisse festhalten, dass die sFlt-1/PlGF-Ratio als zusätzlicher und von klinischen Parametern unabhängiger Marker in der Diagnostik der Präeklampsie fungiert und dessen Bedeutung vor allem in der Bewertung unklarer 
Situationen und atypischer Verläufe liegt. Die Höhe der sFlt-1/PlGF-Ratio korreliert mit dem Risiko für das Auftreten einer Komplikation im Rahmen der Präeklampsie und einer drohenden Entbindung [101, 198].

Der prädiktive Wert ist für das Auftreten beider Ereignisse vor der 34. SSW in Kombination mit der Messung von Blutdruck und Proteinurie höher, als bei alleiniger Bestimmung von Blutdruck und Proteinurie und im Vergleich zu bisher üblichen klinischen Zeichen und Laborparameter [198].

Weitere umfangreichere prospektive Studien müssen das ganze Potential dieses laborchemischen Parameters eruieren und konkrete Empfehlungen für die Nutzung im Praxisalltag und in der klinischen Routine erarbeiten. Es wäre ein unglaublicher Fortschritt anhand der sFlt-1/PlGF-Ratio eine zuverlässige Prognose mit daraus resultierenden Therapieoptionen bzw. Konsequenzen für die Schwangere abzuleiten. Erste Arbeiten zeigen, dass die Vorstellung, sFlt-1 als den entscheidenden Therapieansatz in der Behandlung der Präeklampsie zu sehen, nicht mehr ganz utopisch ist [28]. 


\section{Zusammenfassung}

Die Bedeutung der angiogenen Faktoren „,soluble fms-like tyrosinekinase-1“ (sFlt-1) und ,placental growth factor“ (PIGF) in der Pathogenese der Präeklampsie (PE) ist in den letzten Jahren in zahlreichen Publikationen belegt worden. Bei Patienten mit manifester PE lassen sich dramatisch hohe sFlt-1 bzw. sehr niedrige PIGF-Werte nachweisen. Bereits 5-6 Wochen vor Auftreten von klinischen Zeichen und Symptomen der Präeklampsie zeigen sich markante Veränderungen in den Serumspiegeln der angiogenen Marker. Die sFlt-1/PIGF-Ratio ist mittlerweile unumstritten ein sensitiver Parameter zum Ausschluss oder zur Bestätigung einer Präeklampsie.

Die vorliegende Arbeit untersucht die Zusammenhänge zwischen klinischen Parametern der manifesten Präeklampsie und der sFlt-1/PIGF-Ratio. Es wird geprüft, ob die Höhe der sFlt-1/PlGF-Ratio bei manifester Präeklampsie vor Entbindung klinische Bedeutung hat und mit Parametern des Schwangerschaftsausgangs in Beziehung steht.

Für die Untersuchung des Zusammenhangs wurden an der Abteilung für Geburtsmedizin des Universitätsklinikums Leipzig in einem Zeitraum von 2 Jahren (09/2007-08/2009) insgesamt 33 Fälle mit manifester Erkrankung rekrutiert. Die analysierten Fälle sind eine Subgruppenanalyse der Patientinnen, die durch die Abteilung für Geburtsmedizin in eine von Roche Diagnostics $\mathrm{GmbH}$ initiierte prospektive multizentrische Beobachtungsstudie „Diagnostik der Präeklampsie mittels neuer labordiagnostischer Marker (Elecsys®sFlt-1 und PlGF“ (Protokoll X 06 P 006) eingebracht wurden.

Die Daten unserer Auswertung geben Evidenz für den Zusammenhang zwischen der Höhe der sFlt-1/PlGF-Ratio und sowohl dem Schweregrad der Erkrankung als auch einer möglichen Prognoseabschätzung hinsichtlich fetaler und maternaler Morbidität.

Anhand folgender Ergebnisse schlussfolgern wir, dass die Höhe der sFlt-1/PlGF-Ratio mit der Schwere der Erkankung korreliert:

- Zwischen Early- und Late-onset-Präeklampsie besteht ein signifikanter Unterschied in der sFlt-1/PIGF-Ratio. Vor der 34. SSW werden wesentlich höhere Werte als nach der 34. SSW erreicht. 
- Anhand der sFlt-1/PIGF-Ratio ist es möglich zwischen milder und schwerer Präeklampsie zu differenzieren, wobei der Mittelwert der schweren Präeklampsien signifikant höher ist.

Folgende Daten unterstützen die Aussage, dass ein Zusammenhang zwischen der Höhe der sFlt-1/PlGF-Ratio und dem fetalen Outcome besteht, wobei sich signifkante Unterschiede hauptsächlich zwischen einer Ratio $<250$ und den Werten >500 zeigen:

- Das Gestationsalter zur Geburt sinkt mit steigender sFlt-1/PlGF-Ratio.

- Sowohl absolutes Geburtsgewicht als auch die Gewichtsperzentile korrelieren invers mit der sFlt-1/PlGF-Ratio.

Die Auswertung zeigt des Weiteren, dass mithilfe der sFlt-1/PIGF-Ratio Aussagen bezüglich des maternalen Morbidität möglich sind:

- Die Analyse der Daten lassen einen Zusammenhang zwischen der Schwangerschaftsverlängerung und der sFlt-1/PlGF-Ratio vermuten. Mit höherer sFlt-1/PlGF-Ratio verkürzt sich die Zeit zwischen Diagnose und Entbindung.

- Zwischen folgenden klinischen und anamnestischen Parametern konnte kein Zusammenhang nachgewiesen werden: Blutdruck, Proteinurie, Leberwerte, BMI, Alter, Gewicht.

- Bezüglich der laborchemischen Parameter bilden die Thrombozyten eine Ausnahme. Bei den Präeklampsien besteht ein signifikanter Unterschied zwischen den Thrombozyten bei einer sFlt-1/PlGF-Ratio $<500$ bzw. $>500$, nicht jedoch bei den HELLP-Syndromen.

Zusammenfassend zeigt sich, dass je höher die sFlt-1/PIGF-Ratio ist, umso schneller und früher werden die Patientinnen entbunden und umso schwerer ist die Erkrankung. Für die klinische und ambulante Routine steht mit der sFlt-1/PlGF-Ratio ein zusätzlicher diagnostischer Marker, der unabhängig von bisher üblichen diagnostischen Kriterien und besonders geeignet für die Beurteilung von atypischen Verläufen ist, zur Verfügung. 


\section{Literaturverzeichnis}

[1] M. A. Brown, W. M. Hague, J. Higgins, S. Lowe, L. Mc Cowan, J. Oats, M. J. Peek, J. A. Rowan und B. N. J. Walters, ,The detection, investigation and managment of hypertension in pregnancy: full consensus statement, "Aust NZJ Obstet Gynaecol, Nr. 40, pp. 139-155, 2000.

[2] M. D. Lindheimer, S. J. Taler und F. G. Cunningham, „ASH Position Paper: Hypertension in Pregnancy," $J$ Clin Hypertens (Greenwich), Nr. 11, pp. 214225, 2009.

[3] M. A. Brown, M. D. Lindheimer, M. de Swiet, A. Van Assche und J.-M. Moutquin, „The classification and diagnosis of the hypertensive disorders of pregnancy: Statement from the International Society for the Study of Hypertension in Pregnancy (ISSHP)," Hypertens Pregnancy, Nr. 20, pp. IX-XIV, 2001.

[4] ACOG Practice Bulletin No. 33, „Diagnosis and Managment of Preeclampsia and Eclampsia,“ Obstet Gynecol, Nr. 99, pp. 159 - 167, 2002.

[5] Working Group on High Blood Pressure in Pregnancy, „Report of the National High Blood Pressure Education Program," Am J Obstet Gynecol, Nr. 183, pp. S1-S22, 2000.

[6] K. A. Douglas und C. W. G. Redman, „Eclampsia in the United Kingdom,“ BMJ, Nr. 309, pp. 1395-1400, 1994.

[7] F. Mattar und B. M. Sibai, „Eclampsia. VIII. Risk factors for maternal morbidity,“ Am J Obstet Gynecol, Nr. 182, pp. 307-312, 2000.

[8] W. Rath, „Das HELLP Syndrom,“ Zentralb/ Gynäkol, Nr. 116, pp. 195-201, 1994.

[9] WHO, „WHO Collaborative Study of Hypertensive Disorders of Pregnancy. Geographic variation in the incidence of hypertension in pregnancy.," $A m \mathrm{~J}$ Obstet Gynecol, Nr. 158, pp. 80-83, 1988.

[10] S. Verlohren und J. W. Dudenhausen, „Präeklampsie und hypertensive Schwangerschaftserkrankungen,“ Frauenheilkunde up2date, Nr. 6, pp. 461470, 2009.

[11] W. Rath, „Hypertensive Schwangerschaftserkrankungen,“ Gynäkologe, Nr. 32, pp. 432-442, 1999. 
[12] G. Knichwitz und W. Klockenbusch, „Eklampsie und HELLP- Syndrom,“ Frauenheilkunde up2date, Nr. 3, pp. 175-191, 2009.

[13] WHO, „The World Health Report 2005: Make every mother and child count.,“ World Health Organization, 2005.

[14] L. Duley, „Maternal mortality associated with hypertensive disorders of pregnancy in Africa, Asia, Latin America and the Caribbean," BJOG, Nr. 99, pp. 547-553, 1992.

[15] K. S. Khan, D. Wojdyla, L. Say, A. M. Gülmezoglu und P. F. A. Van Look, „WHO analysis of causes of maternal death: a systematic review," Lancet, Nr. 367, pp. 1066-1074, 2006.

[16] L. Duley, „The global impact of Pre-eclampsia and Eclampsia,“ Semin Perinatol, Nr. 33, pp. 130-137, 2009.

[17] J. M. Roberts, G. Pearson, J. Cutler und M. D. Lindheimer, „Summary of the NHLBI Working Group on Research on Hypertension During Pregnancy,“ Hypertension, Nr. 41, pp. 437-445, 2002.

[18] P. Y. Robillard, T. C. Hulsey, J. Perianin, E. Janky, E. H. Miri und E. Papiernik, „Association of pregnancy induced hypertension with duration of sexual cohabitation before conception," Lancet, Nr. 344, pp. 973-975, 1994.

[19] P. Y. Robillard, G. A. Dekker und T. C. Hulsey, „Revisiting the epidemiological standard of preeclampsia: primigravidity or primipaternity ?," Eur J Obstet Gynecol Reprod Biol, Nr. 84, pp. 37-41, 1999.

[20] G. A. Dekker, P. Y. Robillard und T. C. Hulsey, „Immune maladaption in the etiology of preeclampsia. A review of corroborative epidemiologic studies," Obstet Gynecol Survey, Nr. 53(6), pp. 377-382, 1998.

[21] R. W. Stettler und F. G. Cunningham, „Natural history of chronic proteinuria complicating pregnancy,“ Am J Obstet Gynecol, Nr. 167, pp. 1219-1224, 1992.

[22] K. Duckitt und D. Harrington, „Risk factors for Pre-eclampsia at antenatal booking: a systemic review of controlled studies," BMJ, Nr. 330, pp. 565-570, 2005.

[23] S. Sabus und T. Fischer, „Präeklampsie - ein Blick in die Zukunft lohnt sich: Diagnostik, Behandlung und Langzeitprognose von Frauen im Zustand nach einer Präeklampsie," Frauenheilkunde up2date, Nr. 6 (1), pp. 523-535, 2007. 
[24] B. M. Sibai, A. El-Nazer und A. Gonzalez-Ruiz, „Severe preeclampsiaeclampsia in young primigravid women: Subsequent pregnancy outcome and remote prognosis," Am J Obstet Gynecol, Bd. 155, pp. 1011-1016, 1986.

[25] H. U. Irgens, L. Reisaeter, L. M. Irgens und R. T. Lie, „Long term mortality of mothers and fathers after pre-eclampsia: population based cohort study," BMJ, Nr. 323, pp. 1213-1217, 2001.

[26] L. J. Vatten und R. Skjaerven, „Is pre-eclampsia more than one disease ?,“ BJOG, Nr. 111, pp. 298-302, 2004.

[27] S. Verlohren, A. Galindo, D. Schlembach, H. Zeisler, I. Herraiz, G. M. Moertl, J. Pape, J. W. Dudenhausen, B. Denk und H. Stepan, „An automated method for the determination of the sFIt-1/PIGF ratio in the assessment of preeclampsia," Am J Obstet Gynecol, Nr. 202, pp. 161.e1-11, 2010.

[28] R. Thadhani, T. Kisner, H. Hagmann, V. Bossung, S. Noack, W. Schaarschmidt, A. Jank, A. Kribs, O. A. Cornley, C. Kreyssig, L. Hemphill, A. C. Rigby, S. Khedkar, T. H. Lindner, P. Mallmann, H. Stepan, S. A. Karumanchi und T. Benzing, „Pilot Study of Extracorporeal Removal of Soluble Fms- Like Tyrosine Kinase 1 in Preeclampsia," Circulation, Nr. 124, pp. 940-950, 2011.

[29] C. H. Lam, K. H. Lim und S. A. Karumanchi, „Circulating Angiogenic Factors in the Pathogenesis and Prediction of Preeclampsia," Hypertension, Nr. 46, pp. 1077-1085, 2005.

[30] H. Schneider, P. Husslein und K. T. M. Schneider, Die Geburtshilfe, Springer, 2006, p. 1.2.1 Physiologie der Differenzierung des Trophoblasten.

[31] M. Schmidt, A. Gelhaus, S. Kasimir-Bauer, E. Winterhager und R. Kimmig, „Angiogenesefaktoren in der Schwangerschaft: Indikatoren für die Präeklampsie," Geburtsh Frauenheilk, Nr. 67, pp. 228-235, 2007.

[32] Y. Zhou, C. H. Damsky, K. Chiu, J. M. Roberts und S. J. Fisher, „Preeclampsia is associated with abnormal expression of adhesion molecules by invasive cytotrophoblasts," J Clin Invest, Nr. 91, pp. 950-960, 1993.

[33] M. Egbor, T. Ansari, N. Morris, C. J. Green und P. D. Sibbons, „Morphometric placental villous and vascular abnormalities in early- and late- onset preeclampsia with and without fetal growth restriction,“ BJOG, Nr. 113, pp. 580589, 2006.

[34] B. Huppertz und L. L. H. Peeters, „Vascular biology in implantation and placentation," Angiogenesis, Nr. 8, pp. 157-167, 2005. 
[35] D. S. Charnock- Jones, P. Kaufmann und T. M. Mayhew, „Aspects of Human Fetoplacental Vasculogenesis and Angiogenesis. I. Molecular Regulation,“ Placenta, Nr. 25, pp. 103-113, 2004.

[36] P. Kaufmann, T. M. Mayhew und D. S. Charnock- Jones, „Aspects of Human Fetoplacental Vasculogenesis and Angiogenesis. II. Changes During normal Pregnancy," Placenta, Nr. 25, pp. 114-126, 2004.

[37] T. M. Mayhew, D. S. Charnock-Jones und P. Kaufmann, „Aspects of Human Fetoplacental Vasculogenesis and Angiogenesis. III. Changes in Complicated Pregnancies,“ Placenta, Nr. 25, pp. 127-139, 2004.

[38] P. Kaufmann, U. Bruns, R. Leiser, M. Luckhardt und E. Winterhager, „The fetal vascularisation of term human placental villi. II. Intermediate and terminal villi,“ Anat Embryol, Nr. 173, p. 203-214, 1985.

[39] R. Leiser, M. Luckhardt, P. Kaufmann, E. Winterhager und U. Bruns, „The fetal vascularisation of term human placental villi. I. Peripheral stem villi, " Anat Embryol, Nr. 173, p. 71-80, 1985.

[40] O. Genbacev, Y. Zhou, J. W. Ludlow und S. J. Fisher, „Regulation of human placental development by oxygen tension," Science, Nr. 277, p. 1669-1672, 1997.

[41] Y. Zhou, O. Genbacev, C. H. Damsky und S. J. Fisher, „Oxygen regulates human cytotrophoblast differentiation and invasion: implications for endovascular invasion in normal pregnancy and in pre-eclampsia," $J$ Reprod Immunol, Nr. 39, p. 197-213, 1998.

[42] P. Moran, M. D. Lindheimer und J. M. Davison, „The renal response to preeclampsia," Semin Nephrol, Nr. 24, pp. 588-595, 2004.

[43] B. B. Banias, L. D. Devoe und T. E. Nolan, „Severe pre-eclampsia in preterm pregnancy between 26.-32. weeks gestation," Am J Perinatol, Nr. 9, pp. 357-60, 1992.

[44] J. R. Barton, J. M. O`Brien, N. K. Bergauer, D. L. Jacques und B. M. Sibai, "Mild gestational hypertension remote from term: progression and outcome," Am J Obstet Gynecol, Nr. 184, pp. 979-983, 2001.

[45] B. M. Sibai, B. M. Mercer und E. Schiff, „Aggressive versus expectant managment of severe pre-eclampsia 28-32 weeks gestation: a randomised controlled trial,“ Am J Obstet Gynecol, Nr. 171, pp. 818-22, 1994. 
[46] K. Seck und T. Fischer, „Empfehlung zur Diagnostik und Behandlung der Präeklampsie im internationalen Vergleich: Was ist neu ?," $Z$ Geburtsh Neonatol, Nr. 213, pp. 106-112, 2009.

[47] H. J. Odendaal, R. C. Pattison, R. Bam, D. Grove und T. J. W. Kotze, „Aggressive or expectant managment for patients with severe pre-eclampsia between 28-34 weeks gestation: a randomized controlled trial," Obstet Gynecol, Nr. 76, pp. 1070-1076, 1990.

[48] W. Visser und A. C. S. Wallenburg, „Maternal and perinatal outcome of temporizing managment in 254 consecutive patients with severe pre-eclampsia remote from term," Eur J Obstet Gynecol Reprod Biol, Nr. 63, pp. 147-153, 1995.

[49] D. R. Hall, H. J. Odendaal, D. W. Steyn und D. Greve, „Expectant managment of early onset, severe preeclampsia: maternal outcome," BJOG, Nr. 107, pp. 1252-1257, 2000.

[50] H. Schneider, P. Husslein und K. T. M. Schneider, Die Geburtshilfe, Springer, 2006, p. 1.8.3.5: Managment der Präeklampsie.

[51] S. M. Jenkins, B. B. Head und J. C. Hauth, „Severe preeclampsia at less than 25 weeks of gestation: maternal and neonatal outcomes, " Am J Obstet Gynecol, Nr. 186, pp. 790-795, 2002.

[52] A. Leviton, K. C. Kuban, L. van Marter, M. Pagano und E. N. Allred, „Antenatal corticosteroids appear to reduce the risk of postnatal germinal matrix hemorrhage in intubated low birth weight newborns," Pediatrics, Nr. 91, pp. 1083-1088, 1993.

[53] B. M. Sibai, „Diagnosis and Managment of Gestational Hypertension and Preeclampsia," Obstet Gynecol, Nr. 102, pp. 181 - 192, 2003.

[54] P. von Dadelszen, M. P. Ornstein, S. B. Bull, A. G. Logan, G. Koren und L. A. Magee, „Fall in mean arterial pressure and fetal growth restriction in pregnancy hypertension: a meta-analysis," Lancet, Nr. 355, pp. 87-92, 2000.

[55] B. M. Sibai, „Treatment of hypertension in pregnant women,“ $N$ Engl J Med, Nr. 335, pp. 257-265, 1996.

[56] J. R. Wacker, B. Wagner, V. Briese, B. Schauf, L. Heilmann, C. Bartz und H. Hopp, „Antihypertensive Therapy in patient with preeclampsia: a prospective randomised multicentre study comparing dihydralazine with urapidil,“ Eur J Obstet Gynecol Reprod Biol, Nr. 127, pp. 160-165, 2006. 
[57] L. Duley, D. J. Henderson-Smart und S. Meher, „Drugs for rapid treatment of very high blood pressure during pregnancy," Cochrane Database Syst Rev, Nr. 3, p. CD001449, 2006.

[58] T. Fischer, M. Krause, E. Beinder, D. Schlembach, B. Rabenbauer, L. Wildt und N. Lang, „Schwangerschaftsverlängerung bei Patientinnen mit HELLPSyndrom,“ Geburtsh Frauenheilk, Nr. 59, pp. 335-345, 1999.

[59] E. F. Magann, D. Bass, S. P. Chauan, D. L. Sullivan, R. W. Martin und J. N. Martin (Jr.), ,Antepartum corticosteroids: Disease stabilisation in patients with the syndrome of hemolysis, elevated liver enzyms, and low platelets (HELLP)," Am J Obstet Gynecol, Nr. 171, pp. 1148-53, 1994.

[60] The Magpie Trial Collaborative Group, „Do women with pre-eclampsia, and their babies, benefit from magnesium sulphate ? The Magpie Trial: a randomised placebo controlled trial,“ Lancet, Nr. 359, pp. 1877-90, 2002.

[61] C. M. Craven, T. Morgan und K. Ward, „Decidual Spiral Artery Remodelling Begins Before Cellular Interaction With Cytotrophoblasts," Placenta, Nr. 19, pp. 241-252, 1998.

[62] G. Valdes, P. Kaufmann, J. Corthon, R. Erices, K. P. Brosnihan und J. JoynerGrantham, „Vasodilator factors in the systemic and local adaptations to pregnancy," Reproductive Biology and Endocrinology, Nr. 7, p. 79, 2009.

[63] N. Ferrara, H. P. Gerber und J. LeCouter, „The biology of VEGF and its receptors," Nat Med, Nr. 9, pp. 669-676, 2003.

[64] A. K. Olson, A. Dimberg, J. Kreuger und L. Claesson-Welsh, „VEGF receptor signalling - in control of vascular function," Nat Rev Mol Cell Biol, Nr. 7, pp. 359$371,2006$.

[65] J. A. Nagy, A. M. Dvorak und H. F. Dvorak, „VEGF-A (164/165) and PIGF: roles in angiogenesis and arteriogenesis," Trends Cardiovasc Med, Nr. 13 (5), pp. 169-175, 2003.

[66] N. Ferrara, K. Carver-Moore, H. Chen, M. Dowd, L. Lu, K. S. O’Shea, L. Powell-Braxton, K. J. Hillan und M. W. Moore, „Heterozygous embryonic lethality induced by targeted inactivation of the VEGF gene.," Nature, Nr. 380, pp. 439-442, 1996.

[67] P. Carmeliet, V. Ferreira, G. Breier, S. Pollefeyt, L. Kieckens, M. Gertenstein, M. Fahrig, A. Vandenhoeck, K. Harpal, C. Eberhardt, C. Declerq, J. Pawling, L. Moons, D. Collen, W. Risau und A. Nagy, „Abnormal blood vessel development and lethality in embryos lacking a single VEGF allele.," Nature, Nr. 380, pp. 435-439, 1996. 
[68] H. F. Dvorak, L. F. Brown, M. Detmar und A. M. Dvorak, „Vascular permeability factor / vascular endothelial growth factor, microvascular hyperpermeability, and Angiogenesis.," Am J Pathol, Nr. 146, pp. 1029-1039, 1995.

[69] J. S. Krüssel, B. Behr, A. A. Milki, J. Hirchenhain, Y. Wen, P. Bielfeld und M. Lake Polan, „Vascular endothelial growth factor (VEGF) mRNA splice variants are differentially expressed in human blastocysts.," Mol Hum Reprod, Nr. 7, pp. 57-63, 2001.

[70] D. Clark, S. Smith, D. Licence, A. Evans und D. Charnock-Jones, „Comparison of expression patterns for placenta growth factor, vascular endothelial growth factor (VEGF), VEGF-B and VEGF-C in the human placenta throughout gestation.," J Endocrinol, Nr. 159, pp. 459-467, 1998.

[71] J. J. Tseng, M. M. Chou, Y. T. Hsieh, M. C. Wen, E. S. Ho und S. L. Hsu, „Differential expression of vascular endothelial growth factor, placenta growth factor and their receptors in placentae from pregnancies complicated by placenta accreta,“ Placenta, Nr. 27, pp. 70-78, 2006.

[72] D. Shweiki, A. Itin, D. Soffer und E. Keshet, „Vascular endothelial growth factor induced by hypoxia may mediate hypoxia-initiated angiogenesis," Nature, Nr. 359, p. 843-845, 1992.

[73] H. P. Gerber, F. Condorelli, J. Park und N. Ferrara, „Differential transcriptional regulation of the two vascular endothelial growth factor receptor genes. Flt-1, but not Flk-1/KDR, is up-regulated by hypoxia," J Biol Chem., Nr. 272(38), p. 23659-23667, 1997.

[74] T. Nagamatsu, T. Fujii, M. Kusumi, L. Zou, T. Yamashita, Y. Osuga, M. Momoeda, S. Kozuma und Y. Taketani, „Cytotrophoblasts up-regulate soluble fms-like tyrosine kinase-1 expression under reduced oxygen: an implication for the placental vascular development and the pathophysiology of preeclampsia,“ Endocrinology, Nr. 145(11), p. 4838-4845, 2004.

[75] J. A. Forsythe, B. H. Jiang, N. V. lyer, F. Agani, S. W. Leung, R. D. Koos und G. L. Semenza, „Activation of vascular endothelial growth factor gene transcription by hypoxia-inducible factor 1 ," Mol Cell Biol, Nr. 16(9), p. 46044613, 1996.

[76] A. Rajakumar, K. Doty, A. Daftary, G. Harger und K. P. Conrad, „Impaired oxygen-dependent reduction of HIF-1 $\alpha$ and $-2 \alpha$ proteins in pre-eclamptic placentae," Placenta, Nr. 24, p. 199-208, 2003. 
[77] V. Eremina, M. Sood, J. Haigh, A. Nagy, G. Lajoie, N. Ferrara, H. P. Gerber, Y. Kikkawa, J. H. Miner und S. E. Quaggin, „Glomerular-specific alterations of VEGF-A expression lead to distinct congenital and acquired renal diseases, " $J$ Clin Invest., Nr. 111, p. 707-716, 2003.

[78] V. Eremina, S. Cui, H. Gerber, N. Ferrara, J. Haigh, A. Nagy, M. Ema, J. Rossant, S. Jothy, J. H. Miner und S. E. Quaggin, „Vascular endothelial growth factor a signaling in the podocyte-endothelial compartment is required for mesangial cell migration and survival," J Am Soc Nephrol, Nr. 17, p. 724-735, 2006.

[79] B. C. Kuenen, M. Levi, J. C. Meijers, A. K. Kakkar, V. W. M. van Hinsbergh, P. J. Kostense, H. M. Pinedo und K. Hoekman, „Analysis of coagulation cascade and endothelial cell activation during inhibition of vascular endothelial growth factor/vascular endothelial growth factor receptor pathway in cancer patients," Arterioscler Thromb Vasc Biol, Nr. 22, p. 1500-1505, 2002.

[80] J. C. Yang, L. Haworth, R. M. Sherry, P. Hwu, D. J. Schwartzentruber, S. L. Topalian, S. M. Steinberg, H. X. Chen und S. A. Rosenberg, „A randomized trial of bevacizumab, an anti-vascular endothelial growth factor antibody, for metastatic renal cancer," N Engl J Med, Nr. 349, p. 427-434, 2003.

[81] A. Hunter, M. Aitkenhead, C. Calwell, G. McCracken, D. Wilson und N. McClure, „Serum levels of vascular endothelial growth factor in preeclamptic and normotensive pregnancy.," Hypertension, Nr. 36, pp. 965-969, 2000.

[82] M. Persico, V. Vincenti und T. Di Palma, „Structure, expression and receptorbinding properties of placenta growth factor (PIGF).," Curr Topics Microbiol immunol, Nr. 237, pp. 31-40, 1999.

[83] A. Ahmed, X. F. Li, C. Dunk, M. J. Whittle, D. I. Rushton und T. Rollason, "Colocalisation of vascular endothelial growth factor and its Flt-1 receptor in human placenta.," Growth Factors, Nr. 12, pp. 235-243, 1995.

[84] M. Zygmunt, F. Herr, K. Münstedt, U. Lang und O. D. Liang, „Angiogenesis and vasculogenesis in pregnancy," Eur J Obstet Gynecol Reprod Biol, Nr. 110 (Suppl1), pp. S10-18, 2003.

[85] F. Mc Gabhann und A. S. Popel, „Model of competitive binding of vascular endothelial growth factor and placental growth factor to VEGF receptors on endothelial cells," Am J Physiol Heart Circ Physiol, Nr. 286, pp. H153-H164, 2004. 
[86] R. J. Levine, S. E. Maynard, C. Qian, K. H. Lim, L. J. England, K. F. Yu, E. F. Schisterman, R. Thadani, B. P. Sachs, F. H. Epstein, B. M. Sibai, V. P. Sukhatme und S. A. Karumanchi, „Circulating Angiogenic Factors and the Risk of Preeclampsia,“ N Engl J Med, Nr. 350, pp. 672-683, 2004.

[87] S. Cebe-Suarez, A. Zehnder-Fjällman und K. Ballmer-Hofer, „The role of VEGF receptors in angiogenesis: complex partnerships.," Cell Mol Life Sci, Nr. 63, pp. 601-615, 2006.

[88] N. Ferrara, „Vascular endothelial growth factor: basic science and clinical progress.," Endocrine Reviews, Nr. 25, pp. 581-611, 2004.

[89] W. Risau, „Mechanisms of angiogenesis,“ Nature, Nr. 386 (6626), pp. 671-674, 1997.

[90] R. L. Kendall, G. Wang und K. A. Thomas, „Identification of a natural soluble form of the vascular endothelial growth factor receptor, FLT-1 and its heterodimerization with KDAR.," Biochemical and Biophysical Research Communications, Nr. 226, pp. 324-328, 1996.

[91] Z. Li, Y. Zhang, J. Y. Ma, A. M. Kapoun, Q. Shao, I. Kerr, A. Lam, G. O’Young, F. Sannajust, P. Stathis, G. Schreiner, S. A. Karumanchi, A. A. Protter und N. S. Pollit, „Recombinant Vascular Endothelial Growth Factor 121 Attenuates Hypertension and Improves Kidney Damage in a Rat Model of Preeclampsia," Hypertension, Nr. 50, p. 686-692, 2007.

[92] O. Nevo, N. Soleymanlou, Y. Wu, J. Xu, J. Kingdom, A. Many, S. Zamudio und I. Caniggia, „Increased expression of sFlt-1 in in vivo and in vitro models of human placental hypoxia is mediated by HIF-1," Am J Physiol Regul Integr Comp Physiol, Nr. 291, p. R1085-R1093, 2006.

[93] U. Raab, B. Velasco, P. Lastres, A. Letamendia, C. Cales, C. Langa, E. Tapia, J. P. Lopez-Bote, E. Paez und C. Bernaben, „Expression of normal and truncated forms of human endoglin," Biochem J, Nr. 339, pp. 579-588, 1999.

[94] M. Guerrero-Esteo, T. Sanchez-Elsner, A. Letamendia und C. Bernabeu, „Extracellular and cytoplasmic domains of endoglin interact with the transforming growth factor-beta receptors I and II," J Biol Chem, Nr. 277, pp. 29197-29209, 2002.

[95] E. Torsney, R. Charlton, A. G. Diamond, J. Burn, J. V. Soames und H. M. Arthur, „Mouse model for hereditary hemorrhagic telandiectasia has a generalized vascular abnormality," Circulation, Nr. 107, pp. 1653-1657, 2003. 
[96] S. Venkatesha, M. Toporsian, C. Lam, J. Hanai, T. Mammoto, Y. M. Kim, Y. Bdolah, K. H. Lim, H. T. Yuan, T. A. Libermann, I. E. Stillman, D. Roberts, P. D'Amore, F. H. Epstein, F. W. Selke, R. Roberto, V. P. Sukhatme, M. Letarte und S. A. Karumanchi, „Soluble endoglin contributes to the pathogenesis of preeclampsia,“ Nat Med, Nr. 12, p. 642-649, 2006.

[97] D. C. Darland, L. J. Massingham, S. R. Smith, E. Piek, M. Saint-Geniez und P. A. D'Amore, „Pericyte production of cell-associated VEGF is differentiation dependent and is associated with endothelial survival," Dev Biol, Nr. 264, pp. 275-288, 2003.

[98] F. C. Luft, „Soluble endoglin (sEng) joins the soluble fms-like tyrosine kinase (sFlt) receptor as a pre-eclampsia molecule," Nephrol Dial Transplant, Nr. 21(11), pp. 3052-54, 2006.

[99] J. M. Lopez-Novoa, „Soluble endoglin is an accurate predictor and a pathogenic molecule in pre-eclampsia," Nephrol Dial Transplant, Nr. 22(3), pp. 712-714, 2007.

[100] R. J. Levine, C. Lam, C. Qian, K. F. Yu, S. E. Maynard, B. P. Sachs, B. M. Sibai, F. H. Epstein, R. Romero, R. Thadani und S. A. Karumanchi, „Soluble Endoglin and Other Circulating Antiangiogenic Factors in Preeclampsia," $N$ Engl J Med, Nr. 355, pp. 992-1005, 2006.

[101] S. Verlohren, I. Herraiz, O. Lapaire, D. Schlembach, M. Moertl, H. Zeisler, P. Calda, W. Holzgreve, A. Galindo, T. Engels, B. Denk und H. Stepan, „The sFlt1/ PIGF ratio in different types of hypertensive pregnancy disorders and its prognostic potential in preeclamptic patients," Am J Obstet Gynecol, Nr. 206(1), pp. 58.e1-58.e8, 2012.

[102] D. S. Torry, H. S. Wang, T. H. Wang, M. R. Caudle und R. J. Torry, „Preeclampsia is associated with reduced serum levels of placenta growth factor," Am J Obstet Gynecol, Nr. 179, p. 1539-1544, 1998.

[103] J. Brockelsby, R. Hayman, A. Ahmed, A. Warren, I. Johnson und P. Baker, „VEGF via VEGF receptor-1 (Flt-1) mimics preeclamptic plasma in inhibiting uterine blood vessel relaxation in pregnancy: implications in the pathogenesis of preeclampsia,“" Lab Invest, Nr. 79, p. 1101-1111, 1999.

[104] R. Hayman, A. Warren, J. Brockelsby, I. Johnson und P. Baker, „Plasma from women with pre-eclampsia induces an in vitro alteration in the endotheliumdependent behaviour of myometrial resistance arteries," BJOG, Nr. 107 , p. 108-115, 2000. 
[105] S. E. Maynard, J. Y. Min, J. Merchan, K. H. Lim, J. Li, S. Mondal, T. A. Libermann, J. P. Morgan, F. W. Sellke, I. E. Stillman, F. H. Epstein, V. P. Sukhatme und S. A. Karumanchi, „Excess placental soluble fms-like tyrosine kinase 1 (sFlt1) may contribute to endothelial dysfunction, hypertension, and proteinuria in preeclampsia," J Clin Invest, Nr. 111, p. 649-658, 2003.

[106] M. Wolf, A. Shah, C. Lam, A. Martinez, K. V. Smirnakis, F. H. Epstein, R. N. Taylor, J. L. Ecker, S. A. Karumanchi und R. Thadani, "Circulating levels of the angiogenic markers sFlt-1 are increased in first versus second pregnancies," Am J Gyn Obstet, Nr. 193, pp. 16-22, 2005.

[107] M. J. Kupferminc, Y. Daniel, T. Englender, A. Baram, A. Many, A. J. Jaffa, I. Gull und J. B. Lessing, „Vascular endothelial growth factor is increased in patients with preeclampsia," Am J Reprod Immunol, Nr. 38, p. 302-306, 1997.

[108] P. M. Bosio, T. Wheeler, F. Anthony, R. Conroy, C. O'Herlihy und P. McKenna, „Maternal plasma vascular endothelial growth factor concentrations in normal and hypertensive pregnancies and their relationship to peripheral vascular resistance," Am J Obstet Gynecol, Nr. 184, p. 146-152, 2001.

[109] P. N. Baker, J. Krasnow, J. M. Roberts und K. T. Yeo, „Elevated serum levels of vascular endothelial growth factor in patients with preeclampsia," Obstet Gynecol, Nr. 86, p. 815-821, 1995.

[110] J. C. Livingston, R. Chin, B. Haddad, E. T. McKinney, R. Ahokas und B. M. Sibai, „Reductions of vascular endothelial growth factor and placental growth factor concentrations in severe preeclampsia," Am J Obstet Gynecol, Nr. 183, p. 1554-1557, 2000.

[111] F. Lyall, I. A. Greer, F. Boswell und R. Fleming, „Suppression of serum vascular endothelial growth factor immunoreactivity in normal pregnancy and in preeclampsia,“ BJOG, Nr. 104, p. 223-228, 1997.

[112] A. Reuvekamp, F. V. Velsing-Aarts, I. E. Poulina, J. J. Capello und A. J. Duits, „Selective deficit of angiogenic growth factors characterises pregnancies complicated by pre-eclampsia,“ BJOG, Nr. 106, pp. 1019-1022, 1999.

[113] L. L. Waite, A. K. Atwood und R. N. Taylor, „Preeclampsia, an Implantation Disorder," Rev Endocr Metab Disord, Nr. 3, pp. 151-158, 2002.

[114] R. N. Taylor, J. Grimwood, R. S. Taylor, M. T. McMaster, S. J. Fisher und R. A. North, „Longitudinal serum concentrations of placental growth factor: evidence for abnormal placental angiogenesis in pathologic pregnancies," Am J Obstet Gynecol, Nr. 188, pp. 177-182, 2003. 
[115] O. Lapaire, A. Shennan und H. Stepan, „The preeclampsia biomarkers soluble fms-like tyrosine kinase-1 and placental growth factor: current knowledge, clinical implications and future application," Eur J Obstet Gynecol Reprod Biol, Nr. 151(2), pp. 122-129, 2010.

[116] R. Thadhani, W. P. Mutter, M. Wolf, R. J. Levine, R. N. Taylor, V. P. Sukhatme, J. Ecker und S. A. Karumanchi, „First trimester placental growth factor and soluble fms-like tyrosine kinase 1 and risk for preeclampsia," J Clin Endocrinol Metab, Nr. 89, p. 770-775, 2004.

[117] H. Stepan, A. Unversucht, N. Wessel und R. Faber, „Predicitve Value of Maternal Angiogenic Factors in Second Trimester Pregnancies With Abnormal Uterine Perfusion," Hypertension, Nr. 49, pp. 818-824, 2007.

[118] J. P. Kusanovic, R. Romero, T. Chaiworapongsa, O. Erez, P. Mittal, E. Vaisbuch, S. Mazaki-Tovi, F. Gotsch, S. S. Edwin, R. Gomez, L. Yeo, A. Conde-Agudelo und S. S. Hassan, „A prospective cohort study of the value of maternal plasma concentrations of angiogenic and anti-angiogenic factors in early pregnancy and midtrimester in the identification of patients destined to develop preeclampsia," J Matern Fetal Neonatal Med, Nr. 22 (11), pp. 10211038, 2009.

[119] A. De Vivo, G. Baviera, D. Giordano, G. Todarello, F. Corrado und R. D'anna, „Endoglin, PIGF and sFlt-1 as markers for predicting pre-eclampsia," Acta Obstet Gynecol Scand, Nr. 87 (8), pp. 837-842, 2008.

[120] S.-Y. Kim, H.-M. Ryu, J.-H. Yang, M.-Y. Kim, J.-Y. Han, J.-O. Kim, J.-H. Chung, S.-Y. Park, M.-H. Lee und D.-J. Kim, „Increased sFlt-1 to PIGF Ratio in Women Who Subsequently Develop Preeclampsia,“ J Korean Med Sci, Nr. 22, pp. 873877, 2007.

[121] S. Sunderji, E. Gaziano, D. Wothe, L. C. Rogers, B. M. Sibai, S. A. Karumanchi und C. Hodges- Savola, „Automated assays for sVEGF R1 and PIGF as an aid in the diagnosis of preterm preeclampsia: a prospective clinical study," $A m \mathrm{~J}$ Obstet Gynecol, Nr. 202, pp. 40.e1-7, 2010.

[122] V. Tsatsaris, F. Goffin, C. Munaut, J. F. Brichant, M. R. Pignon, A. Noel, J. P. Schaaps, D. Cabrol, F. Frankenne und J. M. Foidart, „Overexpression of the Soluble Vascular Endothelial Growth Factor Receptor in Preeclamptic Patients: Pathophysiological Consequences, “ J Clin Endocrinol Metab, Nr. 88 (11), pp. 5555-5563, 2003. 
[123] T. Chaiworapongsa, J. Espinoza, F. Gotsch, Y. M. Kim, G. J. Kim, L. F. Goncalves, S. Edwin, J. P. Kusanovic, O. Erez, N. G. Than, S. S. Hassan und R. Romero, „The maternal plasma soluble vascular endothelial growth factor receptor-1 concentration is elevated in SGA and the magnitude of the increase relates to Doppler abnormalities in the maternal and fetal circulation," $J$ Matern Fetal Neonatal Med., Nr. 21 (1), p. 25-40, 2008.

[124] T. Boutsikou, A. Malamitsi-Puchner, E. Economou, M. Boutsikou, K. P. Puchner und D. Hassiakos, „Soluble vascular endothelial growth factor receptor-1 in intrauterine growth restricted fetuses and neonates," Early Hum Dev, Nr. 82, p. 235-239, 2005.

[125] A. Malamitsi-Puchner, T. Boutsikou, E. Economou, A. Sarandakou, E. Makrakis, D. Hassiakos und G. Creatsas, „Vascular Endothelial Growth Factor and Placenta Growth Factor in Intrauterine Growth- Restricted Fetuses and Neonates," Mediators Inflamm, Nr. 5, pp. 293-297, 2005.

[126] H. Stepan, A. Geide und R. Faber, „Soluble fms-like Tyrosine Kinase 1,“ N Engl J Med, Nr. 351, pp. 2241-2242, 2004.

[127] W. Wallner, R. Sengenberger, R. Strick, P. L. Strissel, B. Meurer, M. W. Beckmann und D. Schlembach, „Angiogenic growth factors in maternal and fetal serum in pregnancies complicated by intrauterine growth restriction," Clinical Science, Nr. 112, pp. 51-57, 2007.

[128] N. A. Bersinger und R. A. Odegard, „Second- and third- trimester serum levels of placental proteins in preeclampsia and small-for-gestational age pregnancies,“ Acta Obstet Gynecol Scand, Nr. 83, pp. 37-45, 2004.

[129] C. Signore, J. L. Mills, C. Qian, K. Yu, C. Lam, F. H. Epstein, S. A. Karumanchi und R. J. Levine, "Circulating angiogenic factors and placental abruption,“ Obstet Gynecol, Nr. 108, p. 338-344, 2006.

[130] J. Espinoza, R. Romero, J. Nien, R. Gomez, J. Kusanovic, L. Goncalves, L. Medina, S. Edwin, S. Hassan, M. Carstens und R. Gonzalez, „Identification of patients at risk for early onset and/or severe preeclampsia with the use of uterine artery Doppler velocimetry and placental growth factor," $A m$ J Obstet Gynecol., Nr. 196, pp. 326.e1-326.e13, 2007.

[131] J. P. Kusanovic, R. Romero, J. Espinoza, J. K. Nien, C. J. Kim, P. Mittal, S. Edwin, O. Erez, F. Gotsch, S. Mazaki-Tovi, N. G. Than, E. Soto, N. Camacho, R. Gomez, R. Quintero und S. S. Hassan, „Twin-to-twin transfusion syndrome: an antiangiogenic state?," Am J Obstet Gynecol., Nr. 198, p. 382.e1-e8, 2008. 
[132] J. Espinoza, R. Romero, J. K. Nien, J. P. Kusanovic, K. Richani, R. Gomez, C. J. Kim, P. Mittal, F. Gotsh, O. Erez, T. Chaiworapongsa und S. S. Hassan, „A role of the anti-angiogenic factor sVEGFR-1 in the 'mirror syndrome' (Ballantyne's syndrome), " J Matern Fetal Neonatal Med, Nr. 19, p. 607-613, 2006.

[133] P. Kaufmann, S. Black und B. Huppertz, „Endovascular Trophoblast Invasion: Implications for the Pathogenesis of Intrauterine Growth Retardation and Preeclampsia.," Biology of Reproduction, Nr. 69, pp. 1-7, 2003.

[134] M. D. Savvidou, A. D. Hingorani, D. Tsikas, J. C. Frölich, P. Vallance und K. H. Nicolaides, „Endothelial dysfunction and raised plasma concentrations of asymmetric dimethylarginine in pregnant women who subsequently develop pre-eclampsia,“" Lancet, Nr. 361, pp. 1511-1517, 2003.

[135] F. Fyhrquist und O. Saijonmaa, „Renin-angiotensin system revisited,“ $J$ Intern Med, Nr. 264, pp. 224-236, 2008.

[136] L. Anton, D. C. Merrill, L. A. Neves, K. Stovall, P. E. Gallagher, D. I. Diz, C. Moorefield, C. Gruver, C. M. Ferrario und K. B. Brosnihan, „Activation of Local Chorionic Villi Angiotensin II Levels But Not Angiotensin (1-7) in Preeclampsia,“ Hypertension, Nr. 51, pp. 1066-1072, 2008.

[137] D. C. Merrill, M. Karoly, K. Chen, C. M. Ferrario und K. B. Brosnihan, „Angiotensin-(1-7) in Normal and Preeclamptic Pregnancy,“ Endocrine, Nr. 18(3), pp. 239-245, 2002.

[138] G. Wallukat, V. Homuth, T. Fischer, C. Lindschau, B. Horstkamp, A. Jüpner, E. Baur, E. Nissen, K. Vetter, D. Neichel, J. W. Dudenhausen, H. Haller und F. C. Luft, „Patients with preeclampsia develop agonistic autoantibodies against the angiotensin AT1 receptor," J Clin Invest, Nr. 103, pp. 945-952, 1999.

[139] R. Dechend, V. Homuth, G. Wallukat, J. Kreuzer, J. K. Park, J. Theuer, A. Juepner, D. C. Gulba, N. Mackman, H. Haller und F. C. Luft, „AT1 receptor agonistic antibodies from preeclamptic patients cause vascular cells to express tissue factor," Circulation, Nr. 101, p. 2382-2387, 2000.

[140] R. Dechend, C. Viedt, D. N. Müller, B. Ugele, R. P. Brandes, G. Wallukat, J. K. Park, J. Janke, P. Barta, J. Theuer, A. Fiebeler, V. Hohmuth, R. Dietz, H. Haller, J. Kreuzer und F. C. Luft, „AT1 receptor agonistic antibodies from preeclamptic patients stimulate NADPH oxidase," Circulation, Nr. 107, p. 16321639, 2003. 
[141] C. C. Zhou, S. Ahmad, T. Mi, S. Abbasi, L. Xia, M. C. Day, S. M. Ramin, A. Ahmed, R. E. Kellems und Y. Xia, „Autoantibody from women with preeclampsia induces soluble Fms-like tyrosine kinase-1 production via angiotensin type 1 receptor and calcineurin/nuclear factor of activated T-cells signaling," Hypertension, Nr. 51, p. 1010-1019, 2008.

[142] S. Verlohren, M. Niehoff, L. Hering, N. Geusens, F. Herse, A. N. Tintu, A. Plagemann, F. LeNoble, R. Pijnenborg, D. N. Muller, F. C. Luft, J. W. Dudenhausen, M. Gollasch und R. Dechend, „Uterine vascular function in a transgenic preeclampsia rat model,“" Hypertension, Nr. 51, p. 547-553, 2008.

[143] S. Abdalla, H. Lother, A. Massiery und U. Quitterer, „Increased AT1 receptor heterodimers in preeclampsia mediate enhanced angiotensin II responsiveness," Nature Medicine, Nr. 7 (9), pp. 1003-1009, 2001.

[144] R. J. Gryglewski, „Prostacyclin among prostanoids,“ Pharmacol Rep, Nr. 60, pp. 3-11, 2008.

[145] W. Klockenbusch, T. Somwille, D. Hafner, H. Strobach und K. Schrör, „Excretion of prostacyclin and thromboxan metabolites before, during, and after pregnancy-induced hypertension,“ Eur J Obstet Gynecol Reprod Biol, Nr. 57, pp. 47-50, 1994.

[146] Z. Q. Ding, J. Rowe, B. Ng, M. J. Sinosich und E. D. Gallery, „Modulation of prostacyclin and thromboxane secretion by cytotrophoblasts from normal and pre-eclamptic human pregnancies," Placenta, Nr. 23, pp. 594-599, 2002.

[147] S. W. Walsh, „Preeclampsia: an imbalance in placental prostacyclin and thromboxane production," Am J Obstet Gynecol, Nr. 152, pp. 335-340, 1985.

[148] CLASP (Collaborative Low-dose Aspirin Study in Pregnancy) Collaborative Group, „CLASP: a randomised trial of low-dose aspirin for the prevention and treatment of pre-eclampsia among 9364 pregnant women," Lancet, Nr. 343 (8898), pp. 619-629, 1994.

[149] B. Visegrady, N. G. Than, F. Kilar, B. Sümegi, G. N. Than und H. Bohn, „Homology modelling and molecular dynamics studies of human placental tissue protein 13 (galectin-13)," Prot Eng, Nr. 14, pp. 875-880, 2001.

[150] H. Bohn, W. Kraus und W. Winckler, „Purification and characterization of two new soluble placental tissue proteins (PP13 and PP17)," Oncodev Biol Med, Nr. 4, pp. 343-350, 1983. 
[151] O. Burger, E. Pick, J. Zwickel, M. Klayman, H. Meiri, R. Slotky, S. Mandel, L. Rabinovitch, Y. Paltieli, A. Admon und R. Gonen, „Placental Protein 13 (PP-13): effects on cultured trophoblasts, and its detection in human body fluids in normal and pathological pregnancies," Placenta, Nr. 25, pp. 608-622, 2004.

[152] I. Cetin, V. Cozzi, A. T. Papageorghiou, V. Maina, A. Montanelli, C. Garlanda und B. Thilaganathan, „First trimester PTX3 levels in women who subsequently develop preeclampsia and fetal growth restriction," Acta Obstetrica et Gynecologica, Nr. 88, pp. 846-849, 2009.

[153] K. Leslie, B. Thilaganathan und A. Papageorghiou, „Early prediction and prevention of pre-eclampsia," Best Pract Res Clin Obstet Gynaecol, Nr. 25 (3), pp. 343-354, 2011.

[154] B. Perbal, „CCN proteins: multifunctional signalling regulators,“ Lancet, Nr. 363, pp. 62-64, 2004.

[155] A. W. Rachafl und D. R. Brigstock, „Structural and functional properties of CCN proteins," Vitamins and Hormones, Nr. 70, pp. 69-103, 2005.

[156] F. E. Mo, A. G. Muntean, C. C. Chen, D. B. Stolz, S. C. Watkin und L. F. Lau, "CYR 61 (CCN1) is essential for placental development and vascular integrity," Mol Cell Biol, Nr. 22, pp. 8709-8720, 2002.

[157] F. Milne, C. Redman, J. Walker, P. Baker, J. Bradley, C. Cooper, M. de Swiet, G. Fletcher, M. Jokinen, D. Murphy, C. Nelson- Piercy, V. Osgood, S. Robson, A. Shennan, A. Tuffnell, S. Twaddle und J. Waugh, „The pre-eclampsia community guideline (PRECOG): how to screen for and detect onset of preeclampsia in the community," BMJ, Nr. 330, pp. 576-80, 2005.

[158] A. Conde-Agudelo, J. Villar und M. D. Lindheimer, „World Health Organization Systematic Review of Screening Tests for Preeclampsia," Obstet Gynecol, Nr. 104, pp. 1367-1391, 2004.

[159] C. J. Lookwood und J. H. Peters, „Increased plasma levels of ED1+ cellular fibronection precede the clinical signs of preeclampsia," Am J Obstet Gynecol, Nr. 162, pp. 358-362, 1990.

[160] K. M. Paarlberg, C. L. De Jong, H. P. van Geijn, G. J. van Kamp, A. G. Heinen und G. A. Dekker, ,Total plasma fibronectin as a marker of pregnancy- induced hypertensive disorders: a longitudinal study, "Obstet Gynecol, Nr. 91, pp. 383388, 1998.

[161] L. W. Hess, W. F. O’Brien, J. A. Holmberg, C. A. Winkel, P. Monaghan und V. G. Hemming, „Plasma and amniotic fluid concentrations of fibronectin during normal pregnancy,“ Obstet Gynecol, Nr. 68 (1), pp. 25-28, 1986. 
[162] R. D’Anna, G. Baviera, D. Giordano, S. Russo, N. Dugo, A. Santamaria und F. Corrado, „First trimester serum PAPP-A and NGAL in the prediction of lateonset preeclampsia," Prenat Diagn, Nr. 29, pp. 1066-1068, 2009.

[163] R. D’Anna, G. Baviera, D. Giordano, G. Todarello, S. Russo, S. Recupero, D. Bolignano und F. Corrado, „Neutrophil gelatinase-associated lipocalin serum evaluation through normal pregnancy and in pregnancies complicated by preeclampsia,“ Acta Obstet Gynecol Scand, Nr. 89, pp. 275-278, 2010.

[164] K. Kristensen, I. Larsson und S. R. Hansson, „Increased cystatin C expression in the pre-eclamptic placenta,“ Mol Hum Reprod, Nr. 13, pp. 189-195, 2007.

[165] B. Thilaganathan, E. Ralph, A. T. Papageorghiou, K. Melchiorre und J. Sheldon, „Raised maternal serum cystatin C: an early pregnancy marker for preeclampsia,“ Reprod Sci, Nr. 16, pp. 788-793, 2009.

[166] B. Thilaganathan, B. Wormald, C. Zanardini, J. Sheldon, E. Ralph und A. T. Papageorghiou, „Early pregnancy multiple serum markers and second trimester uterine artery Doppler in predicting preeclampsia," Obstet Gynecol, Nr. 115, pp. 1233-1238, 2010.

[167] L. Sanchez-Ramos, D. Jones und M. T. Cullen, „Urinary calcium as early marker for preeclampsia,“ Obstet Gynecol, Nr. 77, pp. 685-688, 1991.

[168] V. R. Suarez, J. G. Trelles und J. M. Miyahira, „Urinary calcium in asymptomatic primigravidas who later developed preeclampsia," Obstet Gynecol, Nr. 87, pp. 79-82, 1996.

[169] A. M. Ashour, E. S. Liebermann, L. E. Wilkins Hang und J. T. Repke, „The value of elevated second-trimester $B$ - human chorionic gonadotropin in prediction development of preeclaampsia," Am J Obstet Gynecol, Nr. 176, pp. 438-442, 1997.

[170] H. Cuckle, I. Sehmi und R. Jones, „Maternal serum inhibin A can predict preeclampsia,“ BJOG, Nr. 105, pp. 1101-1103, 1998.

[171] T. Krauss, W. Kuhn, C. Lakoma und H. G. Augustin, „Circulating endothelial cell adhesion molecules as diagnostic marker for the early identification of pregnant women at risk for development of preeclampsia," Am J Obstet Gynecol, Nr. 177, pp. 443-449, 1997.

[172] K. Spencer, N. J. Cowans, I. Chefetz, J. Tal und H. Meiri, „First-trimester maternal serum PP-13, PAPP-A and second trimester uterine artery Doppler pulsatility index as markers of pre-eclampsia," Ultrasound Obstet Gynecol, Nr. 29, pp. 128-134, 2007. 
[173] K. Spencer, N. J. Cowans und K. H. Nicolaides, „Low levels of maternal serum PAPP-A in the first trimester and the risk of preeclampsia," Prenat Diagn, Nr. 28, pp. 7-10, 2008.

[174] K. Spencer, C. K. Yu, N. J. Cowans, C. Otigbah und K. H. Nicolaides, „Prediction of pregnancy complications by first trimester maternal serum PAPPA and free B HCG and with second trimester uterine artery Doppler," Prenat Diagn, Nr. 25, pp. 949-953, 2005.

[175] G. C. S. Smith, E. J. Stenhouse, J. A. Crossley, D. A. Aitken, A. D. Cameron und J. M. Connor, „Early pregnancy levels of pregnancy associated plasma protein a and the risk of intrauterine growth restriction, premature birth, preeclaampsia and stillbirth,“ J Clin Endocrinol Metab, Nr. 87, pp. 1762-1767, 2002.

[176] S. Campbell, D. R. Griffin, J. M. Pearce, J. Diaz- Recasens, T. E. CohenOverbeek und K. Willson, „New doppler technique for assessing uteroplacental blood flow,“ Lancet, Nr. 321 (8326), pp. 675-677, 1983.

[177] S. Campbell, J. M. Pearce, G. Hackett, T. E. Cohen-Overbeek und C. Hernandez, „Qualitative assessment of uteroplacental blood flow: early screening test for high-risk pregnancies," Obstet Gynecol, Nr. 68, pp. 649-653, 1986.

[178] P. F. Chien, N. Arnott, A. Gordon, P. Owen und K. S. Khan, „How useful is uterine artery Doppler flow velocimetry in the prediction of pre-eclampsia, intrauterine growth retardation and perinatal death ? An overview.," BJOG, Nr. 107, pp. 196-208, 2000.

[179] S. Bower, S. Bewley und S. Campbell, „Improved prediction of preeclampsia by two-stage screening of uterine arteries using the early diastolic notch and color Doppler imaging,“ Obstet Gynecol, Nr. 82, pp. 78-83, 1993.

[180] W. Plasencia, N. Maiz, S. Bonino, C. Kaihura und K. H. Nicolaides, „Uterine artery Doppler at $11+0$ to $13+6$ weeks in the prediction of preeclampsia," Ultrasound Obstet Gynecol, Nr. 30, pp. 742-749, 2007.

[181] H. Stepan, A. Geipel, F. Schwarz, T. Krämer, N. Wessel und R. Faber, „Circulatory soluble endoglin and its predictive value for preeclampsia in second-trimester pregnancies with abnormal uterine perfusion," Am J Obstet Gynecol, Nr. 198, pp. 175.e1-175.e6, 2008.

[182] L. C. Poon, N. A. Kametas, N. Maiz, R. Akolekar und K. H. Nicolaides, „Firsttrimester prediction of hypertensive disorders in pregnancy," Hypertension, Nr. 53, pp. 812-18, 2009. 
[183] B. M. Sibai, G. Dekker und M. Kupferminc, „Pre-eclampsia,“ Lancet, Nr. 365, p. 785-799, 2005.

[184] L. M. Askie, L. Duley, D. J. Henderson-Smart und L. A. Stewart, „Antiplatelet agents for prevention of pre-eclampsia: a meta-analysis of individual patient data,“ Lancet, Nr. 369, pp. 1791-1798, 2007.

[185] L. Duley, D. J. Henderson-Smart, S. Meher und J. F. King, „Antiplatelet agents for preventing pre-eclampsia and its complications.," Cochrane Database Syst Rev, Nr. 18 (2), p. CD004659, Apr 2007.

[186] S. Roberge, P. Villa, K. Nicolaides, Y. Giguere, M. Vainio, A. Bakthi, A. Ebrashy und E. Bujold, „Early Administration of Low-Dose Aspirin for the Prevention of Preterm and Term Preeclampsia: A Systematic Review and Meta-Analysis," Fetal Diagn Ther, Nr. 31, pp. 141-146, 2012.

[187] R. A. North, C. Ferrier, G. Gamble, K. F. Fairley und P. Kincaid-Smith, „Prevention of preeclampsia with heparin and antiplatelet drugs in women with renal disease,“" Aust NZJ Obstet Gynaecol, Nr. 35, pp. 357-62, 1995.

[188] M. J. Kupferminc, G. Fait, A. Many, J. B. Lessing, D. Yair, A. Bar-Am und A. Eldor, „Low molecular weight heparin for the prevention of obstetric complications in women with thrombophilia," Hypertens Pregnancy, Bd. 20, pp. 35-44, 2001.

[189] E. Rey, P. Garneau, M. David, R. Gauthier, L. Leduc, N. Michon, F. Morin, C. Demers, S. R. Kahn, L. A. Magee und M. Rodger, „Dalteparin for the prevention of recurrence of placental - mediated complications of pregnancy in women without thrombophilia: a pilot randomized controlled trial," $J$ Thromb Haemost, Nr. 7, pp. 58-64, 2009.

[190] G. J. Hofmeyr, L. Duley, T. A. Lawrie und A. N. Atallah, „Calcium supplementation during pregnancy for preventing hypertensive disorders and related problems," Cochrane Database Syst Rev, Nr. 1, p. CD001059, 2002.

[191] C. Kähler, E. Schleußner, A. Möller und H. J. Seewald, „Nitric oxide donors: effects on fetoplacental blood flow," Eur J Obstet Gynecol Reprod Biol, Nr. 115, pp. 10-14, 2004.

[192] Roche, „Roche Diagnostics,“ [Online]. Available: http://lerncenter.roche.de/elecsys/elecsys.asp.

[193] E. Schneider, A. Gleixner, R. Hänel, Y. Leyhe, C. Kleinschmidt, G. Beck, M. Steinberg, B. Denk und D. Gassner, „Technical performance of the first fully automated assays for human soluble fms-like tyrosine kinase 1 and human placental growth factor," Z Geburtshilfe Neonatol, Nr. 213, p. 69, 2009. 
[194] Roche, „Roche Diagnostics/ Labordiagnostik,“ [Online]. Available: http://www.roche.de/diagnostics/labor/serumarbeitsplatz/praeeklampsie.htm?si $d=4 b 475 c b 3820 d 9531$ a11452726a018f4d.

[195] E. O’Brien, R. Asmar, L. Beilin, Y. Imai, G. Mancia, T. Mengden, M. Myers, P. Padfield, P. Palatini, G. Parati, T. Pickering, J. Redon, J. Staessen, G. Stergiou und $P$. Verdecchia, „Practice guidelines of the European Society of Hypertension for clinic, ambulatory and self blood pressure measurement, " $J$ Hypertens, Nr. 23 (4), pp. 697-701, 2005.

[196] H. Stepan, W. Schaarschmidt, A. Jank, S. Verlohren und J. Kratzsch, „Angiogene Faktoren zur Diagnosesicherung bei Präeklampsie in der klinischen Routine: erste Erfahrungen,“ Z Geburtsh Neonatol, Nr. 214, pp. 234-238, 2010.

[197] S. Salahuddin, Y. Lee, M. Vadnais, B. P. Sachs, S. A. Karumanchi und K. H. Lim, „Diagnostic utility of soluble fms-like tyrosine kinase 1 and soluble endoglin in hypertensive diseases of pregnancy," Am J Obstet Gynecol, Nr. 197, pp. 28.e1-28.e6, 2007.

[198] S. Rana, C. E. Powe, S. Salahuddin, S. Verlohren, F. H. Perschel, R. J. Levine, K. H. Lim, J. B. Wenger, R. Thadhani und S. A. Karumanchi, „Angiogenic Factors and the Risk of Adverse Outcomes in Women With Suspected Preeclampsia," Circulation, Nr. 125, pp. 911-919, 2012.

[199] M. D. Lindheimer, S. J. Taler und F. G. Cunningham, „ASH Position Paper: Hypertension in Pregnancy, " $J$ Clin Hypertens (Greenwich), Nr. 11, pp. 214225, 2009.

[200] J. Menzies, L. A. Magee, Y. C. MacNab, J. M. Ansermino, J. Li, M. J. Douglas, A. Gruslin, P. Kyle, S. K. Lee, M. P. Moore, J. M. Moutquin, G. N. Smith, J. J. Walker, K. R. Walley, J. A. Russell und P. von Dadelszen, „Current CHS and NHBPEP Criteria for Severe Preeclampsia Do Not Uniformly Predict Adverse Maternal or Perinatal Outcomes," Hypertens in Pregn, Nr. 26, pp. 447-462, 2007.

[201] W. Ganzevoort, A. Rep, J. I. P. de Vries, G. J. Bonsel und H. Wolf, „Prediction of maternal complications and adverse infant outcome at admission for temporizing managment of early-onset severe hypertensive disorders of pregnancy," American Journal of Obstetrics and Gynecology, Nr. 195, pp. 495503, 2006.

[202] H. Stepan und W. Schaarschmidt, „Bluttest auf Präeklampsie reif für den klinischen Einsatz ?,“ Geburtshilfe und Frauenheilkunde, Nr. 70, pp. 6-9, 2010. 
[203] F. Crispi, C. Dominguez, E. Llurba, P. Martin-Gallan, L. Cabero und E. Gratacos, „Placental angiogenic growth factors and uterine artery Doppler findings for characterization of different subsets in preeclampsia and in isolated intrauterine growth restriction," Am J Obstet Gynecol, Nr. 195, pp. 201-207, 2006.

[204] R. Romero, J. K. Nien, J. Espinoza, D. Todem, W. Fu, H. Chung, J. P. Kusanovic, F. Gotsch, O. Erez, S. Mazaki-Tovi, R. Gomez, S. Edwin, T. Chaiworapongsa, R. J. Levine und S. A. Karumanchi, „A longitudinal study of angiogenic (placental growth) and antiangiogenic (soluble endoglin and soluble vascular endothelial growth factor receptor-1) factors in normal pregnancy and patients destined to develop preeclampsia and deliver a SGA neonate," The Journal of Maternal-Fetal and Neonatal Medicine, Nr. 21(1), pp. 9-23, 2008.

[205] Y. N. Kim, D. S. Lee, D. H. Jeong, M. S. Sung und K. T. Kim, „The relationship of the level of circulating antiangiogenic factors to the clinical manifestations of preeclampsia,“" Prenat Diagn, Nr. 29, pp. 464-470, 2009.

[206] R. Troisi, K. Braekke, N. K. Harsem, M. Hyer, R. N. Hoover und A. C. Staff, „Blood pressure augmentation and maternal circulating concentrations of angiogenic factors at delivery in preeclamptic and uncomplicated pregnancies," Am J Obstet Gynecol, Nr. 199, pp. 653.e1-653.e10, 2008.

[207] A. Molvarec, A. Szarka, S. Walentin, E. Szucs, B. Nagy und J. Rigo Jr., „Circulating angiogenic factors determined by electrochemiluminescence immunoassay in relation to the clinical features and laboratory parameters in women with pre-eclampsia," Hypertension Research, Nr. 33, pp. 892-898, 2010.

[208] B. Young, R. J. Levine, S. Salahuddin, C. Qian, K. H. Lim, S. A. Karumanchi und S. Rana, "The use of angiogenic biomarkers to differentiate non-HELLP related thrombocytopenia from HELLP syndrome," The Journal of MaternalFetal and Neonatal Medicine, Nr. 23(5), pp. 366-370, 2010. 


\section{Abbildungsverzeichnis}

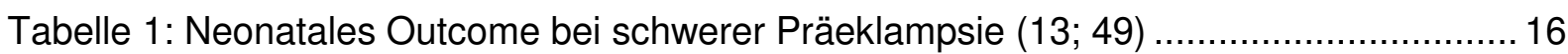

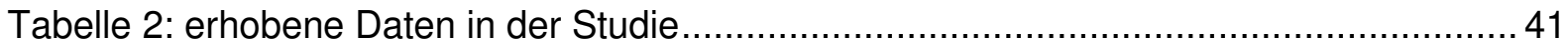

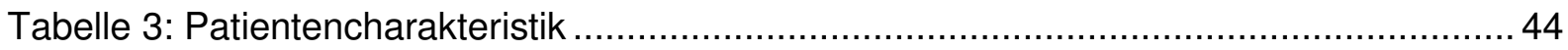

Tabelle 4: Anteil der Early-/ Late-onset-Präeklampsien und Wachstumsretardierungen ...... 46

Abbildung 1: Pathogenese der Präeklampsie (mod. nach $(10 ; 31)$ )................................. 11

Abbildung 2: schematische Darstellung der Plazentation (33)....................................... 12

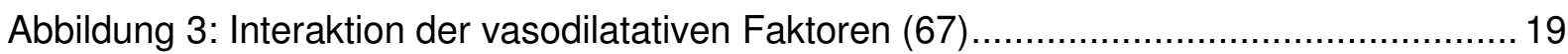

Abbildung 4: VEGF Formen, deren biologische Wirkung und Rezeptoren (67) ..................21

Abbildung 5: Rezeptoren der verschiedenen VEGF Subtypen(94) ..................................24

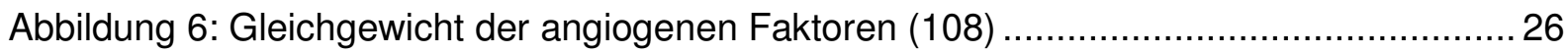

Abbildung 7: Prädiktive Wertigkeit der uterinen Perfusionsdiagnostik und angiogener

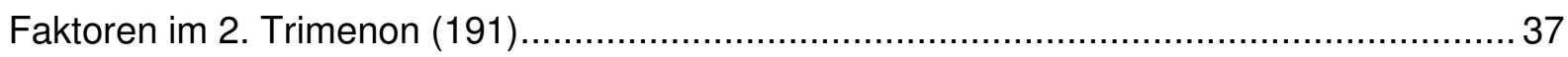

Abbildung 8: quantitative Verteilung der Erkrankungsmanifestationen in der Kohorte .......... 45

Abbildung 9: sFlt-1/PIGF-Ratio vs Gestationsalter zur Geburt (SSW) ................................ 50

Abbildung 10: Gestationsalter zur Geburt (SSW) vs sFlt-1/PIGF-Ratio ............................. 51

Abbildung 11: Gestationsalter zur Geburt (SSW) vs sFlt-1/PIGF-Ratio ............................... 52

Abbildung 12: sFlt-1/PIGF-Ratio vs milder/schwerer Präeklampsie.................................. 53

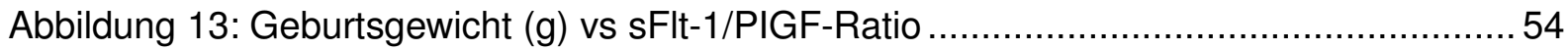

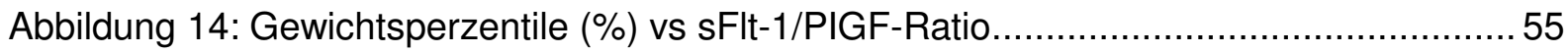

Abbildung 15: Gewichtsperzentile (\%) vs sFlt-1/PIGF-Ratio ohne IUGR ...........................56

Abbildung 16: Verlängerung Schwangerschaft (in Tagen) vs sFlt-1/PIGF-Ratio...................58

Abbildung 17: Verlängerung Schwangerschaft (in Tagen) vs sFlt-1/PIGF-Ratio (ohne

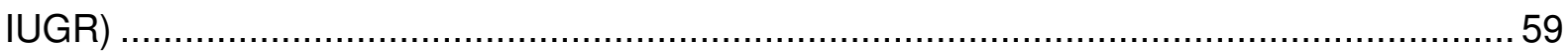

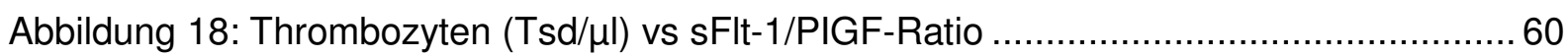




\section{Selbstständigkeitserklärung}

Hiermit erkläre ich, dass ich die vorliegende Arbeit selbstständig und ohne unzulässige Hilfe oder Benutzung anderer als der angegebenen Hilfsmittel angefertigt habe. Ich versichere, dass Dritte von mir weder unmittelbar noch mittelbar geldwerte Leistungen für Arbeiten erhalten haben, die im Zusammenhang mit dem Inhalt der vorgelegten Dissertation stehen, und dass die vorgelegte Arbeit weder im Inland noch im Ausland in gleicher oder ähnlicher Form einer anderen Prüfungsbehörde zum Zweck einer Promotion oder eines anderen Prüfungsverfahrens vorgelegt wurde. Alles aus anderen Quellen und von anderen Personen übernommene Material, das in der Arbeit verwendet wurde oder auf das direkt Bezug genommen wird, wurde als solches kenntlich gemacht. Insbesondere wurden alle Personen genannt, die direkt an der Entstehung der vorliegenden Arbeit beteiligt waren.

Datum

Unterschrift 


\section{Danksagung}

„Wege entstehen dadurch, dass man sie geht.“ (Franz Kafka)

Manche Wege sind verdammt lang und erreichen ihr Ziel erst über Umwege. All meinen Wegbegleitern möchte ich aus tiefstem Herzen für ihre großartige Unterstützung danken.

In erster Linie gilt ein ganz besonderer Dank meinem Chef, Herrn Prof. Dr. med. H. Stepan, der mir das Dissertationsthema zur Verfügung gestellt hat und bei der Auswertung der Daten und der Erstellung der Arbeit in allen fachlichen Fragen stets hilfreich zur Seite stand. Die Mitarbeiter der Abteilung für Geburtsmedizin des Universitätsklinikums Leipzig haben durch ihre motivierenden Worte und fachlichen Ratschläge ebenso entscheidend an der Umsetzung der Arbeit mitgewirkt - danke Wiebke und Alexander.

Ohne die ausdauernde und vielseitige Unterstützung von Matthias wäre die Fertigstellung der Dissertation kaum möglich gewesen. Besonders bei ihm und unserer Familie möchte ich mich mit all meiner Liebe für die aufgebrachte Geduld und Hilfe bedanken. Das Lachen der Kinder und das gemeinsame Familienleben haben mir immer wieder unglaublich viele Glücksmomente geschenkt.

Ebenso seien die wertvollen und kritischen Mithelfer erwähnt, allen voran meine Schwester Helga für ihre unersetzlichen Ratschläge bei der Erstellung des Literaturverzeichnisses, Maria für das Korrekturlesen der Arbeit und den vielen Freunden für ihre immer wieder ermutigenden Gesten. $\mathrm{Zu}$ guter Letzt möchte ich meiner lieben Oma danken, dass sie trotz aller Schwierigkeiten all die Jahre für mich da war und ich mir zu jeder Zeit ihrer Unterstützung sicher sein konnte. 